LUMA FONSECA DO CANTO

\title{
DESIGN, CONSTRUCTION AND TESTS OF A HIGH FLUX SOLAR SIMULATOR
}

São Paulo

2020 


\section{DESIGN, CONSTRUCTION AND TESTS OF A HIGH FLUX SOLAR SIMULATOR}

\section{Corrected and Revised Version}

Dissertation presented to the Escola Politécnica of the Universidade de São Paulo to obtain the degree of Master of Sciences.

Concentration field: Energy and Fluids.

Advisor: Prof. Dr. José Roberto SimõesMoreira

São Paulo 
Autorizo a reprodução e divulgação total ou parcial deste trabalho, por qualquer meio convencional ou eletrônico, para fins de estudo e pesquisa, desde que citada a fonte.

Este exemplar foi revisado e corrigido em relação à versão original, sob responsabilidade única do autor e com a anuência de seu orientador.

São Paulo, de de

Assinatura do autor:

Assinatura do orientador:

Catalogação-na-publicação

Canto, Luma

DESIGN, CONSTRUCTION AND TESTS OF A HIGH FLUX SOLAR

SIMULATOR / L. Canto -- versão corr. -- São Paulo, 2020.

$124 \mathrm{p}$.

Dissertação (Mestrado) - Escola Politécnica da Universidade de São Paulo. Departamento de Engenharia Mecânica.

1.ENERGIA SOLAR 2.FONTES ALTERNATIVAS DE ENERGIA 3.REFLEXÃO DO CALOR (SIMULAÇÃO) 4.RADIAÇÃO (CALOR) I.Universidade de São Paulo. Escola Politécnica. Departamento de Engenharia Mecânica II.t. 


\section{DEDICATION}

To my family, especially my mother, Elzira, my father, Acacio, and my brother, Acácio, who have always unconditionally supported me.

To my husband, Paulo Tamer, who has been on my side bringing lightness even to the most difficult times.

To my friends, who supported me and kept me company, from near or far, even before the beginning of this journey. 


\section{ACKNOWLEDGMENTS}

To Prof. Dr. José Roberto Simões-Moreira for the attention, time and guidance.

To my colleague Dr. Lina Maria Varon Cadorna for the emotional support and help in all the processes of this work.

To the technician Thyago José Reynaldo Miranda for giving life to my crazy ideas.

To the whole Sisea group for the help in several other moments.

To CAPES (Coordenação de Aperfeiçoamento de Pessoal de Nível Superior - Brasil) for personal financial support.

To RCGI - Research Centre for Gas Innovation, hosted by University of São Paulo (USP) and sponsored by FAPESP - São Paulo Research Foundation (2014/50279-4) and Shell Brazil for appreciating my work. 


\begin{abstract}
The growth on energy consumption worldwide in the last year, along with the increasingly care about the amount of pollutants emitted to the atmosphere when working with fossil sources have revealed the need of diversifying the energy grid. The solar fuels are produced enriching the calorific power of combustibles such as biomass or shale gas, by using the thermal energy of the Sun as activating energy for the given conversion processes. Considering the great direct solar radiation index of center-west and northeast of Brazil, the generation of solar fuels appears as a fine option in this country. However, this technology is not yet fully developed and research with known input parameters is still needed. Given the seasonal and intermittent characteristics of the solar radiation, the use of a simulator capable of emulating the high thermal flux of the concentrated solar power (CSP), while maintaining steady conditions is required. In this way, this work aims in the design, construction and tests of a high flux solar simulator (HFSS) to be used on the research of solar fuels. After carrying out an extensive literature review, an HFSS composed of two commercial sky searchlights ,working as light sources, and parabolic reflectors, as concentrators, has been proposed. Using the Monte Carlo ray tracing (MCRT) method, the geometry of the concentrators has been designed and the concentrated heat flux, holding or not a secondary concentrator device, have been previously analyzed. The development of a mathematical analysis for a black body cavity has been conducted, and it has drawn the basis for the design and construction of a calorimeter cavity. Then tests have been conducted, among which are: the definition of the electric-to-radiant ratio of the light sources, following three different methods; the evaluation of the concentrated heat flux of the HFSS; and the analysis of the power intensity inside the cavity calorimeter, when using a secondary concentrator. The use of a black and white camera, a near-Lambertian target and a heat flux gauge have granted the calibration of the gray-scale of the camera, hence if the HFSS proposed is expanded by adding more lamps, it can be easily photographically characterized in terms of heat flux.
\end{abstract}

Keywords: High Flux Solar Simulator, HFSS, Concentrated Solar Power, CSP, Solar fuel. 


\section{RESUMO}

O acréscimo de consumo de energia no último ano, bem como a crescente preocupação relacionada à produção de poluentes emitidos à atmosfera, quando trabalha-se com fontes fósseis, relevou a necessidade de diversificação da matriz energética. Os combustíveis solares são produzidos enriquecendo o poder calorífico de outros combustíveis como biomassa e gás natural, utilizando o calor do Sol como fonte de ativação dos processos de conversão. Dado o alto índice de radiação solar direta nas regiões nordeste e centro-oeste do Brasil, a geração de combustíveis solares aparece como uma boa opção no país. Entretanto, esta tecnologia ainda não se encontra em total desenvolvimento e, portanto, a pesquisa com parâmetros conhecidos ainda é necessária. Dadas as características sazonal e intermitente da radiação solar, o uso de um simulador capaz de emular o alto fluxo térmico da energia solar concentrada, enquanto mantém condições de trabalho constantes, é indispensável. Assim, este trabalho objetiva o design, construção e testes de um simulador solar de alto fluxo a ser aplicado à pesquisa de combustíveis solares. Após uma extensiva revisão literária, um simulador composto por dois sky searchlights comerciais, utilizados como fonte de luz, e refletores parabólicos como concentradores foi proposto. Aplicando o método de traçado de raios Monte Carlo, a geometria dos concentradores foi definida, e o fluxo de energia térmica, utilizando ou não concentrador secundário foi previamente analisado. A análise matemática para cavidade de corpo negro foi implementada, o que serviu de base para o design e construção de uma cavidade calorimétrica. Posteriormente, testes foram conduzidos, entre os quais estão a definição de taxa de eletricidade-para-radiação das fontes luminosas segundo três metodologias distintas; a avaliação do fluxo de calor concentrado do simulador; e a análise da intensidade de energia dentro da cavidade calorimétrica, com o concentrador secundário em uso. O emprego da câmera em preto e branco, da placa Lambertiana e do sensor de fluxo garantiram a calibração da escala de cinza da câmera, assim é possível em caso de expansão do simulador adicionando novas lâmpadas, caracterizá-lo fotograficamente em termos de fluxo de calor com facilidade.

Palavras-chave: Simulador Solar de Alto Fluxo, HFSS, Energia Solar Concentrada, CSP, combustível solar. 


\section{LIST OF FIGURES}

Figure 1.1. Concentrated Solar Power plant with Thermal Energy Storage system.....

Figure 1.2 Routes for the production of Solar fuels from $\mathrm{H}_{2} \mathrm{O} / \mathrm{CO}_{2}$-splitting or decarbonization

Figure 1.3. The long-term average of the daily/yearly sum of DNI worldwide (Solargis, 2019)

Figure 1.4. Average of the daily/yearly sum of DNI in Brazil from 1999 to 2005 (Solargis, $2019 b)$

Figure 2.1. Schematics of optical-geometrical characteristics of an ellipsoid reflector....

Figure 2.2. Schematics of optical-geometrical characteristics of a paraboloid. a) light source at the focus; b) collimated beams reaching the paraboloid and being reflected to the focus

Figure 2.3. HFSS developed in the ETH-Zentrum, Zurich (Hirsch et al., 2003) .31

Figure 2.4. Some of the modules of Xenon arc lamps and truncated ellipsoid reflectors of the HFSS developed in the PSI, Zurich (Petrasch et al., 2007).

Figure 2.5. HFSS located at MIT, Cambridge, containing the seven metal halide outdoor stadium lights, the flow-line concentrator, and the adjustable structure (Codd et al., 2010)

Figure 2.6. HFSS developed in the University of Minnesota, and parametric table and Lambertian target used to the characterization of the simulator (Krueger, 2012)...... 36

Figure 2.7. Four lamps inner circle and eight lamps external circle array of the HFSS developed in KTH Royal Institute of Technology, Stockholm (Garrido et al., 2017)....38

Figure 2.8. KIRAN-42, the HFSS located in IMDEA Energy Institute, Mósteles (Li et al., 2015)

Figure 2.9. Off-the-shelf HFSS developed in Sandia National Laboratories, Albuquerque (Boubault et al., 2015)....

Figure 2.10. HFSS developed in Swinburne University of Technology, Hawthorn (Ekman et al., 2015)

Figure 2.11. HFSS developed by SISEA research group in operation (Rodrigues, 2016).....43

Figure 2.12. Synlight, the HFSS developed in DLR, at Jülich ("Sun at the push of a button," 2017) 
Figure 2.13. Test chamber of the Synlight HFSS developed in DLR, Jülich (Wieghardt et al., 2017)

Figure 2.14. Schematics of the solar simulator that can be used for high flux research applications and collimated beams applications (Jin et al., 2019). 46

Figure 3.1. Geometrical relations between the Earth and the Sun .48

Figure 3.2. Solar spectral distribution outside and inside Eart's atmosphere at $A M=1.5$ (derivate from SMARTS v.2.9.2. ASTM G173-03) 49

Figure 3.3. Influence of the Earth atmosphere on the solar irradiation. .50

Figure 3.4. Main kinds of solar collectors: (a) parabolic trough (b) parabolic dish (c) tower (d) Fresnel lens (Guerrero-Lemus and Martínez-Duart, 2013)....

Figure 3.5. Rays reflected inside a light cone entering and those that do not enter the exit aperture.

Figure 3.6. Rays reflected inside a compound parabolic concentrator reaching the parabola focus. .54

Figure 3.7. A cylindrical thermally insulated cavity 56

Figure 3.8. Heat transfers occurring between the light source and the cavity.... 56

Figure 3.9. Analogic electric circuit of the losses by radiation occurring from inside the cavity to the surrounding.....

Figure 3.10. The relation between the effective absorptivity of the cavity, the cavity absorptivity and the ratio between the window and cavity areas.

Figure 3.11. Equilibrium temperature of the cavity as a function of the incident irradiation and ratio of heat absorbed by a given reaction

Figure 4.1. Proposed layout of the new High Flux Solar Simulator

Figure 4.2. Sky Searchlight used in this work and its components. a) Frontal view; b) Side view

Figure 4.3. Manufacturing of the square fiber glass concentrator's base, displaced $200 \mathrm{~mm}$ from the center of the master mould.

Figure 4.4. Parabolic concentrator attached to the support in a) front view; b) upper view..63

Figure 4.5. Schematics of the off-set parabolic concentrator....

Figure 4.6. Tonatiuh simulation for parallel beams reaching the off-set concentrators, boundary volume, and a virtual plate at the focal plane of the paraboloids.... 
Figure 4.7. Simulation of the heat flux distribution at the focal plane of the off-set paraboloids

Figure 4.8. Triangle used to determine the acceptable angle in red. The dimensions are presented in $\mathrm{mm}$.

Figure 4.9. Simulated heat flux distribution at the exit of the light cone ...................... 68

Figure 4.10. Simulated heat flux distribution at the exit of the CPC.... 68

Figure 4.11. Rays reflected by the optimized cone. In red, portrayal of the rays reflected back to the entering aperture, in blue the rays reflected to the exit aperture and in green the rays reaching the exit aperture directly.... .70

Figure 4.12. Simulated heat flux distribution at the exit of the optimized cone ..................71

Figure 4.13. Calorimeter cavity. a) Spiral tube walls; b) Frontal part; c) Bottom part........74

Figure 4.14. Transmissivity of a commercial quartz disc(Technical Glass Products, 2010) 75

Figure 4.15. Optimized cone with a base to pin at cavity front a) side view; b) upper view...75

Figure 4.16. Calorimeter cavity insulated by glass wool, aluminized tape, and an alumina

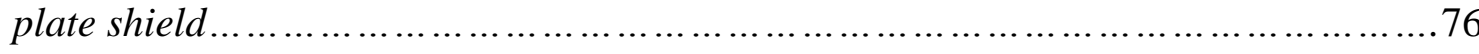

Figure 5.1. Gardon gauge from Vatell Comporation Inc ................................... 77

Figure 5.2. Spectrophotometer USB+XR1 from Ocean Optics Inc.............................78

Figure 5.3. Calibration lights a) HL-3P-CAL b) HL-2000-LL .............................. 78

Figure 5.4. Optic fibers a) path cord QP50-2-VIS-NIR b) bifurcated fiber R400-7-VIS-NIR..79

Figure 5.5. Ocean Optics' cosine corrector ................................................ 79

Figure 5.6. Ocean Optics' reflection probe holder...........................................79

Figure 5.7. Ocean Optics' specular standard of high reflectivity ..........................79

Figure 5.8. Near-lambertian plate manufactured ......................................... 81

Figure 5.9. Camera DMK 33 GP1300 with the lens, neutral density filters, and adaptors mounted...... 82

Figure 5.10. Test layout to determine the sky searchlight's irradiance using the Gardon Gauge

Figure 5.11. Transmissivity of a commercial glass (Tanner, 2003).

Figure 5.12. Calorimeter developed in Sisea laboratory to determine the irradiance of the sky searchlights

Figure 5.13. Survey to determine the irradiance of the sky searchlights. The thermocouples placed at the water inlet and exit have been indicated..... 
Figure 5.14. Test layout to determine the sky searchlight's irradiance using the spectrometer

Figure 5.15. Test layout to determine the concentrated heat flux of the HFSS.....

Figure 5.16. Test for determination of concentrated heat flux, with the radiometer, plugged to the near-Lambertian plate, which is mounted on the coordinated table. The black and white camera is placed $700 \mathrm{~mm}$ away from the plate....

Figure 5.17. Test layout of the calorimeter cavity

Figure 5.18. Test with the calorimeter cavity in progress....

Figure 6.1. Relative irradiance of the sky searchlights, determined by experimental procedure and of the Sun, inside Earth's atmosphere via ASTM G173-03. The blue and purple lower lines correspond to the sky searchlights and the red higher to the Sun. The dotted line is the Planck's law radiation for a black body of color temperature $6200 K$

Figure 6.2. Absolute spectral irradiance at the center, $50 \mathrm{~mm}$ and $160 \mathrm{~mm}$ away from the center of the sky searchlight for a fiber located $500 \mathrm{~mm}$ away from the lamp. IR peaks in detail. 95

Figure 6.3. Absolute Irradiance distribution along the sky searchlight window radius...... 96

Figure 6.4. Heat flux along the horizontal central line of the sky search line window, with lamp adjusted to the reflector to concentrate the beams. The solid line corresponds to the measurements and the dotted line to a tendency line derivated from the survey starting at $-5 \mathrm{~mm}$ to the left and $5 \mathrm{~mm}$ to the right....

Figure 6.5. The reflectivity of different materials. Purple line in the middle corresponds to the aluminum highly reflective foil, the red lower line to the mirror tape and the blue higher line to the aluminum powder coat...

Figure 6.6. Detail for the deformations caused by the screws on the paraboloid's surface.....

Figure 6.7. Data on the drop on the heat flux measured by the Gardon gauge with the time and tendency line, with its respective equation and $R^{2}$ 101

Figure 6.8. Photograph of the near-Lambertian plate containing the Gardon gauge located at the point of maximum heat flux....

Figure 6.9. Photograph of the near-Lambertian plate without the Gardon gauge, located at the focal plane of the paraboloid concentrator, with exposure time of 1/480 s 102

Figure 6.10. Data for calibration of the grayscale of the black and white camera and the heat gauge measurements, including tendency lines, their equations and $R^{2}$ 103 
Figure 6.11. Photograph of the near-Lambertian plate located at the focal plane of the paraboloid concentrator, with an exposure time of $1 / 480 \mathrm{~s}$ converted to an RGB scale

Figure 6.12. Concentrated heat flux and accumulated thermal power in terms of target radius 104

Figure 6.13. Concentrated heat flux distribution on the central horizontal line of maximum concentration on the Near-Lamberian plate. The solid line represents the values acquired with the heat gauge and the dashed lines are tendency lines starting from the last 10 measurements of each side.

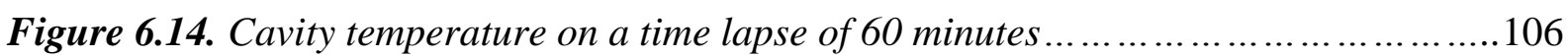

Figure 6.15. Difference of temperature of water in inlet and outlet on a time lapse of 60 minutes...... 107

Figure 6.16. Photograph of the deterioration of the secondary concentrator after the experiment. 107

Figure 6.17. Concentrated heat flux on the cavity calorimeter window on a time lapse of 60 minutes. 108

Figure A.1. Perforation of the plate by a CNC machine....

Figure A.2. Plate holes interconnected by the flexible aluminum tubes..... 119

Figure A.3. Plate with aluminum insert.... .120 


\section{LIST OF TABLES}

Table 2.1. Summary of the characteristics of the HFSS presented in this chapter....

Table 4.1. Simulated total thermal power, maximum and average heat flux, heat flux ratio, efficiency and stagnation temperature for the use of light cone and CPC

Table 4.2. Simulated total thermal power, maximum and average heat flux, heat flux ratio, efficiency using the optimized cone..... 71

Table 4.3. Summary of the HFSS final layout...

Table 4.4. Radius and corresponding lengths for a cylindrical cavity, with a $35 \mathrm{~mm}$ diameter window and areas ratio of 0.005 .

Table 6.1. Radiation thermal power measured by three different methods, equipment error limits and electric-to-radiant efficiency..... .98 


\section{LIST OF ABBREVIATIONS}

$\begin{array}{ll}\text { PV } & \text { Photovoltaics } \\ \text { CSP } & \text { Concentrated Solar Power } \\ \text { O\&M } & \text { Operational and Maintenance } \\ \text { ORC } & \text { Organic Rankine Cycle } \\ \text { TES } & \text { Thermal Energy Storage } \\ \text { FT } & \text { Fischer-Thompson } \\ \text { DNI } & \text { Direct Normal Iradiation } \\ \text { HFSS } & \text { High Flux Solar Simulator } \\ \text { LED } & \text { Light-Emitting Diode } \\ \text { CPC } & \text { Compound Parabolic Concentrator } \\ \text { MCRT } & \text { Monte Carlo Ray Tracing } \\ \text { AM } & \text { Air Mass ratio }\end{array}$


Latin letters:

\begin{tabular}{|c|c|}
\hline$q ”$ & Heat flux per unity of area $\left[\mathrm{kW} / \mathrm{m}^{2}\right]$ \\
\hline$Q$ & Heat flux $[\mathrm{kW}]$ \\
\hline$T$ & Temperature $\left[{ }^{\circ} \mathrm{C}\right]$ or $[\mathrm{K}]$ \\
\hline$C$ & Concentration ratio [-] \\
\hline$a^{\prime}$ & Aperture diameter $[\mathrm{mm}]$ \\
\hline$a$ & Exit diameter $[\mathrm{mm}]$ \\
\hline$n$ & Refraction index in the entrance medium [-] \\
\hline$n^{\prime}$ & Refraction index in the exit medium [-] \\
\hline$f$ & Focal distance $[\mathrm{mm}]$ \\
\hline$L$ & Length $[\mathrm{mm}]$ \\
\hline$F$ & Shape factor [-] \\
\hline$E$ & Radiation $\left[\mathrm{kW} / \mathrm{m}^{2}\right]$ \\
\hline$J$ & Radiosity $\left[\mathrm{kW} / \mathrm{m}^{2}\right]$ \\
\hline$A$ & Area $\left[\mathrm{m}^{2}\right]$ \\
\hline$U$ & Thermal losses $\left[\mathrm{kW} / \mathrm{m}^{2} . \mathrm{K}\right]$ \\
\hline$G$ & Incident radiation $\left[\mathrm{kW} / \mathrm{m}^{2}\right]$ \\
\hline$N$ & Number of spirals [-] \\
\hline$r$ & Radius [mm] \\
\hline$I$ & Irradiance $[\mathrm{kW}]$ \\
\hline$R$ & Ratio [-] \\
\hline$P$ & Power [W] \\
\hline$m$ & Mass $[\mathrm{kg}]$ \\
\hline$C p$ & Calorific power $[\mathrm{kJ} / \mathrm{kg} . \mathrm{K}]$ \\
\hline$c$ & Speed of light $[\mathrm{m} / \mathrm{s}]$ \\
\hline$k$ & Boltzmann constant $[\mathrm{J} / \mathrm{K}]$ \\
\hline$h$ & Planck's constant [J.s] \\
\hline$d$ & Distance $[\mathrm{mm}]$ \\
\hline
\end{tabular}


Greek letters:

$\begin{array}{ll}\sigma & \text { Stefan-Boltzmann constant }\left[\mathrm{W} / \mathrm{m}^{2} \cdot \mathrm{K}^{4}\right] \\ \gamma & \text { Cone semi-angle }\left[{ }^{\circ}\right] \\ \theta & \text { Acceptance angle }\left[{ }^{\circ}\right] \\ \varepsilon & \text { Emissivity [-] } \\ \tau & \text { Transmissivity [-] } \\ \alpha & \text { Absorptivity [-] } \\ \rho & \text { Reflectivity [-] } \\ \beta & \text { Fraction of absorbed heat }[-] \\ \eta & \text { Efficiency [\%] } \\ \lambda & \text { Wavelength [nm] }\end{array}$

Subscripts:

$\begin{array}{ll}e q & \text { Equilibrium } \\ \text { max } & \text { Maximum } \\ w & \text { Window } \\ \text { Ref } & \text { Reflected } \\ \text { Reir } & \text { Re-irradiated } \\ \text { Cw } & \text { Conduction and convection through the window } \\ \text { Cc } & \text { Conduction and convection through cavity body } \\ \text { Abs } & \text { Absorbed } \\ \infty & \text { Surrounding } \\ \text { eff } & \text { Effective } \\ \text { Tube } & \text { Spiral tube of the cavity } \\ \text { Lateral } & \text { Lateral of the cavity } \\ \text { Elec } & \text { Electrical } \\ \text { Rad } & \text { Radiation } \\ \text { SSL } & \text { Sky Searchlight }\end{array}$




$\begin{array}{ll}\text { paint } & \text { Copper paint } \\ W & \text { Water } \\ g & \text { Glass } \\ \text { out } & \text { Outlet } \\ \text { in } & \text { Inlet } \\ \text { min } & \text { Minimum }\end{array}$




\section{SUMMARY}

1 INTRODUCTION...................................................... 20

1.1 Solar Energy Scenario Outlook........................................20

1.2 Brazilian Heliothermal Power Potential..................................... 23

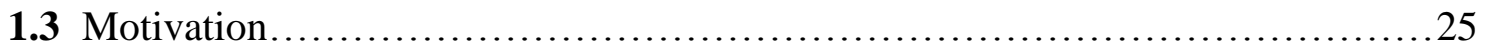

1.4 Objectives............................................................ 25

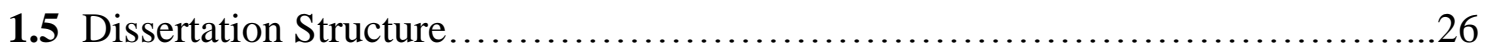

2 STATE OF ART AND LITERATURE REVIEW ............................... 27

2.1 High Flux Solar Simulators Types..........................................27

2.1.1. Light Sources.......................................................... 27

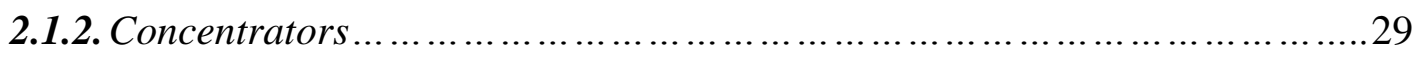

2.2 Literature Review..................................................... 30

2.2.1.ETH-Zentrum, Zurich, Switzerland (2003)...................................30

2.2.2. PSI, Zurich, Switzerland (2005) ........................................... 32

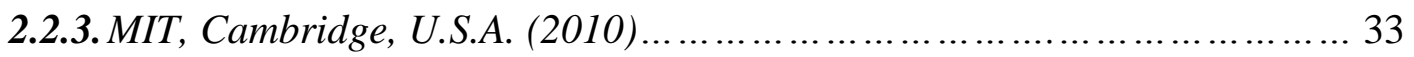

2.2.4. University of Minnesota, Minneapolis, U.S.A (2011)......................... 35

2.2.5. KTH Royal Institute of Technology, Stockohlm, Sweden (2014)................36

2.2.6. KIRAN-42, IMDEA Energy Institute, Mósteles, Spain (2014)...................38

2.2.7. Sandia National Laboratories, Albuquerque, U.S.A. (2015).................. 39

2.2.8. Swinburne University of Technology, Hawthorn, Australia (2015)........... 41

2.2.9. SISEA, Escola Politécnica, USP, Brazil (2016)............................................42

2.2.10. Synlight, DLR, Jülich, Germany (2017)...................................43

2.2.11. Institute of Engineering Termophysics, Beijing, China (2019)...............45

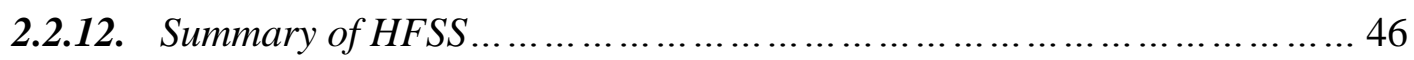

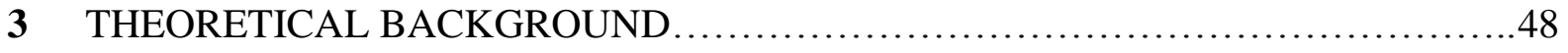

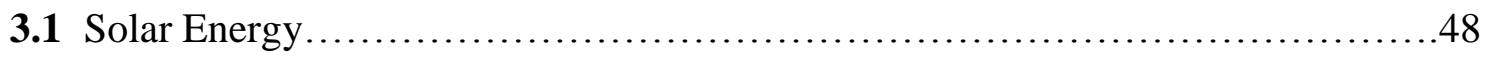

3.1.1. Solar Thermal Radiation .................................................. 48

3.1.2. Solar Concentrators .......................................................... 50

3.1.3. Nonimaging Solar Concentrators..................................... 52

3.2 Chemical Reactors for Solar Fuels...................................... 54

3.2.1. Cavity Receptor and Chemical Reactors .................................... 54

3.2.2. Thermal Equilibrium of the black body cavity ............................... 55

4 THE HIGH FLUX SOLAR SIMULATOR ......................................61 
4.1 New High Flux Solar Simulator proposed.................................6 61

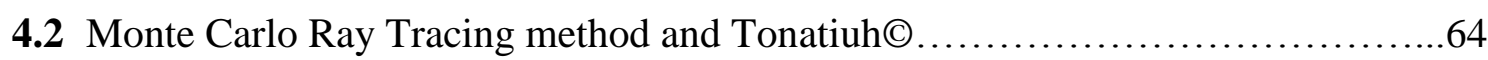

4.2.1. Off-set Concentrators ...................................................... 64

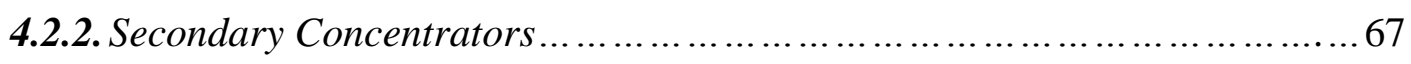

4.3 Final High Flux Solar Simulator Layout.................................... 72

4.4 Calorimeter Cavity Design............................................ 72

5 TEST RIG AND INSTRUMENTATION ...................................... 77

5.1 Instrumentation .......................................................... 77

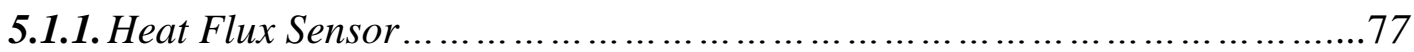

5.1.2. Spectrophotometer........................................... 77

5.1.3. Near-Lambertian Plate .................................................... 80

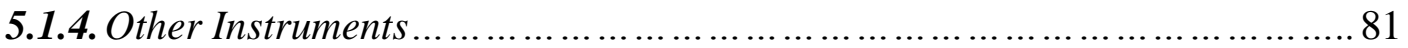

5.2 Thermal Power of the Sky Searchlights Analyses.............................82

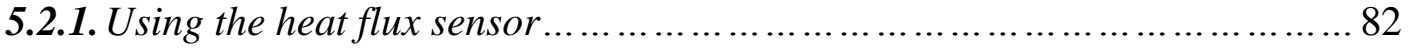

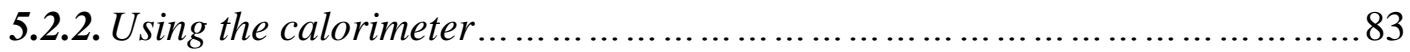

5.2.3. Using the spectrophotometer .......................................... 86

5.3 Reflectivity of Materials............................................. 88

5.4 Determination of the Concentrated Heat Flux................................. 89

5.5 Calorimeter Cavity Test................................................ 91

6 RESULTS AND ANALYSES .............................................. 94

6.1 Thermal Characterization of the Sky Searchlights............................94

6.2 Concentrators Material................................................... 98

6.3 High Flux Solar Simulator thermal power................................ 100

6.3.1. Calibration of the grayscale and radiometer............................ 101

6.3.2. Near-Lambertian plate analyzes........................................ 103

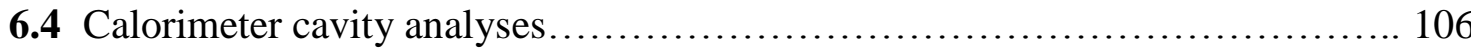

7 CONCLUSIONS........................................................ 109

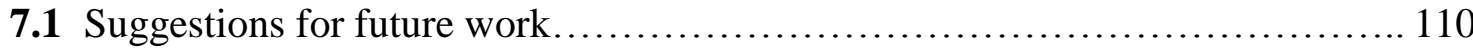

REFERENCES ................................................................ 111

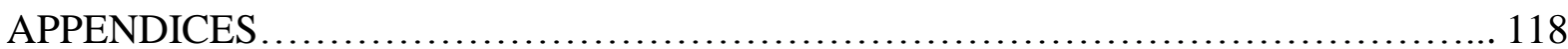

APPENDIX A - MANUFACTURING OF THE NEAR-LAMBERTIAN PLATE........ 119

ANNEXES ................................................................ 121

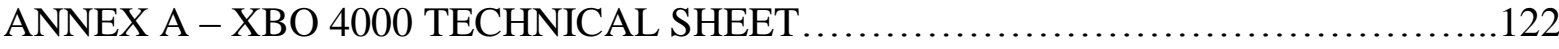


ANNEX B - CALIBRATION CURVE OF THE HEAT GAUGE PROVIDED BY VATELL

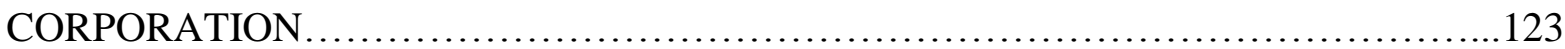

ANNEX C - SPECTRAL SENSITIVITY OF THE CAMERA......................... 124 


\section{INTRODUCTION}

The energy demand worldwide has grown $2.3 \%$ (Jungcurt, 2019) only in 2018, which is faster than any rate in the last ten years, from which $31 \%$ correspond to Solar sources. In Brazil, the forecast for increase in energy consumption in 2019 has been 4\% (Polito, 2019). As the need for energy grows faster every day, the urge to develop renewable, sustainable and efficient ways of producing it becomes more urgent.

\subsection{Solar Energy Scenario Outlook}

There is an extremely important subject when dealing with renewable energies: the pollutants emissions formed during energy conversion processes, such as nitrates, sulfates, among others. Biomass, solar, and wind energies are responsible for low emission levels.

A 40\% growth of PV (photovoltaics) power generation between 2017 and 2016 (IEA, 2019) may be significantly explained by the abrupt price fall of $70 \%$ of this technology since 2010 (IEA, 2019). Though, Kabir et al. (2018) highlight that the initial investment and payback time are still high because of the use of rare precious metals like silver, tellurium, and indium in the manufacturing of silicon cells, the most applied technology and also that there are only a few recycle units for those metals. The low gravimetric and volumetric energy density of the electrochemical batteries used for storage, almost 100 times lower than gasoline or diesel fuels, is another drawback (Chu et al., 2016).

Once PV relies on Sun's irradiance, it becomes imperative to deal with intermittency, seasonality, and installation location. It is also very abundant and responsible for really low $\mathrm{CO}_{2}$ emissions. CSP (Concentrated Solar Power or heliothermic energy), being also Sun dependent, shares those singularities with PV technology.

On the other hand, Khan \& Arsalan (2016) state that CSP leads to lower environmental impacts than PV for the same level of generation capacity and also that CSP plant generates more electrical power than a PV plant. This comparison indicates that the economic return for the CSP is faster even though its initial investment is higher. Concerning O\&M costs both technologies present reasonable rates: $2 \%$ of the initial investment for PV power plants and $5 \%$ for CSP.

Solar plants account more human resources than other kinds of electrical power plants, even taking into account the automation of the sector for hundreds of people are needed on the 
operation of a large Solar plant and the average time of construction of such a plant is 18 months (Peters, 2017). In the United States, Solar and Carbon plants register the same amount of employees nonetheless Solar sector sums up only $1.3 \%$ of the electrical grid (Peters, 2017), growing 17 times more than the National economy according to Egan (2017). In South Africa, the construction of a 100 MW Solar plant has employed around 1,200 workers (Writer, 2019) and a total of 120 jobs are estimated to be created after all the three power plants, summing $200 \mathrm{MW}$, are in operation (Moyo et al., 2017). Egan (2017) claims the large natural availability of Sun irradiance in some areas of the Globe, favors the hiring of people in these places for installation, production, and selling.

The electrical power generation from CSP works by transferring heat to the working fluid of a known thermodynamic cycle such as Rankine, Brayton, ORC (Organic Rankine Cycle) or a Brayton-Rankine combined. Thermal Energy Storage (TES) system may be included to store thermal energy to be used during low or none Solar irradiation, which is a great advantage compared to PV technology. Figure 1.1 shows the schematics of a tower CSP power plant with the TES system. The Solar irradiation is reflected in a tower receptor, where a fluid is heated. This fluid is partially stored in the TES, and another portion is directed to the boiler, in which the working fluid is heated and transmitted to the turbine, responsible for electricity generation.

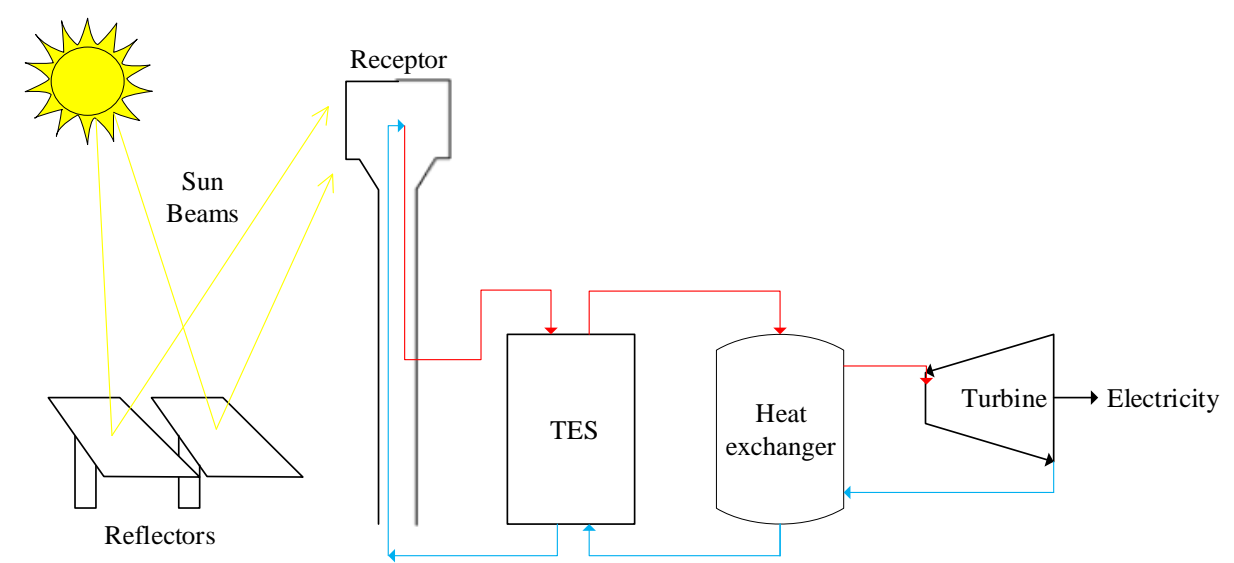

Figure 1.1. Simplified Concentrated Solar Power plant with Thermal Energy Storage system.

CSP systems hybridized with fossil fuels, on a way of producing Solar fuels, are now widespread, measuring up to $77 \%$ of the CSP plants operational in 2017 , being the shale gas the primary fuel used (Pelay et al., 2017). Although this percentage tends to fall as the price of this type of fuel keeps rising. A less pollutant alternative to fossil fuels and 100\% 
renewable is the use of different kinds of biomass, i.e., forest residue, sugarcane bagasse, or urban solid waste. These are sources of high volumetric energy density that could directly replace fossil fuels.

A way of producing Solar fuels is using CSP as activating power source for endothermic thermochemical reactions, which may occur by several routes, as shown in Figure 1.2. Two main divisions may be determined: $\mathrm{H}_{2} \mathrm{O} / \mathrm{CO}_{2}$-splitting, which works with thermal dissociation of water or $\mathrm{CO}_{2}$ and decarbonization, which thermally decomposes hydrocarbonates. Two routes may be followed in the $\mathrm{H}_{2} \mathrm{O} / \mathrm{CO}_{2}$-splitting. The solar thermolysis works by only supplying energy to split the components of the compound, but the high temperature requirement for dissociation and the danger of the separation of the explosive hydrogenoxygen mixture are engendered risks. The solar thermochemical cycle, on the other hand, works of more moderate temperatures and suppresses the step separation of $\mathrm{H}-\mathrm{O}$ mixtures by procucing each one in a different stage (Yadav \& Banerjee, 2016).

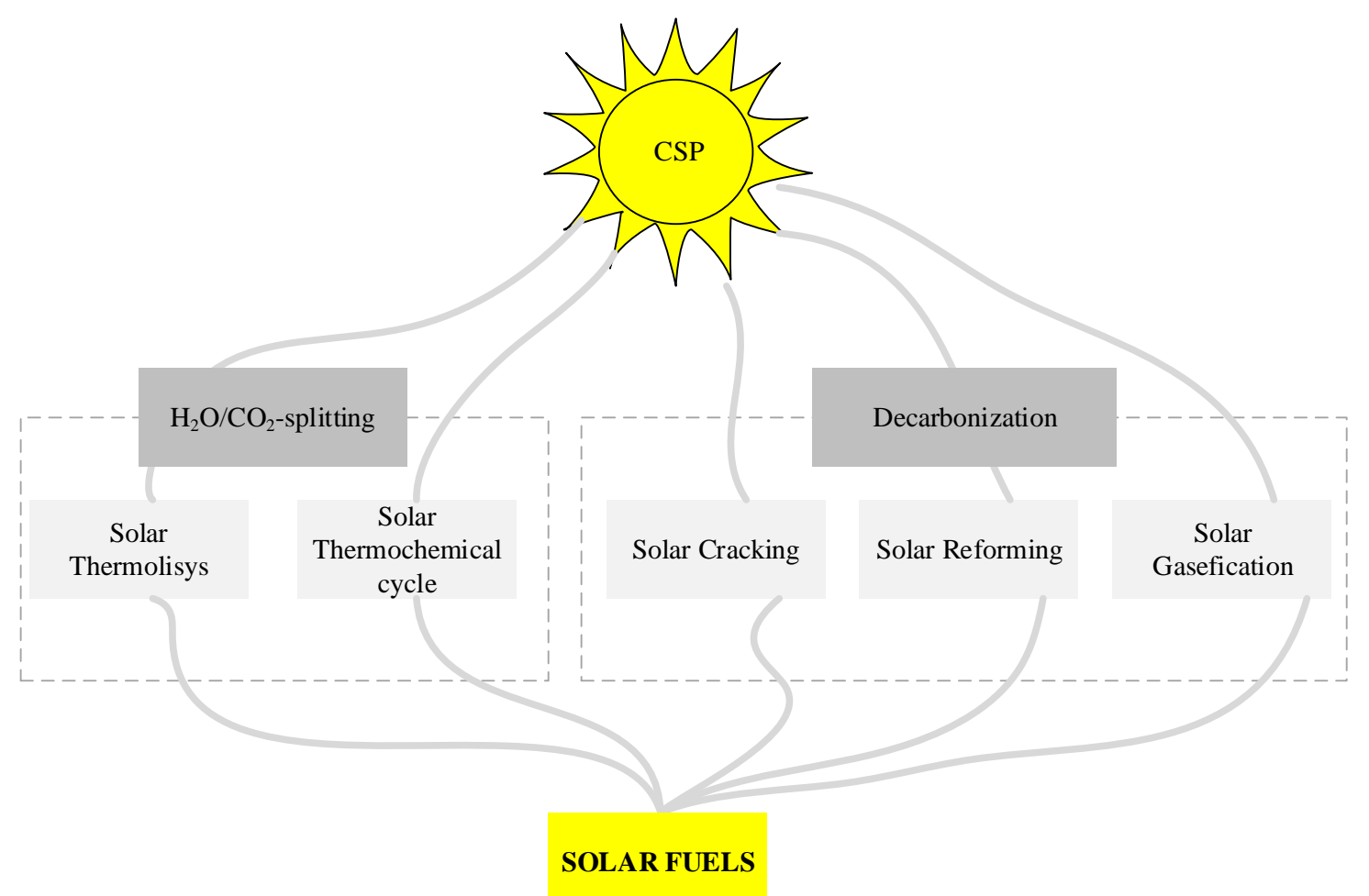

Figure 1.2. Routes for the production of Solar fuels from $\mathrm{H}_{2} \mathrm{O} / \mathrm{CO}_{2}$-splitting or decarbonization.

A promising application is the use of solar thermochemical cycle to produce syngas (a $\mathrm{CO}+$ $\mathrm{H}_{2}$ mixture), which can be fed into a synthesis reactor to generate methanol or in a FischerThompson (FT) plant to produce FT fuels. Aside from the thermochemical reactor, this 
technology is well developed, leading to production costs of, approximately, $1.29 \$ / \mathrm{kg}$ of methanol and $2.55 \$ / \mathrm{kg}$ of FT fuel (Detz et al., 2018).

Regarding the scenario where the syngas mixture is not the aim, the cracking of a fossil fuel generates a solid phase rich in carbon and a gasosous rich in hydrogen. while the later is largely used in refinaries and in the chemical industry, the former is a commodity and can be used as redactor agent in metallurgical processes (Simões-Moreira et al., 2017).

Other application of CSP includes water heating, used for showering and building heat and cooling. Khan \& Arsalan (2016) highlight that CSP is more indicated for big scale commercial use, given the large area needed to place the collectors.

\subsection{Brazilian Heliothermal Power Potential}

The yearly average of global Solar irradiance varies between 60 and $250 \mathrm{~W} / \mathrm{m}^{2}$. Although there are some "black dots" on Earth, areas where the Sun irradiance is so big they could be responsible for making up for all world primary energy demand, considering a conversion rate of only 8\% (Kabir et al., 2018).

Other than PV systems, which operate both with direct and diffuse irradiation, mirrors and optical concentrators are capable of focusing only DNI (Direct Normal Irradiation), obeying the Law of Reflection. This way DNI is a good reference of the CSP generation capacity. Generally arid and semiarid regions, where the sky is usually blue, at latitudes from $15^{\circ}$ to $40^{\circ}$ North or South point to ideal DNI (Guerrero-Lemus \& Martínez-Duart, 2013).

According to Guerrero-Lemus \& Martínez-Duart (2013), the minimum DNI estimated to a region to present a good CSP potential is between 1,900 and 2,100 $\mathrm{kWh} / \mathrm{m}^{2} /$ ano. Figure 1.3 shows DNI worldwide, pointing out great CSP potential at some portions of the west of North and South America, South of Africa and Australia, places located at regions of characteristics above mentioned.

Figure 1.3 and 1.4 point out Brazil regions center-west and north-east as presenting good CSP potential, where DNI reaches $2,264 \mathrm{kWh} / \mathrm{m}^{2} /$ year, close to India and South of Spain and more than twice of Germany, countries widely recognized by CSP investment. According to Malagueta et al. (2014), the Brazilian area reaching the minimum intensity of DNI for CSP setup sums $97,700 \mathrm{~km}^{2}$. 


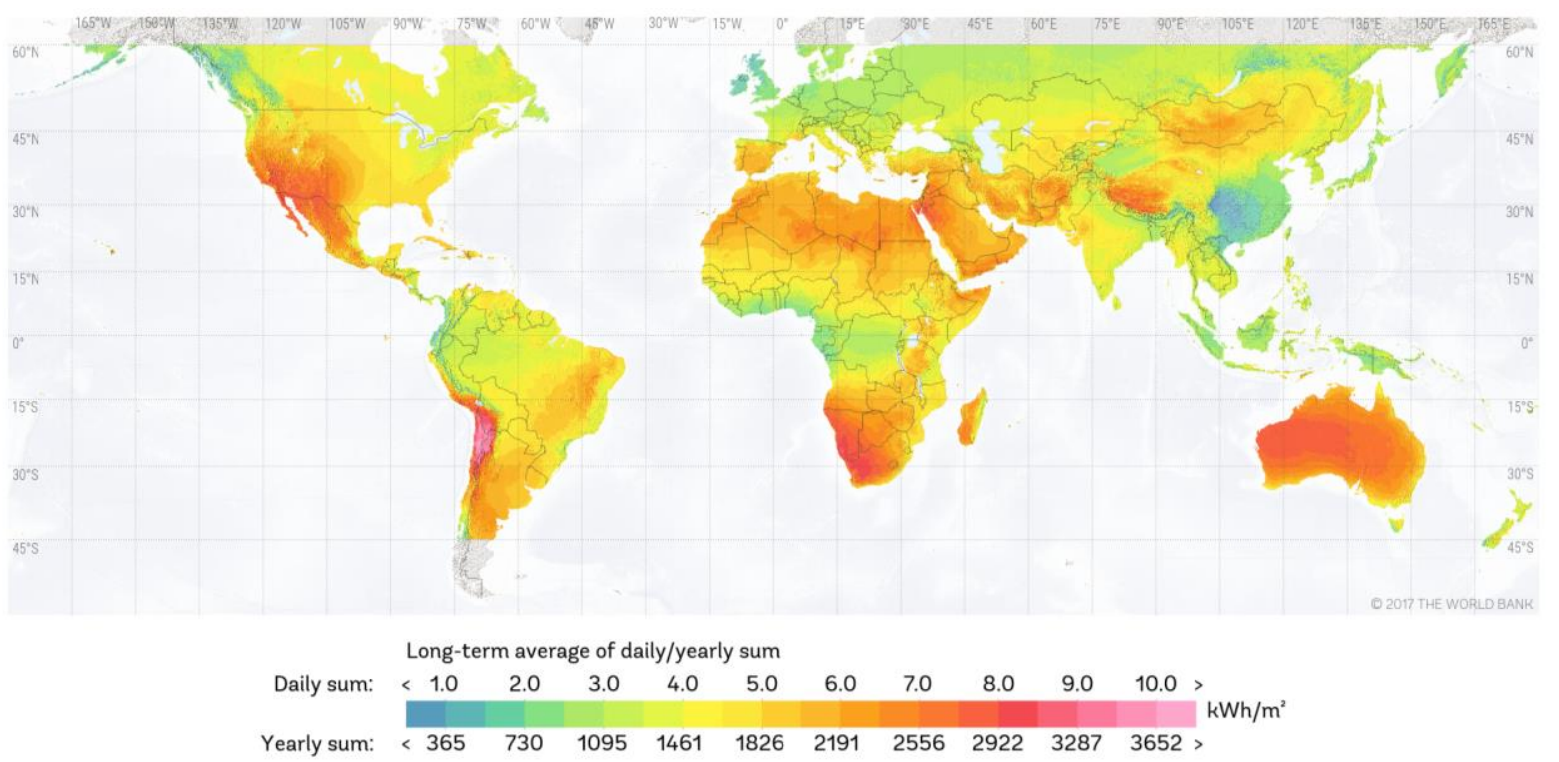

Figure 1.3. The long-term average of the daily/yearly sum of DNI worldwide (Solargis, 2019).

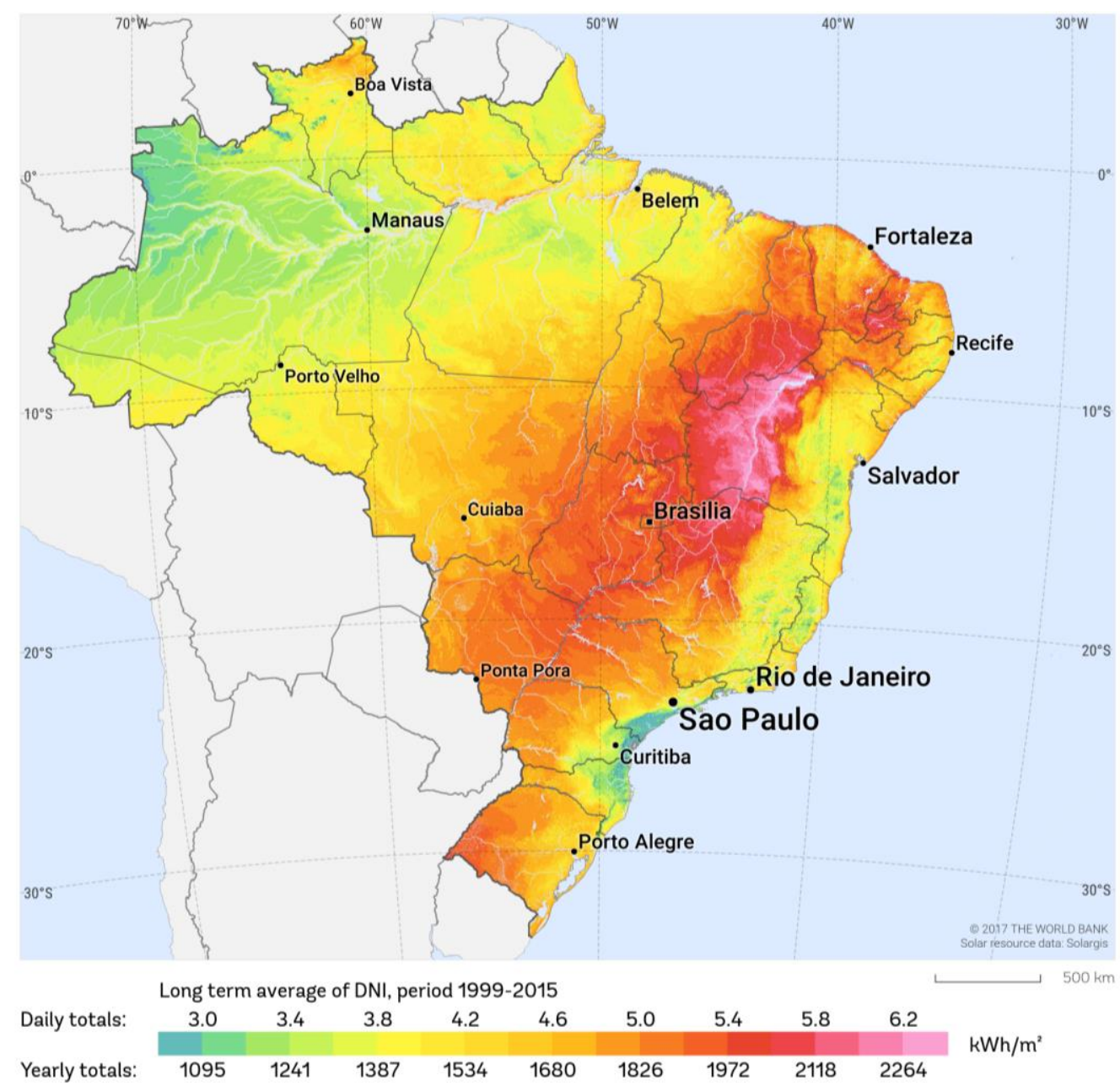

Figure 1.4. Average of the daily/yearly sum of DNI in Brazil from 1999 to 2005 (Solargis, 2019b). 
The instruments used to measure DNI are pyrheliometer and pyranometer. A pyrheliometer measures the DNI directly and requires a tracking system, so it is always perpendicular to Solar beams. A pyranometer derivates the DNI from the total radiation, and so there is no positioning requirement. Both depend on clear sky condition, which is fundamental for the stability of DNI, and need daily inspection and maintenance, given the complex assemblage and the high sensibility to dust and pollution (Pape et al., 2009). These characteristics lead to uncertainties such as those measured by (Myers, 2010) on which the particular pyranometer has pointed $\pm 8 \%$ error and the pyrheliometer $\pm 20 \%$ error for DNI lower than $400 \mathrm{~W} / \mathrm{m}^{2}$ and $\pm 10 \%$ error for DNI higher than $600 \mathrm{~W} / \mathrm{m}^{2}$. The error calculated for the pyranometer is acceptable; on the other hand, the error for the pyrheliometer are not. DNI is also dimensioned from satellite data, which depends on the Sun azimuth, steam, and gases in the atmosphere and other factors.

\subsection{Motivation}

The high rate of DNI in Brazil turns the country into a potential territory for the development of concentrated solar power. Meanwhile, the production of Solar fuels appears as a promising way of storing the Sun's energy as much as diversifying the sector, finding new usages for biomass such as urban solid waste or increasing the energetic power of combustibles already in use, for example, the shale gas.

The enlargement of the solar fuel field of research, which is not yet fully developed, requires the application of previously known parameters such as the amount of input energy and its stability in a given time-lapse. The Sun's thermal energy is an intermittent and seasonable energy source though. Thus, the use of a solar simulator, which mimics the Sun's high thermal flux, shows up as a solution to deal with those difficulties. So, the design, building, and characterization of a High Flux Solar Simulator (HFSS) are indispensable in the investigation of Solar fuels.

\subsection{Objectives}

The main goal of this work is to design, build, and characterize in means of concentrated heat flux an off-the-shelf High Flux Solar Simulator (HFSS). Therefore the following specific objectives have been proposed: 
- Design of the geometry, selection of materials and building of the reflector concentrators;

- Evaluation of the thermal power provided by the light sources;

- Characterization of the HFSS in means of concentrated heat flux and total thermal energy provided.

- Carry out a mathematical analysis of a black-body cavity;

- Build of a calorimeter cavity and tests with it;

\subsection{Dissertation Structure}

The present work is going to be divided in a state of art and literature review (section 2), in which HFSS successfully developed around the world are going to be presented. A summary of their main characteristics of those HFSS is going to be included at the end of the chapter. Then, section 3 is going to present the theoretical background needed to understand the parameters of designing and evaluation of the HFSS. Section 4 is going to contain computational simulations and other analyzes used as base for the HFSS and calorimeter cavity proposed, and also the final layout that is going to be studied. The instrumentation and test rigs applied to the characterization of the HFSS are going to be presented in section 5, followed by the concerning results and analyzes in section 6 . In the last section (number 7), the conclusions of this work as well as suggestions for future work are going to be introduced. 


\section{STATE OF ART AND LITERATURE REVIEW}

\subsection{High Flux Solar Simulators Types}

Sun's seasonality and intermittency render difficulties when doing research related to this power source. In this context, the design and construction of a Solar simulator, which mimics indoor the operation of an outdoor apparatus is of great significance.

The research on Solar simulators has started in the 1960s, because of the Nasa's interest in satellites and spatial vehicles, leading to investment in spatial environment chambers, aiming at the spatial research on Earth (Wang et al., 2014). In 1975, Solar simulators used for tests of photovoltaic's Solar cells have been developed and standardized (Wang et al., 2014).

From the 2000s, the High Flux Solar Simulators (HFSS) have begun to gain special attention due to the growing interest in CSP technologies. Those differ from previous Solar simulators for mimicking not only the spectral distribution of the Sun, but also the Sun's high thermal and luminous flux needed in these systems.

An HFSS is composed mainly by light sources and optical concentrators. Some more advanced simulators may can contain spectral optical filters.

\subsubsection{Light Sources}

According to Wang (2014), the light source of a solar simulator must be analyzed in terms of spectral distribution, luminous uniformity, beams collimation, stability, and thermal flux intensity.

At the beginning of the spatial simulators research, carbon arc lamps and mercury-xenon lamps (also referred to as mercury arc lamps) were the most applied. After verifying the short operational time and instability and the high emission of blue radiation of the carbon arc lamps (Esen et al., 2017), and the danger of explosion, mercury leakage and ozone creation of the mercury arc lamps (Wang, 2014), their use has been interrupted

In the HFSS field, various lamps have been studied. The quartz-tungsten-halogen lamps are an example of a light source that does not match the solar spectrum, once the black body color temperature of the lamps is $3500 \mathrm{~K}$ maximum, and the Sun is approximately $5900 \mathrm{~K}$, but can be used as an infrared light source on solar simulators of lesser requirements (Wang, 2014). 
Because of the almost monochromatic LED (light-emitting diode) lamps spectrum, they can be combined, leading to a spectrum very similar to the Sun's. They also can be controlled in a milliseconds interval, have a long lifespan and low power consumption (Wang, 2014). On the other hand, they require a cooling system because of the unfavorable influence of high temperatures in their output energy, efficiency, and lifespan (Wang, 2014). Also, given their low current intensity, they are not fit for HFSS applications but are widely used in PV applications.

In terms of spectral distribution, the metal halide arc lamps are the most similar to the Sun, except between $850 \mathrm{~nm}$ and $950 \mathrm{~nm}$ wavelengths, where they are more intense, and according to Ekman et al. (2015), 90\% of the electrical input is converted and irradiated as thermal energy. The low beams collimation, though, is more frequently used in low concentration ratio solar simulation (Wang, 2014).

Currently, the xenon arc lamps are the most used light sources in HFSS. They present a close spectral distribution to the Sun's, except between $800 \mathrm{~nm}$ and $1000 \mathrm{~nm}$, where they show intensity peaks. Their very shinning and almost punctual characteristics lead to the ease of lighting collimation (Matson et al., 1984).

As the most significant drawbacks of the xenon arc lamps are the high operation pressure, which may lead to explosion danger, the high cost due to the individual needs on the power supply and the low lifespan to research (less than 600 hours, according to Gallo et al., 2017), may be named.

Dong et al. (2015) state that even though the spectrum aberration of metal halide lamps, when compared to the Sun's, is smaller, the xenon arc lamps offer a much more stable radiation intensity. Compared to the LED lamps, Leary et al. (2016) suggest the xenon arc lamp's electrical output is less stable, their lifespan shorter and the input required power is higher, but LED lamps are not thermally stable.

Finally, argon arc lamps are mentioned due to the high power a single lamp can offer. Similarlay to xenon arc lamps, they are highly pressurized and present a close spectrum to the Sun's, but present peaks between $750 \mathrm{~nm}$ and $1000 \mathrm{~nm}$ (Gallo et al., 2017).

Dichroic optical filters, which limit the way of a given wavelength, changing the spectral distribution, may be used with the light source to reduce the aberrations compared to the Sun spectrum. They are commercially available to various wavelengths and can be combined according to the lamp bulb chosen and the need. On the other hand, when filters are used, the 
energy intensity is reduced, which may be a significant drawback when high heat fluxes and temperatures are aimed.

\subsubsection{Concentrators}

The concentrator is an optical apparatus used to reflect the beam of a light source, redirecting them to a given direction and increasing the heat flux by area at this region.

Due to the optical-geometrical characteristics, the ellipsoid concentrator is the most adopted one. Ellipsoids have two focuses and when a light is placed at one of them, its beams are first reflected on the other one, as shown in Figure 2.1. This way, it is usual in HFSS to place a lamp at one of the concentrator focus, assuring that, ideally, all beams are directed to the other focus.

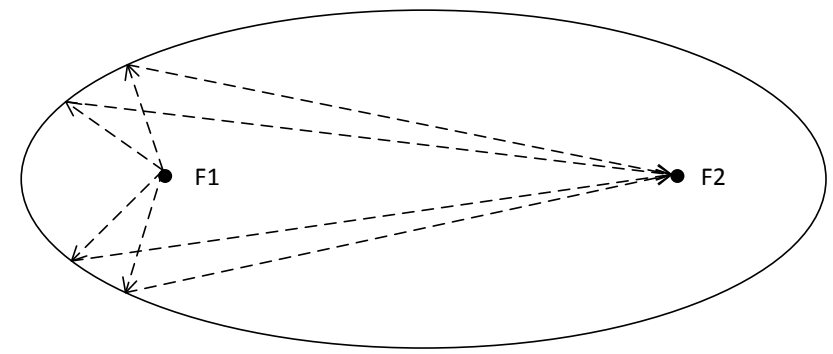

Figure 2.1. Schematics of optical-geometrical characteristics of an ellipsoid reflector.

The parabolic dish presents a unique optical-geometrical characteristic: when a light source is placed at its focus, all beams are reflected on its surface area collimated (Figure 2.2a). Also, all beams reaching the paraboloid parallel to its axis are reflected to its focus (Figure 2.2b).
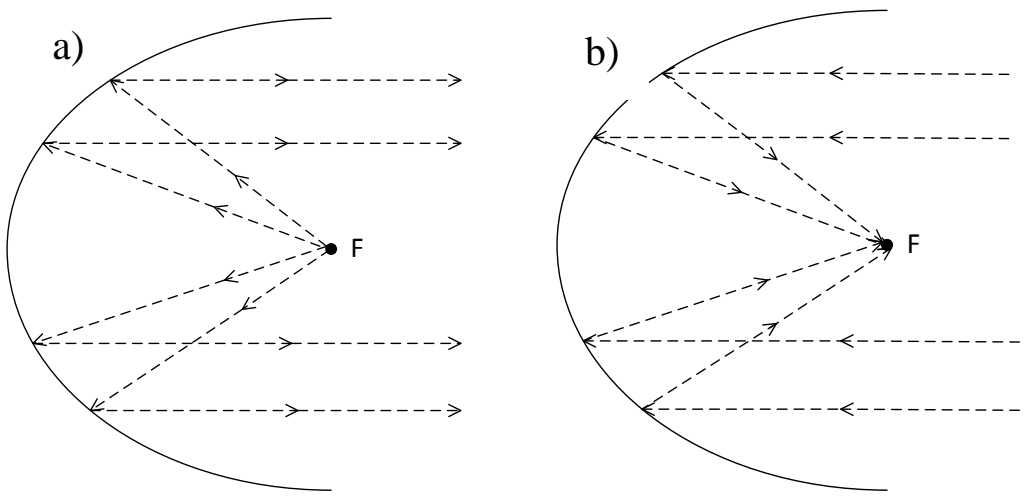

Figure 2.2. Schematics of optical-geometrical characteristics of a paraboloid. a) light source at the focus; b) collimated beams reaching the paraboloid and being reflected to the focus. 
Usually, HFSS used in thermochemical research count with two concentrators: one used to concentrate and redirect the light source beams (frequently ellipsoidal) and a secondary nonimaging concentrator, placed at the cavity reactor aperture window, which reduces the concentration area even further.

High flux solar simulators (HFSS) are apparatus composed by light sources and optical concentrators, used in the research of solar fuels, as a way of providing constant and reliable heat flux to study the occurring process.

This section presents HFSS used on concentrated solar power research, developed by many groups from different worldwide regions. It is going to provide useful information to select the light source, concentrators, and physical arrays fit the goal of this work.

In the literature, it is usual to define the parameter 1 "Sun" as the amount of $1 \mathrm{~kW} / \mathrm{m}^{2}$ heat flux. The stagnation temperature, determined by the Stefan-Boltzmann law, Equation (2.1), is also often referred.

$$
\dot{q}^{\prime \prime}=\sigma T_{e q}^{4}
$$

Where:

$\dot{q}^{\prime \prime}$ is the heat flux per unit of area $\left[\mathrm{W} / \mathrm{m}^{2}\right]$;

$\sigma$ is the Stefan-Boltzmann constant equals to $5.67 \times 10^{-8} \mathrm{~W} / \mathrm{m}^{2} \mathrm{~K}^{4}$;

$T_{e q}$ is the equilibrium temperature $[\mathrm{K}]$.

\subsection{Literature Review}

In this section, it has been presented the main types of HFSS located in international solar research centers.

\subsubsection{ETH-Zentrum, Zurich, Switzerland (2003)}

The HFSS reported by Hirsch et al. (2003), developed in the ETH-Zentrum (Switzerland) includes a pressurized $200 \mathrm{~mm}$ length argon arc enclosed lamp, $200 \mathrm{~kW}$ DC, under maximum current of $700 \mathrm{~A}$. It is located at one of the focuses of an elliptical trough reflector, which can be seen in Figure 2.3. Given the tubular geometry of the lamp and the shape of the concentrator, the focus is also linear. 


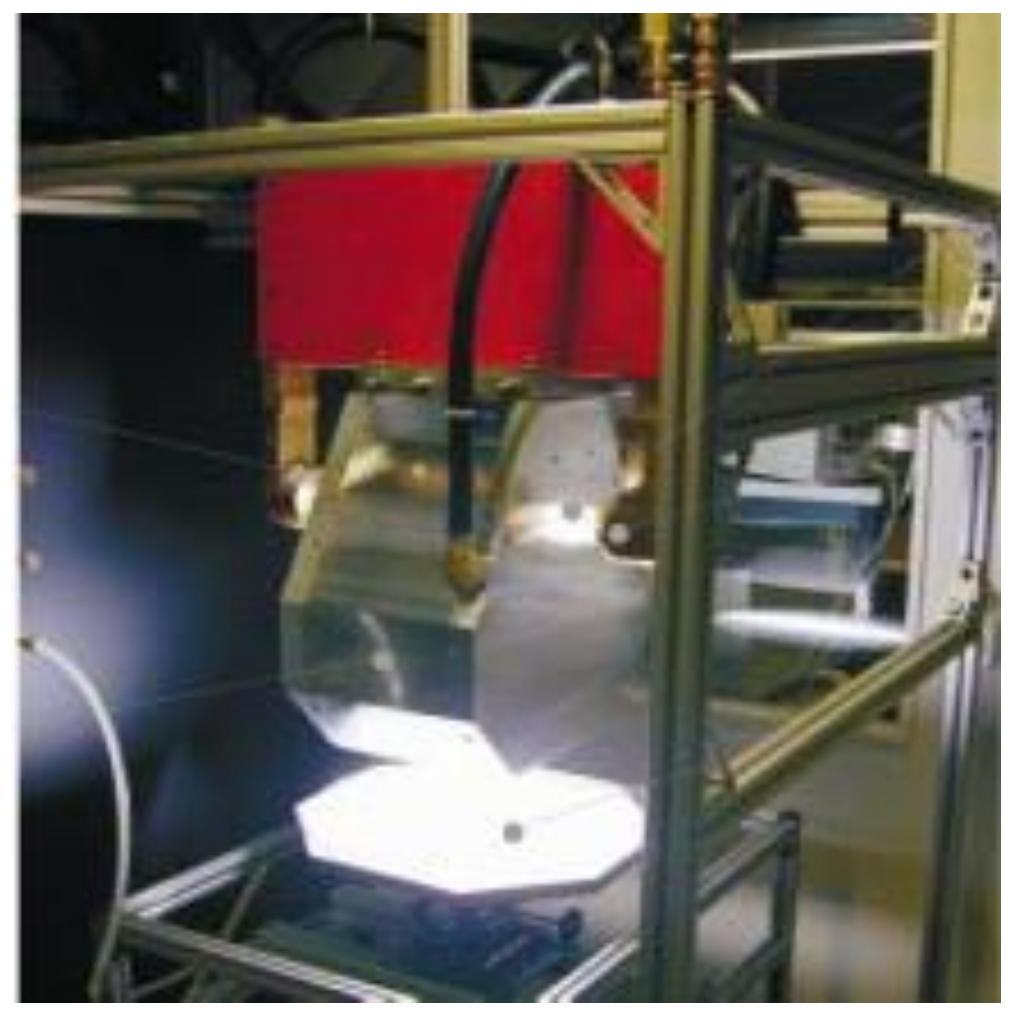

Figure 2.3. HFSS developed in the ETH-Zentrum, Zurich (Hirsch et al., 2003).

The authors show that the analysis of heat flux changes with the diameter of the target: the point of maximum power flux is located at the center of the target, reaching 3250 Suns, for a 500 A lamp and declines fast the larger the diameter. On the other hand, the intercepted radiative power (the mean energy in that area) is more powerful when a more significant area is considered, reaching almost $7 \mathrm{~kW}$ in a $6 \mathrm{~cm}$ diameter target for the same configuration.

The electrical arc current also affects the power flux intensity, which is more intense, the stronger the arc current. The maximum power flux of over 4250 Suns has been attained with 600 A current, corresponding to more than $2900 \mathrm{~K}$ stagnation temperature.

In this way, the power can be adjusted depending on the application by varying the electrical current or by changing the position of the target around the ellipse focus.

The use of a 2D CPC as a secondary reflector, of $90 \%$ reflectivity, located at the focal plane of the through, with a half acceptance angle of $45^{\circ}$ has increased the mean power flux at its exit by $30 \%$ and a 3D CPC by $90 \%$. 


\subsubsection{PSI, Zurich, Switzerland (2005)}

Information regarding the HFSS designed in the Paul Scherrer Institute (PSI), placed at the ETH-Zentrum, in Zurich, has been firstly released by Petrasch \& Steinfeld (2005). In this study they have analyzed, using an Monte Carlo ray tracing (MCRT) software, the most suited optical design, in terms of transfer efficiency, for three arrays of xenon arc lamps Ushio UXW, each one placed at one of the foci of a truncated ellipsoid of revolution. They have stated that an array of ten $15 \mathrm{~kW}_{\mathrm{e}}$ (electrical power) should be able of delivering $16.8 \mathrm{~kW}$ to a $6 \mathrm{~cm}$ diameter circular target, reaching an electrical-to-radiant efficiency of $35 \%$ and average radiative power flux over 5,900 Suns.

Then, Petrasch et al. (2007) have manufactured the array previously proposed (Figure 2.4) and matched the results attained. At a $6 \mathrm{~cm}$ diameter circular target, an input thermal power of $20 \mathrm{~kW}$, average radiative power flux of 6,800 Suns and stagnation temperature of $3300 \mathrm{~K}$ are reached, corresponding to more significant values than the MC simulation, but still close. A peak value of 11,000 Suns is attained at a circular radius of $3 \mathrm{~mm}$. As expected, the radiative power grows higher when the target area analyzed becomes bigger: over $50 \mathrm{~kW}$ at a $24 \mathrm{~cm}$ diameter.

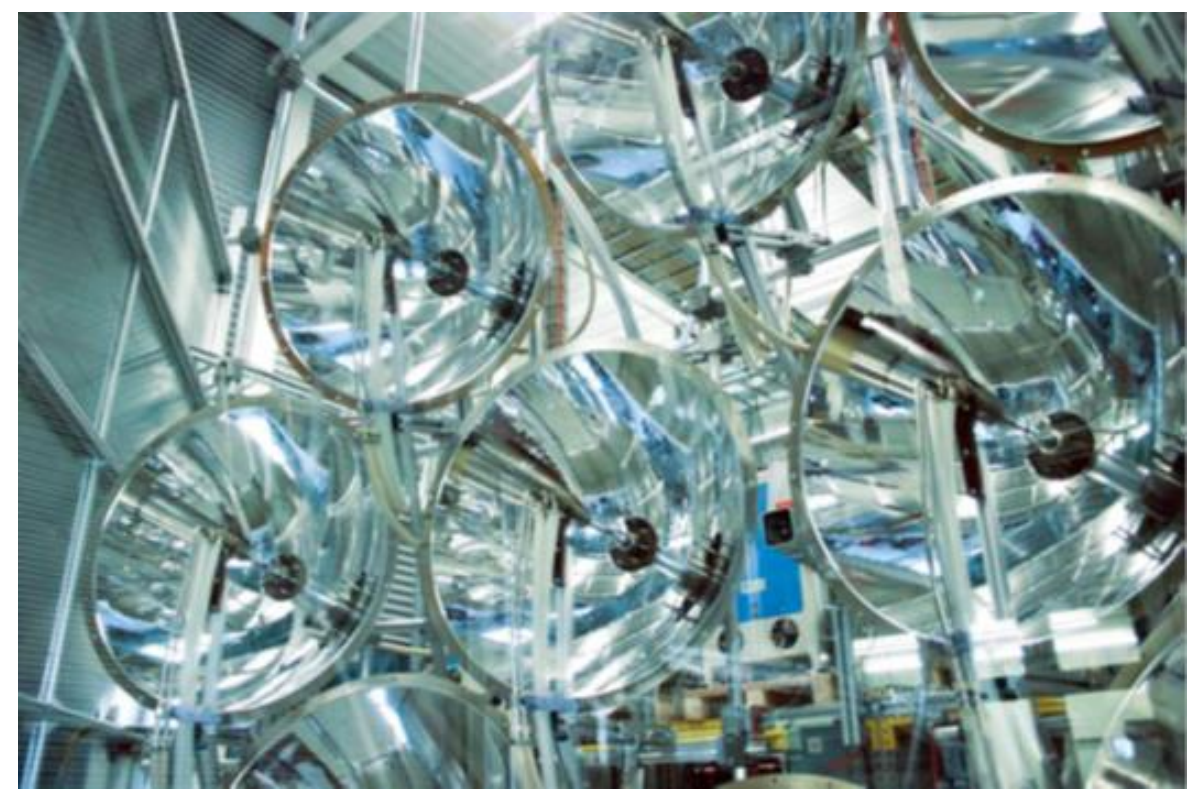

Figure 2.4. Some of the modules of Xenon arc lamps and truncated ellipsoid reflectors of the HFSS developed in the PSI, Zurich (Petrasch et al., 2007).

The influence of the target position about the focal plane have also been studied, and the authors have concluded that the peak flux decays by a factor of 2 for each $50 \mathrm{~mm}$ further from the focal plane. The spectral distribution of the lamps have been characterized by Alxneit \& 
Schmit (2011), who starting from the recognition of an almost circular flux distribution, have described that the intensity of the spectrum decreases when the measurement is made further from the center of the circle, although a unique color temperature of $6000 \mathrm{~K} \pm 200 \mathrm{~K}$ is settled regardless of the position. The color temperature of the Sun at AM $=1.5$ is $5800 \mathrm{~K}$, so this result shows that the xenon lamp compares well.

\subsubsection{MIT, Cambridge, U.S.A. (2010)}

Codd et al, (2010) have developed an off-the-shelf low cost HFSS at the Massachusets Institute of Technology (MIT), using seven metal halide outdoor stadium light of $1500 \mathrm{~W}$ each, which are less expensive than xenon arc lamps, but are complicated to focus in a small area due to the long filament inside de bulb. These lamps are commercially available with spun-aluminum ellipsoidal reflectors. Peaks of energy between 800 and $1000 \mathrm{~nm}$ wavelengths have been identified, corresponding to $11 \%$ of the energy at $350-1000 \mathrm{~nm}$ range, while it is only $6 \%$ of the Sun's.

The seven light sources are displayed in a widespread hexagonal array, containing one lamp in the center and mounted in a completely adjustable structure, of changeable height and rotatable axis.

A hexagonal truncated flow-line concentrator (hyperboloid), of $38 \mathrm{~cm}$ diameter output and $24.9^{\circ}$ half angle is used. Although an average of two reflections occur inside the concentrator, it has been verified that the natural convection and the climate-controlled laboratory at $25{ }^{\circ} \mathrm{C}$ are enough to keep acceptable heat flux and temperature. Figure 2.5 represents the mounted and running simulator. 


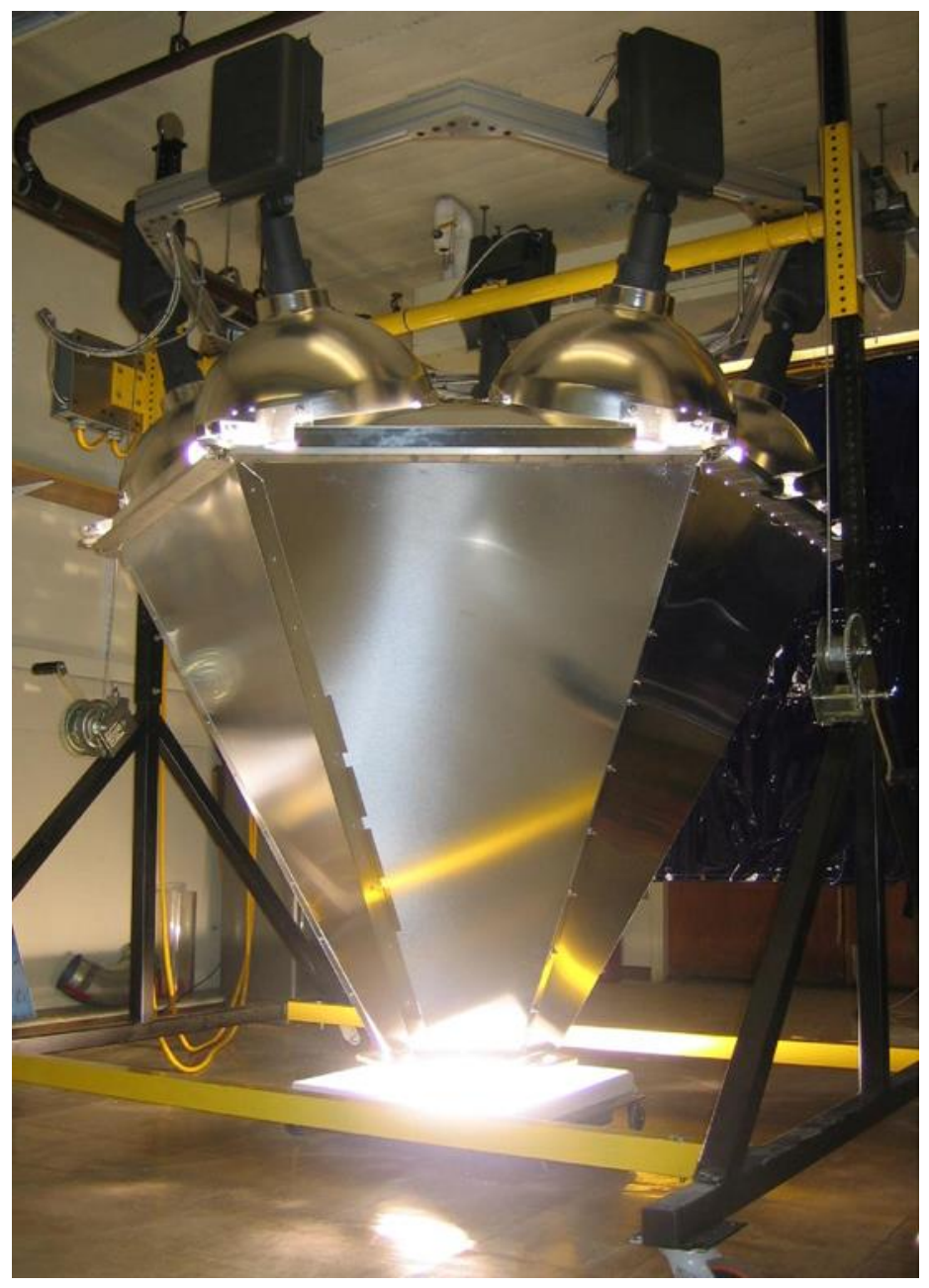

Figure 2.5. HFSS located at MIT, Cambridge, containing the seven metal halide outdoor stadium lights, the flow-line concentrator, and the adjustable structure (Codd et al., 2010).

The optical power attained by this HFSS is calculated using energy balance and assuming steady-state conditions, from the measurement of the temperature of an aluminum plate, located at the output of the secondary concentrator. The temperature reaches the thermal equilibrium after only 20 minutes, and it decreases when the plate is moved away from the center of the hexagon, being $730 \mathrm{~K}$ when centered and $654 \mathrm{~K}$ when displaced at $102 \mathrm{~mm}$. A maximum heat flux of 60 Suns and an average of 45 Suns across a $38 \mathrm{~cm}$ diameter have been attained. 
2.2.4. University of Minnesota, Minneapolis, U.S.A (2011)

The dissertation of Krueger (2012) and the paper works of Krueger et al. (2013, 2011) present an HFSS composed of seven xenon arc lamps Osram XBO 6500W/HSLA OFR, of $6500 \mathrm{~W}_{\mathrm{e}}$, arrayed in a hexagon structure, containing a lamp in the center. Concerning the spectral distribution, it has been specified that the lamp emits $49 \%$ more energy between $280 \mathrm{~nm}$ and $500 \mathrm{~nm}$ wavelengths than the Sun at AM 1.5 and $76 \%$ more energy between $700 \mathrm{~nm}$ and $1100 \mathrm{~nm}$.

Each lamp is placed in one of the focuses of a truncated ellipsoid concentrator, which geometry has been determined using MC simulations, as well as the position of each lampconcentrator module, that can be observed in Figure 2.6. This photograph also contains the parametric table, and the Lambertian target (the white plate) used to determine the heat flux of the array. 


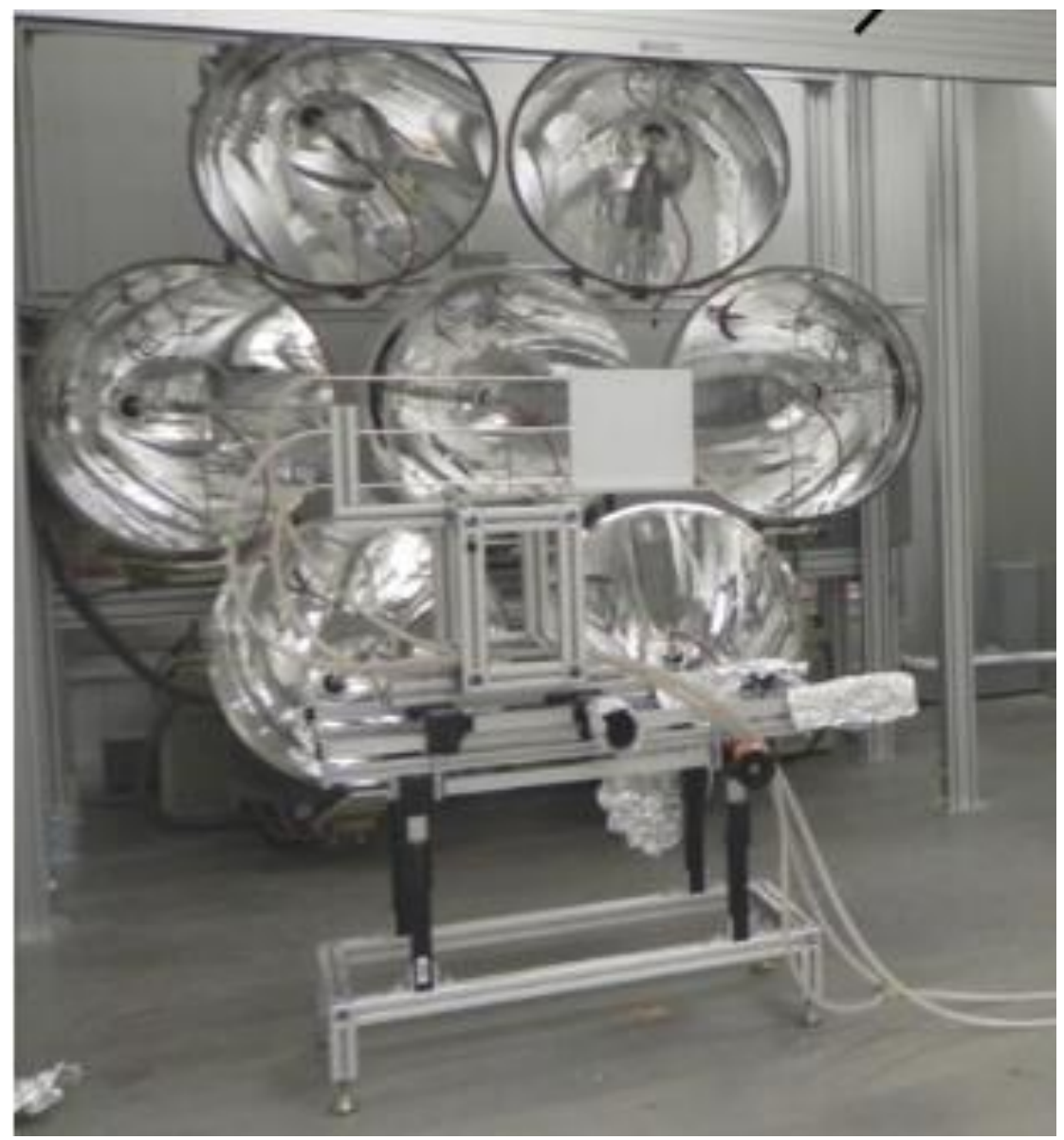

Figure 2.6. HFSS developed in the University of Minnesota, and parametric table and Lambertian target used to the characterization of the simulator (Krueger, 2012).

An axisymmetric circular target of $6 \mathrm{~cm}$ diameter has been achieved, providing $9.2 \mathrm{~kW}$ of thermal power and average heat flux of 3240 Suns. A peak flux of 7300 Suns has been attained at the center, spread at a $1 \mathrm{~cm}$ diameter area. The stagnation temperature is $2740 \mathrm{~K}$ under these conditions.

\subsubsection{KTH Royal Institute of Technology, Stockohlm, Sweden (2014)}

Wang et al. (2014) propose a low-cost HFSS composed of twelve xenon arc lamps NOYE N7, of $7 \mathrm{~kW}_{\mathrm{e}}$ and Fresnel lenses, which can be applied directly to the light source. The authors state as a significant problem of ellipsoidal concentrators the magnifying characteristic of the image of the light source of those, which leads to high dependency on the emitter arc size. Additionally, the Fresnel lenses are a much cheaper option, of optical efficiency up to $86 \%$, compared to $90 \%$ of a highly reflective ellipsoid concentrator and $79 \%$ of a parabolic dish. 
The lamps are positioned in the focus of a parabolic reflector, that collimates the light beams and contain a Fresnel lens on the front. They are arrayed in two circles, the inner one with four modules and the outer one with eight modules, as shown in Figure 2.7.

The MC ray tracing model delivers results close to the experimental data, acquired by Aichmayer et al. (2016), mainly at the outer region of the target. The total radiative power spread on a $20 \mathrm{~cm}$ diameter target has been measured as $19.7 \mathrm{~kW}$, corresponding to optical efficiency of $23.4 \%$ and with a peak flux of 675 Suns.

Garrido et al. (2017) have characterized this HFSS by three methods, closing results of 14.7 $\mathrm{kW}$ in a target of $18 \mathrm{~cm}$ diameter, the same 675 Suns peak flux, and thermal-electric conversion efficiency of $25.8 \%$.

Later improvements have been applied by Aichmayer et al. (2017), which consisted of the use of rectifiers in the power conversion units of the lamps and a new reflective coating on the parabolic reflectors. This way, carrying out the evaluation for one single lamp, a radiative power of $1446 \mathrm{~W}$ have been measured on a target of $28 \mathrm{~cm}$ diameter, which is much better than the former value, informed in this work, of $831 \mathrm{~W}$ in the same diameter. Also, the peak flux when using all the lamps has escalated to 905 Suns. 


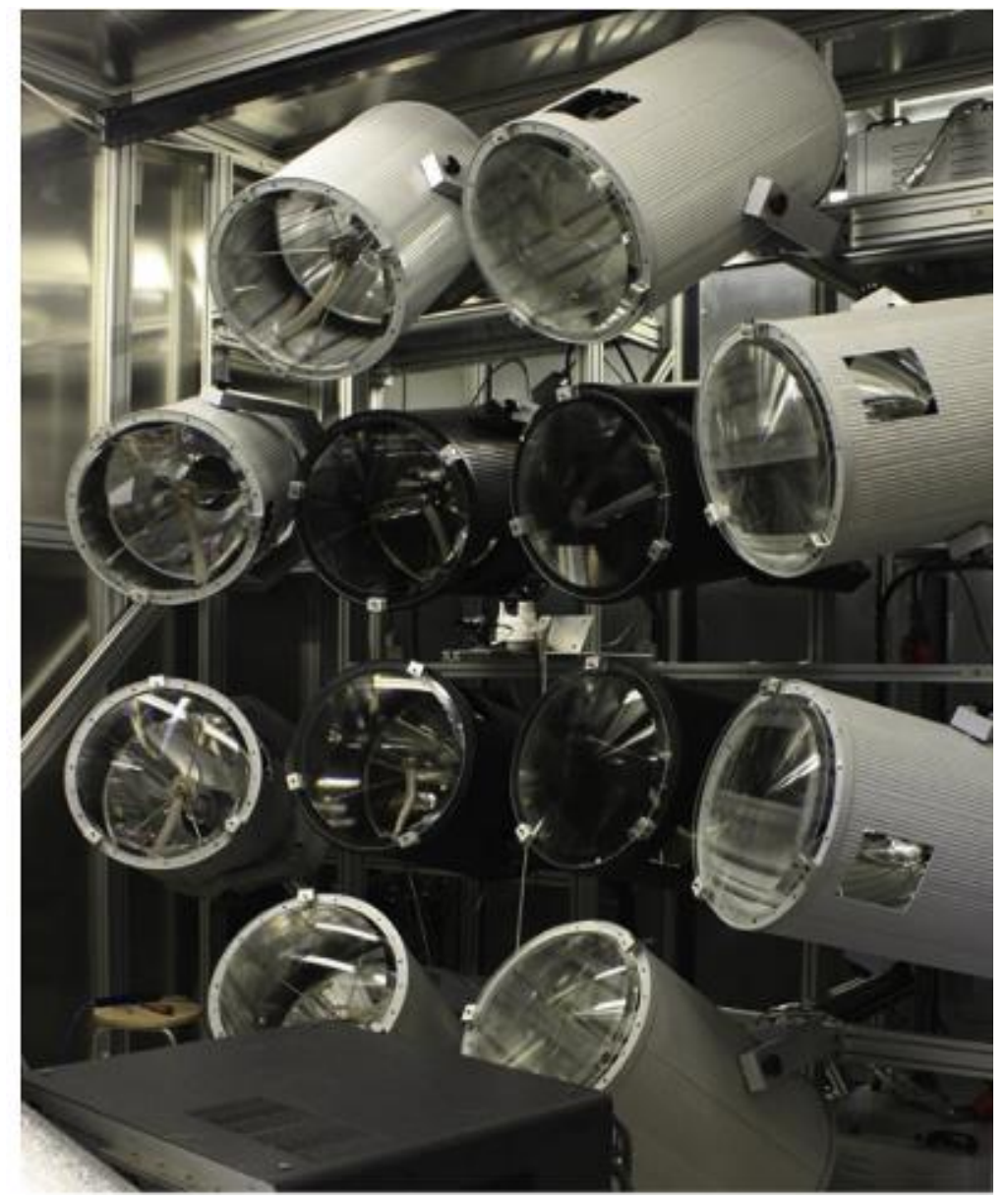

Figure 2.7. Four lamps inner circle and eight lamps external circle array of the HFSS developed in KTH Royal Institute of Technology, Stockholm (Garrido et al., 2017).

\subsubsection{KIRAN-42, IMDEA Energy Institute, Mósteles, Spain (2014)}

The KIRAN-42 is an HFSS built in Spain, at the IMDEA Energy Institute, named due to the electric input of $42 \mathrm{~kW}_{\mathrm{e}}$ provided by seven xenon arc lamps of $6 \mathrm{~kW}_{\mathrm{e}}$ each. The light sources are individually located at one of the focuses of truncated ellipsoids and disposed as a hexagonal array, with one lamp-concentrator module in the center, as pictured in Figure 2.8 The characterization of the system has been carried out by Li et al. $(2015,2014)$ 


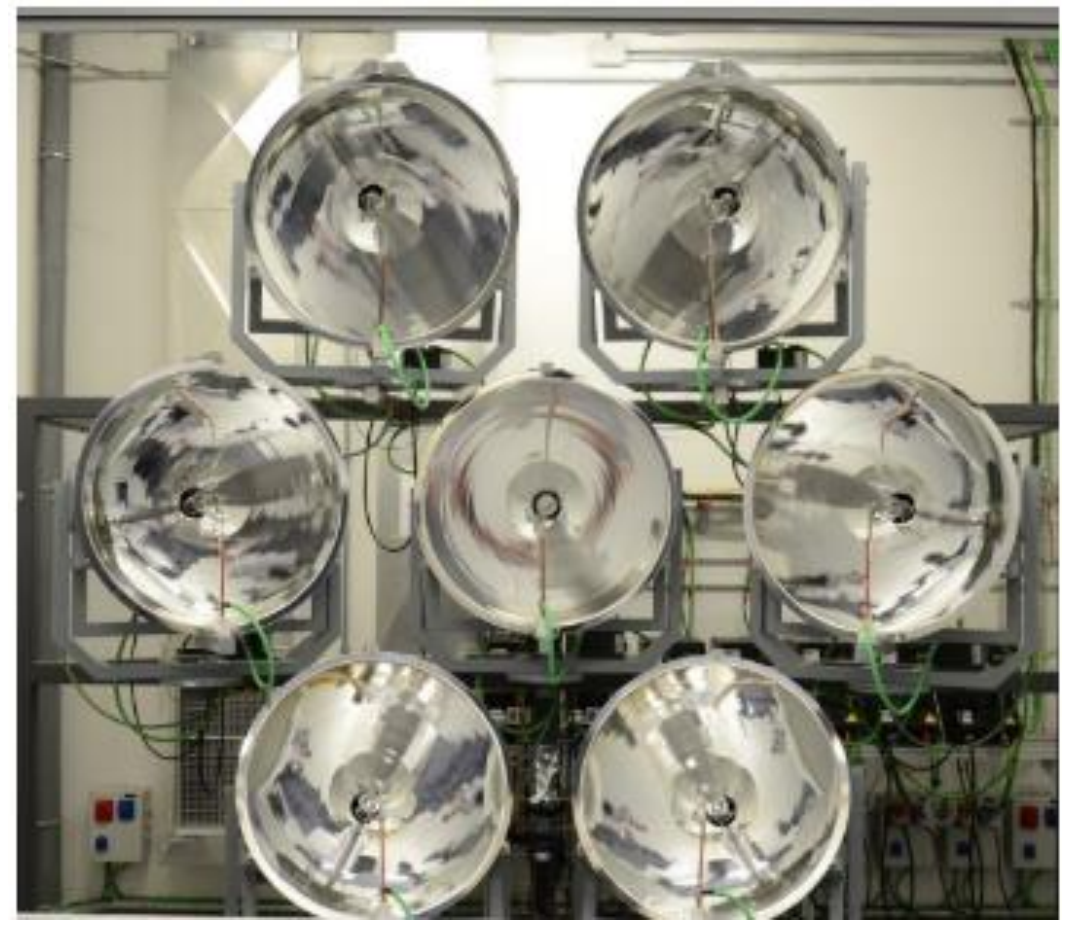

Figure 2.8. KIRAN-42, the HFSS located in IMDEA Energy Institute, Mósteles (Li et al., 2015).

The modules of this HFSS have been separated by a space sufficiently wide to move each one, in ways of changing the target shape. When they are all focused at one single point, the target is an axisymmetric circle, of $14 \mathrm{~kW}$ thermal power, extended over $20 \mathrm{~cm}$ diameter, peak flux of 3600 Suns, and stagnation temperature of $2800 \mathrm{~K}$.

When the modules are aligned to create a line, the maximum peak flux measured has been of only 1000 Suns. In the MC ray tracing model developed for this configuration, a peak flux of 1400 Suns have been achieved and $16 \mathrm{KW}$ of thermal radiative power across a target of 300 $\mathrm{mm}$ width in the vertical direction and $100 \mathrm{~mm}$ horizontally has been calculated.

\subsubsection{Sandia National Laboratories, Albuquerque, U.S.A. (2015)}

Boubault et al. (2015) have suggested an off-the-shelf, low-cost HFSS, composed of four ellipsoidal reflectors of large acceptance angle, made out of nickel coated with silver and by a silicon dioxide layer, that prevents corrosion and oxidation, and four short-arc metal halide lamps, of $1800 \mathrm{~W}$. Figure 2.9 represents the final configuration of the HFSS developed. The reflectivity of the silver is almost $100 \%$ in wavelengths from the visible to the near infra-red, and the electric-to-radiative efficiency of the lamps is $86 \%$, prompting $1550 \mathrm{~W}$ of radiative power per lamp. 


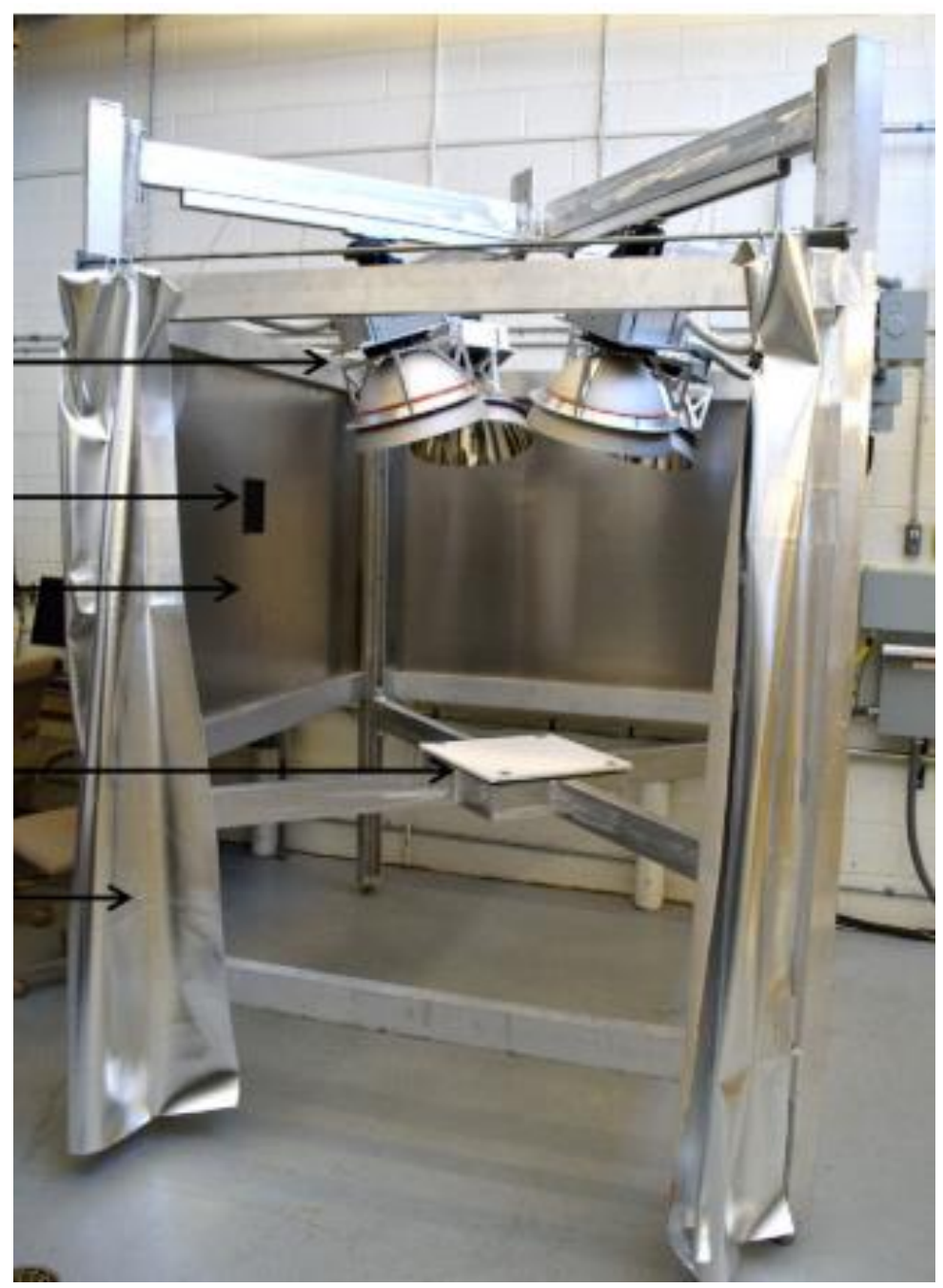

Figure 2.9. Off-the-shelf HFSS developed in Sandia National Laboratories, Albuquerque (Boubault et al., 2015).

Numerical analyses have been carried to determine the most suited relative position between the lamps, the reflector, and the target and preview the irradiance maps at the plane of the target. At the best position, the average irradiance for one single lamp-reflector module found have been 568 Suns over a target of $25.4 \mathrm{~mm}$ diameter, adding up to $288 \mathrm{~W}$, which is $1.8 \%$ higher than the value attained at the nominal position, of 558 Suns. In the numerical study of the four lamps together, at the same position found for one lamp, the average irradiance is 2029 Suns, over the same target of $25.4 \mathrm{~mm}$, adding up to $3811 \mathrm{~W}$ and peak irradiance of 3998 Suns.

The experimental array has relied on one single lamp, as the assumption of similarity among the four lamps has been made. By waiting 30 minutes before starting the measurements, a temperature of $90{ }^{\circ} \mathrm{C}$ has been quantified at the center of the target. Four flux maps have been 
obtaining by rotating the lamp in $90^{\circ}$ to emulate the position of each lamp of the HFSS, and all four have been combined to predict the behavior of the actual configuration.

The peak flux of one single lamp is 255 Suns at an area of $25.4 \mathrm{~mm}$ diameter, which is $45.7 \%$ lower than the predicted nominal number of 558 Suns. This difference has been attributed either to imperfections on the manufacturing of the concentrators or wrong assumptions in the numerical model. In this experiment, $90 \%$ of the total incident energy has been spread at a $122 \mathrm{~mm}$ diameter. By combining the four flux maps, the peak irradiance of 1440 Suns has been estimated as well as an average irradiance greater than 878 Suns at a diameter of 25.4 $\mathrm{mm}$. To regulate the flux, it is possible to fade the lamp intensity or change the target and modules position.

\subsubsection{Swinburne University of Technology, Hawthorn, Australia (2015)}

The HFSS described by Ekman et al. (2015), developed in the Swinburne University, Australia, is composed of seven metal halide lamps of $6 \mathrm{~kW}$, totalizing an electric power of $42 \mathrm{~kW}_{\mathrm{e}}$, each one placed at the primary focal point of a nickel ellipsoid, covered by aluminum. The chosen array has been a hexagonal shape, with one lamp at the center, as demonstrated in Figure 2.10. The input radiative power can be controlled by turning on and off each lamp.

Each module reaches a heat flux between 117 Suns and 148 Suns, and peak flux of 927 Suns. The total radiative power of the simulator has been measured as $12 \mathrm{~kW}$ in a target of $175 \mathrm{~mm}$ diameter, and the blackbody temperature calculated as $2011 \mathrm{~K}$. The authors estimate that the use of a CPC would double the power delivered at the same diameter. 


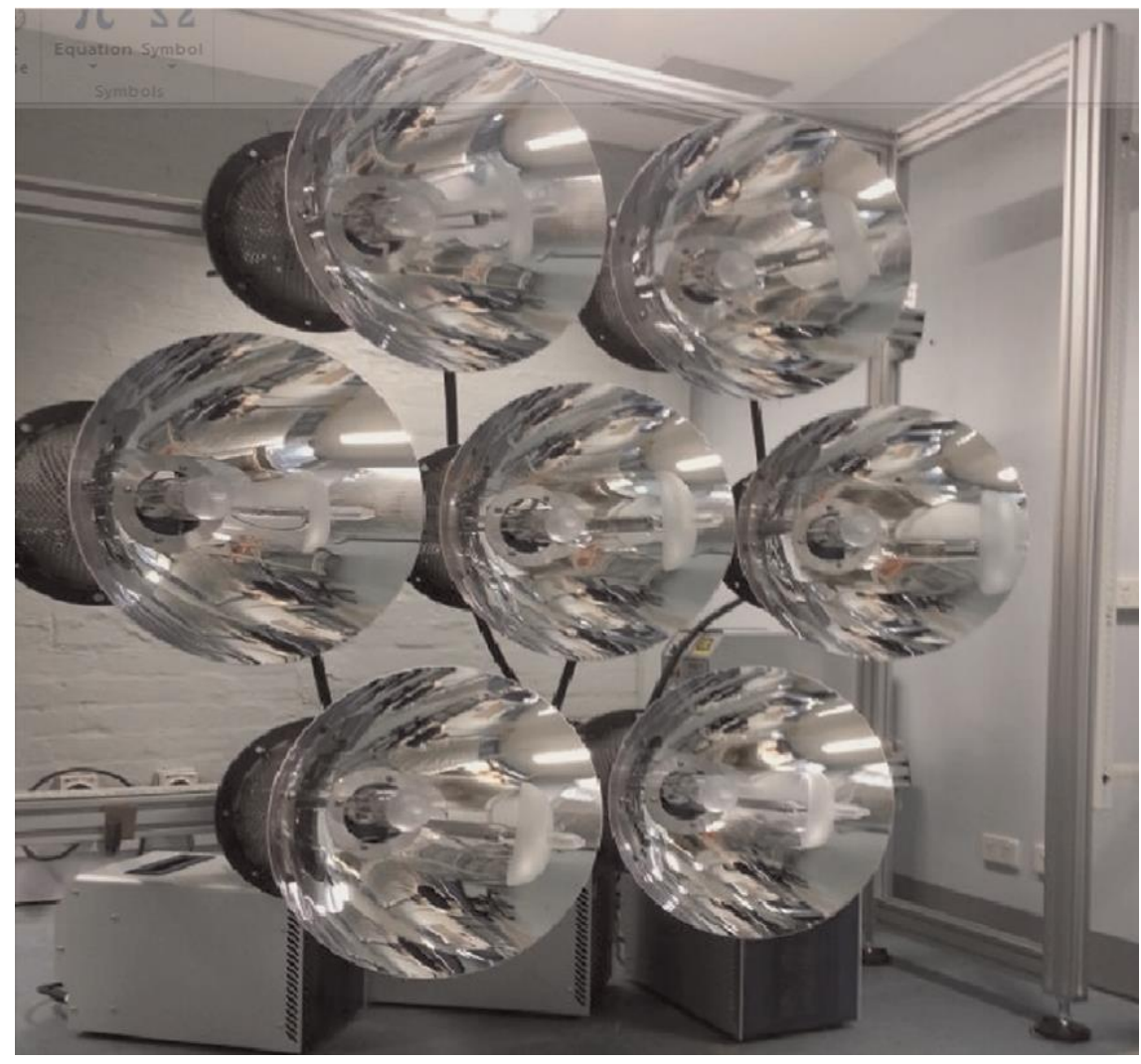

Figure 2.10. HFSS developed in Swinburne University of Technology, Hawthorn (Ekman et al., 2015).

\subsubsection{SISEA, Escola Politécnica, USP, Brazil (2016)}

The HFSS proposed by Rodrigues (2016), developed by the SISEA research group, located at the Polytechnic School of the University of São Paulo, São Paulo, Brazil, is an off-the-shelf and low cost containing two xenon short arc lamps, $4 \mathrm{~kW}_{\mathrm{e}}$ each, enclosed inside an sky searchlight, an apparatus used in places such as stadiums to illuminate the sky. This equipment is already fan cooled which minimizes the chance of explosion, and has a parabolic reflector around the lamp, responsible for collimating the beams. In the array elected, these parallel rays reach a parabolic dish, thus being reflected to the focal point of the paraboloid, where a calorimeter cavity has been placed. Figure 2.11 is a picture of the HFSS developed in operation. 


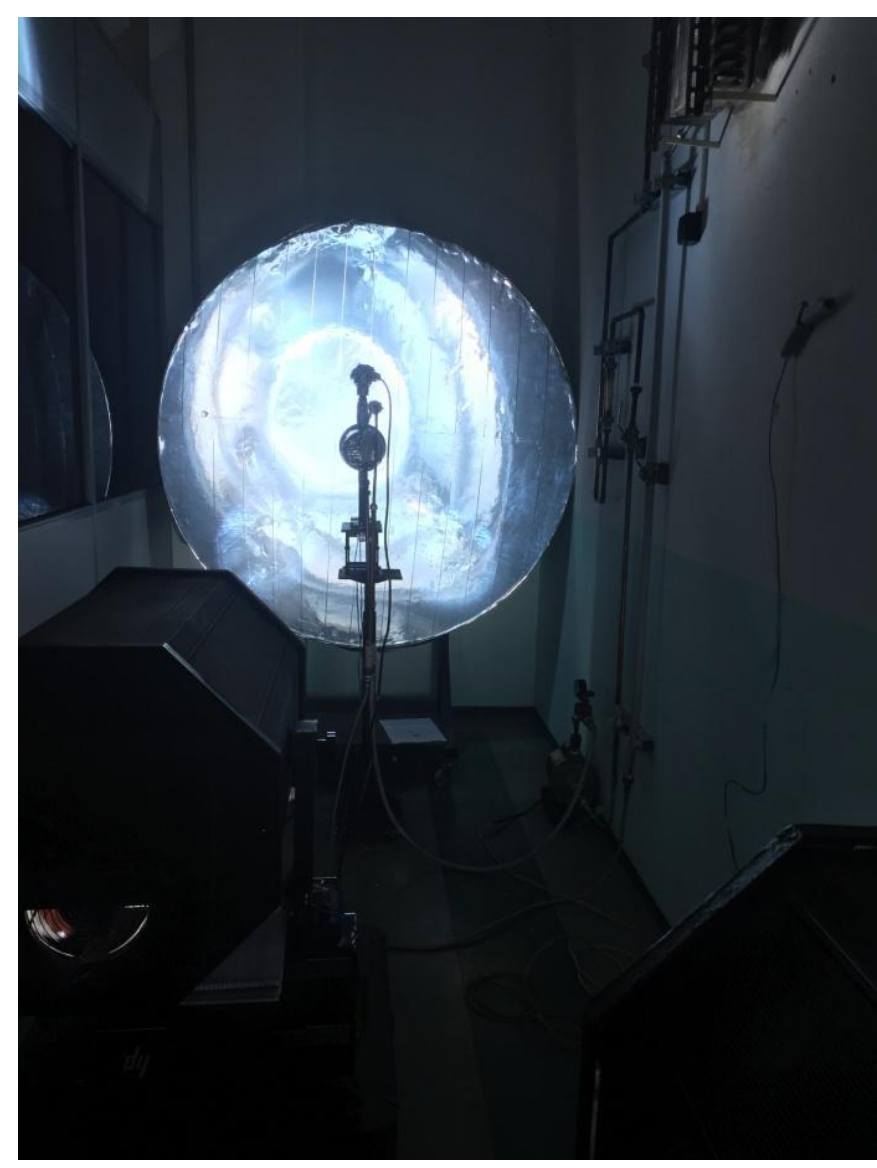

Figure 2.11. HFSS developed by SISEA research group in operation (Rodrigues, 2016).

The concentrator has been made of fiberglass, covered by a reflective adhesive film. The cavity has been manufactured in steel, with a copper coil inside, entirely covered by a thick layer of thermal insulation. Using water as the working fluid, a survey on the temperatures in the inlet and the outlet of the cavity has been carried, and thermal power of $1183 \mathrm{~W}$ has been measured after the thermal equilibrium has been reached, as well as the temperature inside the cavity, that have reached $242^{\circ} \mathrm{C}$ after $2 \mathrm{~h} 40 \mathrm{~min}$. An $87 \%$ of concentration efficiency has been determined for the concentrator.

\subsubsection{Synlight, DLR, Jülich, Germany (2017)}

Concluded in March 2017, located in Jülich, Germany, developed by the Deutsches Zentrum für Luft (DLR), the Synlight is the biggest high flux solar simulator built so far. Its manufacture particularities and performance are documented in Wieghardt et al. $(2018,2017$, 2016) and the project's website. 
The 149 short-arc xenon lamps of $7 \mathrm{kWe}$ and the ellipsoidal concentrators comprise the simulator, designed as a beehive (Figure 2.12). The cooling system and electrical equipment of the facility have been designed in ways of using lamps of $10 \mathrm{~kW}_{\mathrm{e}}$ xenon arc lamps instead, which is a future improvement.

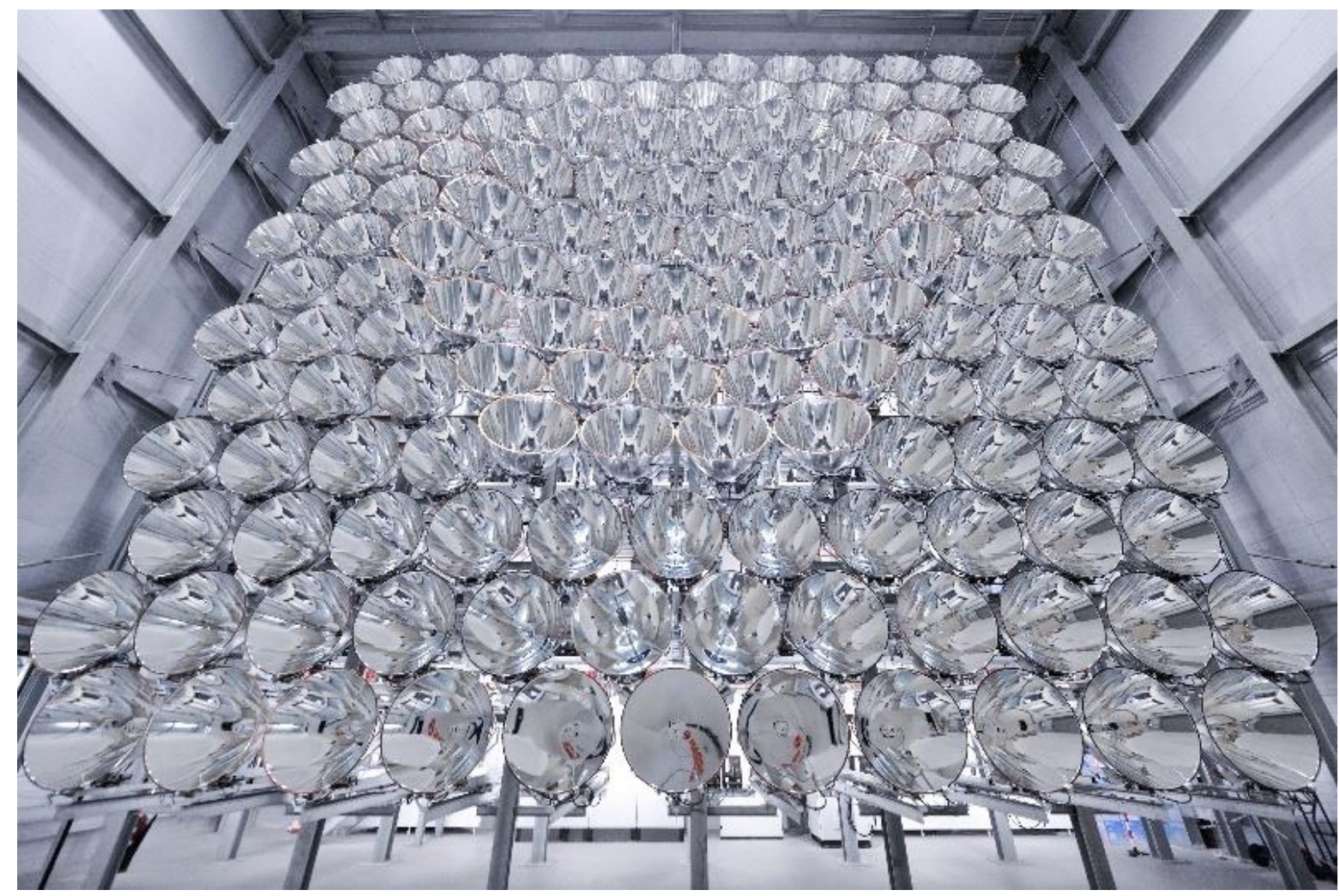

Figure 2.12. Synlight, the HFSS developed in DLR, at Jülich ("Sun at the push of a button," 2017).

Three test chambers have been built, two of those appropriate for solar chemical applications, connected to washer rooms and another for UV (ultraviolet) aging tests of components to be used in desert conditions or extreme temperature requirement. The test platforms have been positioned side by side, as shown in Figure 2.13 one at the center, at where 121 lamps can be focused, and other two, at which 96 lamps can be focused. All of them have a square target of $20 \mathrm{~cm} \times 20 \mathrm{~cm}$. 


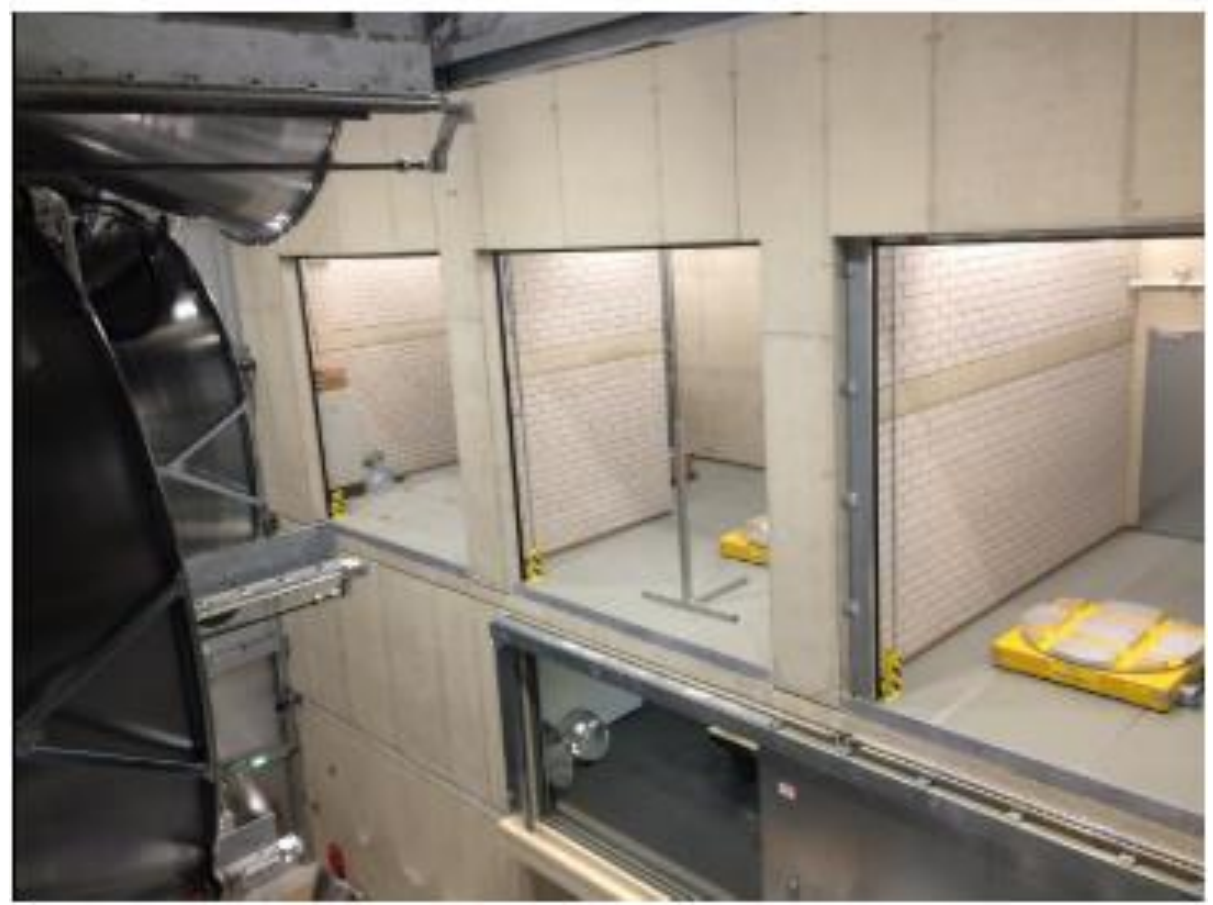

Figure 2.13. Test chamber of the Synlight HFSS developed in DLR, Jülich (Wieghardt et al., 2017).

The central chamber reaches a peak flux of $12.5 \mathrm{MW} / \mathrm{m}^{2}$, this means, 12,500 Suns and maximum radiation power of $310 \mathrm{~kW}$. The marginal chambers reach a peak heat flux of 10 $\mathrm{MW} / \mathrm{m}^{2}$ and maximum radiation power of $240 \mathrm{~kW}$. The expected temperature to be attained hits more than $3460^{\circ} \mathrm{C}$.

\subsubsection{Institute of Engineering Termophysics, Beïing, China (2019)}

Recently, Jin et al. (2019) have developed a solar simulator that can be used both when a high flux is a need, and when tests with collimated beams are the main goal. The HFSS comprises seven $10 \mathrm{~kW}_{\mathrm{e}}$ short arc xenon arc lamps and ellipsoidal reflectors, displayed in a hexagonal shape, with a lamp in the center. The peak flux experimentally determined has been 9.2 $\mathrm{MW} / \mathrm{m}^{2}$. In a target of $60 \mathrm{~mm}$ diameter, the radiation power has been $14.45 \mathrm{~kW}$ and in a target of $100 \mathrm{~mm}$ diameter, the power has been $23.83 \mathrm{~kW}$. This leads to efficiencies of $20.6 \%$ and $34 \%$, respectively. The blackbody temperature attained is $3300{ }^{\circ} \mathrm{C}$. To verify this estimative, the simulator has been used to melt a sheet of tantalum, leading to the conclusion that the actual temperature attained is at least $3017{ }^{\circ} \mathrm{C}$ (melting point of the tantalum).

To use this simulator in situations where collimation and uniformity are important, an optical integrator has been used. This apparatus function is to produce uniform illumination from a 
non-uniform source; it includes rectangular lenses with convex surfaces on one side. This way, the light arriving at the collimating lens has already been homologized. Forced air cooling has been used at the integrator to keep the temperature below $150{ }^{\circ} \mathrm{C}$. The schematic of the simulator is presented in Figure 2.14, where the optical integrator as well as the collimating lens are indicated, as well as the path of the beam (in yellow).

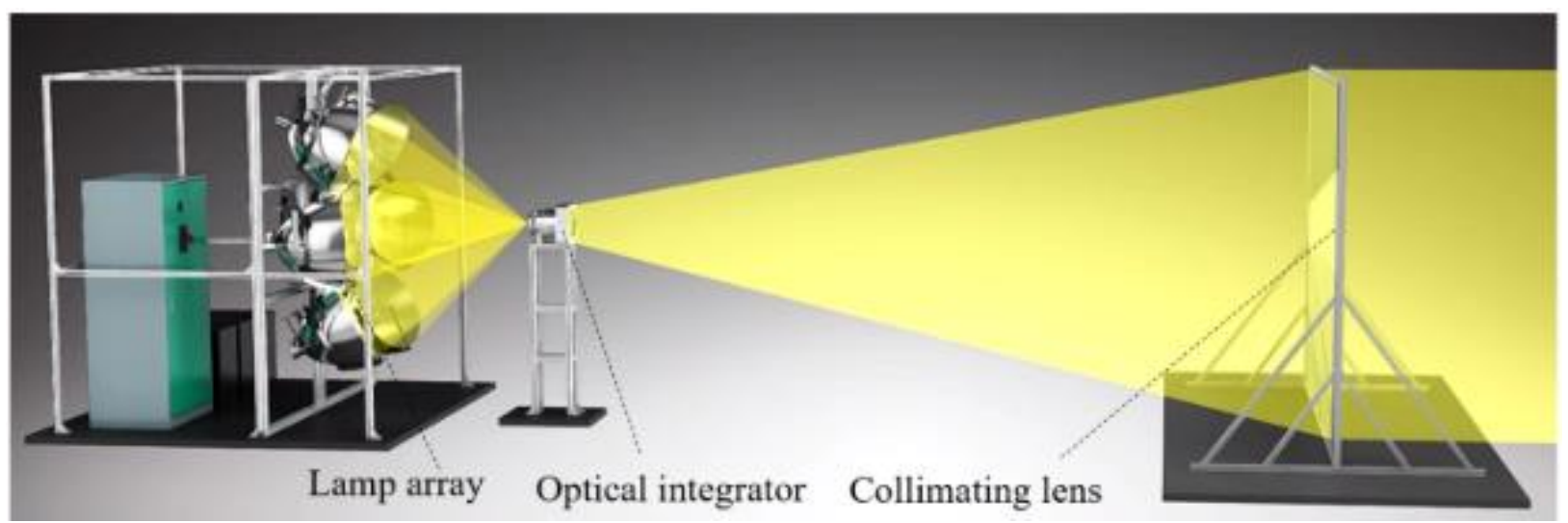

Figure 2.14. Schematics of the solar simulator that can be used for high flux research applications and collimated beams applications (Jin et al., 2019).

The radiative flux when using the optical integrator has been measured as less than 1 Sun, the half divergence angle as $1.3^{\circ}$ and the uniformity of the collimation as $92 \%$ in a rectangular area of $4 \mathrm{~m} \times 3 \mathrm{~m}$. These parameters have been demonstrated by placing a parabolic trough collector at behind the collimating lens, and its receiver has reached $350{ }^{\circ} \mathrm{C}$ and the heat flux $250 \mathrm{~W} / \mathrm{m}^{2}$, when the input power is set to $27 \%$, revealing that most of the light is redirected by the reflector to the receiver.

\subsubsection{Summary of HFSS}

A summary of the HFSS described in this chapter is presented in Table 2.1. The developer is referred by the research's center name and the total electrical power in given in $\mathrm{kW}$. The maximum electric-to-radiant efficiency is determined as the ratio between the maximum radiative thermal power measured in the experiments and the total electrical power, and given in percentage. 
Table 2.1. Summary of the characteristics of the HFSS presented in this chapter.

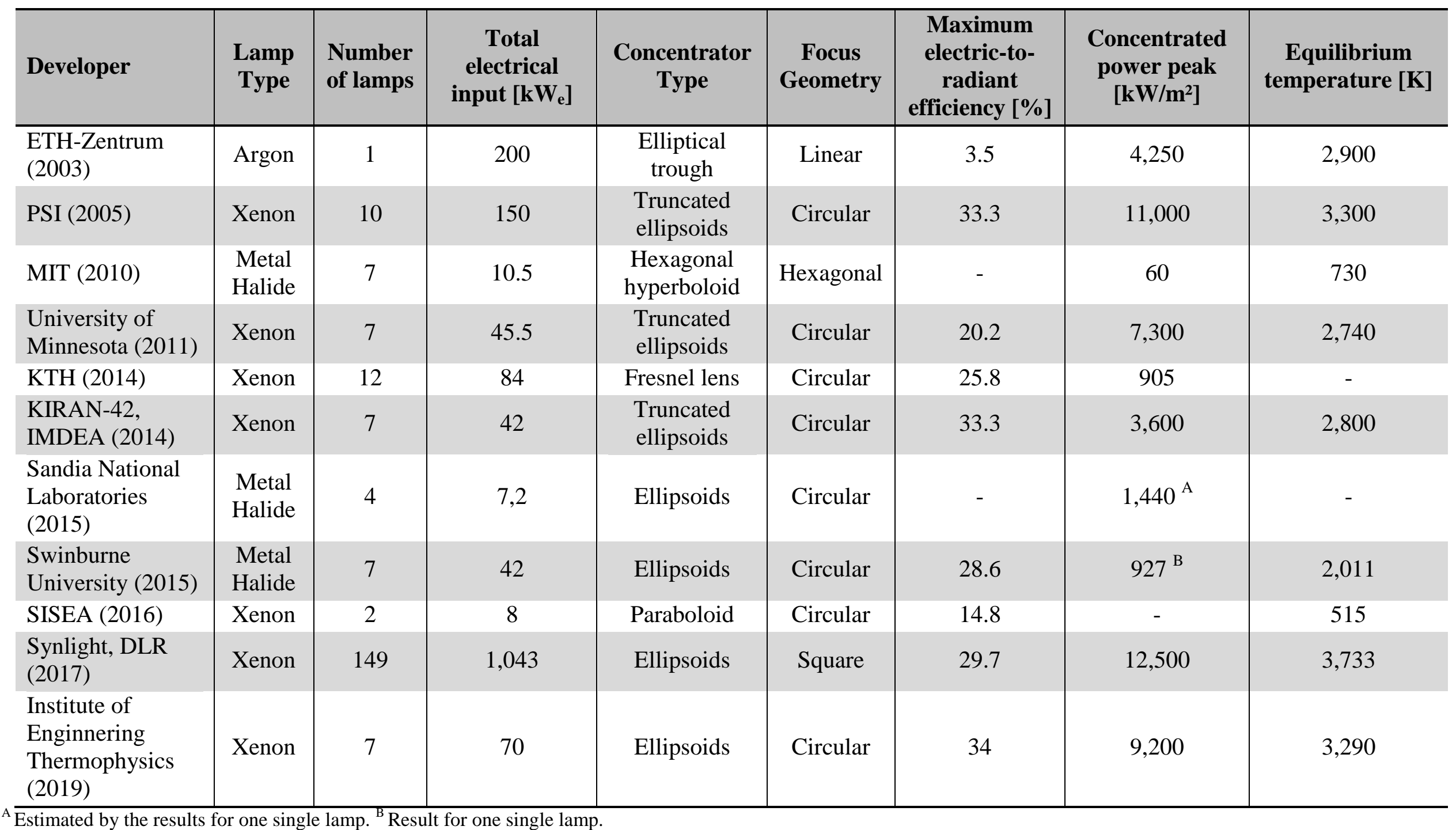

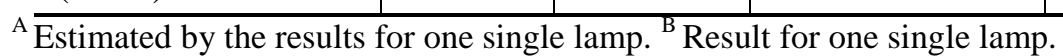




\section{THEORETICAL BACKGROUND}

\subsection{Solar Energy}

\subsubsection{Solar Thermal Radiation}

The Sun's diameter is $1.39 \times 10^{9} \mathrm{~m}$, the effective avarage superficial temperature is $5760 \mathrm{~K}$, and the radiant power is $3.8 \times 10^{20} \mathrm{MW}$. The avarage distance between the Sun and the Earth is $1.496 \times 10^{11} \mathrm{~m}$. For a referential observer on Earth, the angle from the Sun is 32', as shown in Figure 3.1. For this reason, the Sun is not considered as a punctual light source in many analyses (Kalougirou, 2014). The distance between the Earth and the Sun depends on the time of the year given the elliptical terrestrial orbit.

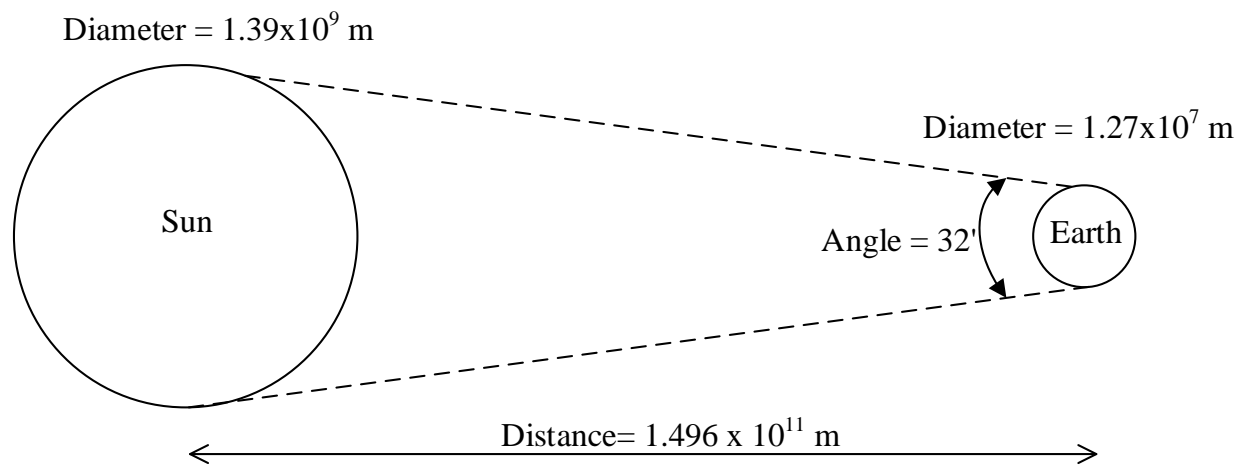

Figure 3.1. Geometrical relations between the Earth and the Sun.

The extraterrestrial solar irradiation is defined as energy rate reaching a unity of surface of an outer portion from the Earth atmosphere and perpendicular to the propagation direction. When the Sun is at the closest to the Earth, in January $3^{\text {rd }}$, the solar irradiation is circa $1,400 \mathrm{~W} / \mathrm{m}^{2}$ and in July $4^{\text {th }}$, when the Sun is at the farthest, it is about $1,330 \mathrm{~W} / \mathrm{m}^{2}$ (Kalougirou, 2014). This way, a solar constant has been defined by the World Radiation Center (WRC) as 1,367 $\mathrm{W} / \mathrm{m}^{2}$, based on the mean distance between the Earth and the Sun (Duffie \& Beckman, 2013). Inside the terrestrial atmosphere, the solar irradiation is partially mitigated mainly because of the dispersion, caused by the interaction with air molecules $\left(\mathrm{N}_{2}+\mathrm{O}_{2}\right)$, steam or droplets of water and dust, the absorptivity of the solar power by the Ozone, water steam and carbon dioxide and the reflection of the Sun beams by the atmosphere, clouds, among others. Figure 3.2 represents the extraterrestrial and the attenuated at $\mathrm{AM}=1.5$ solar spectral distribution. 


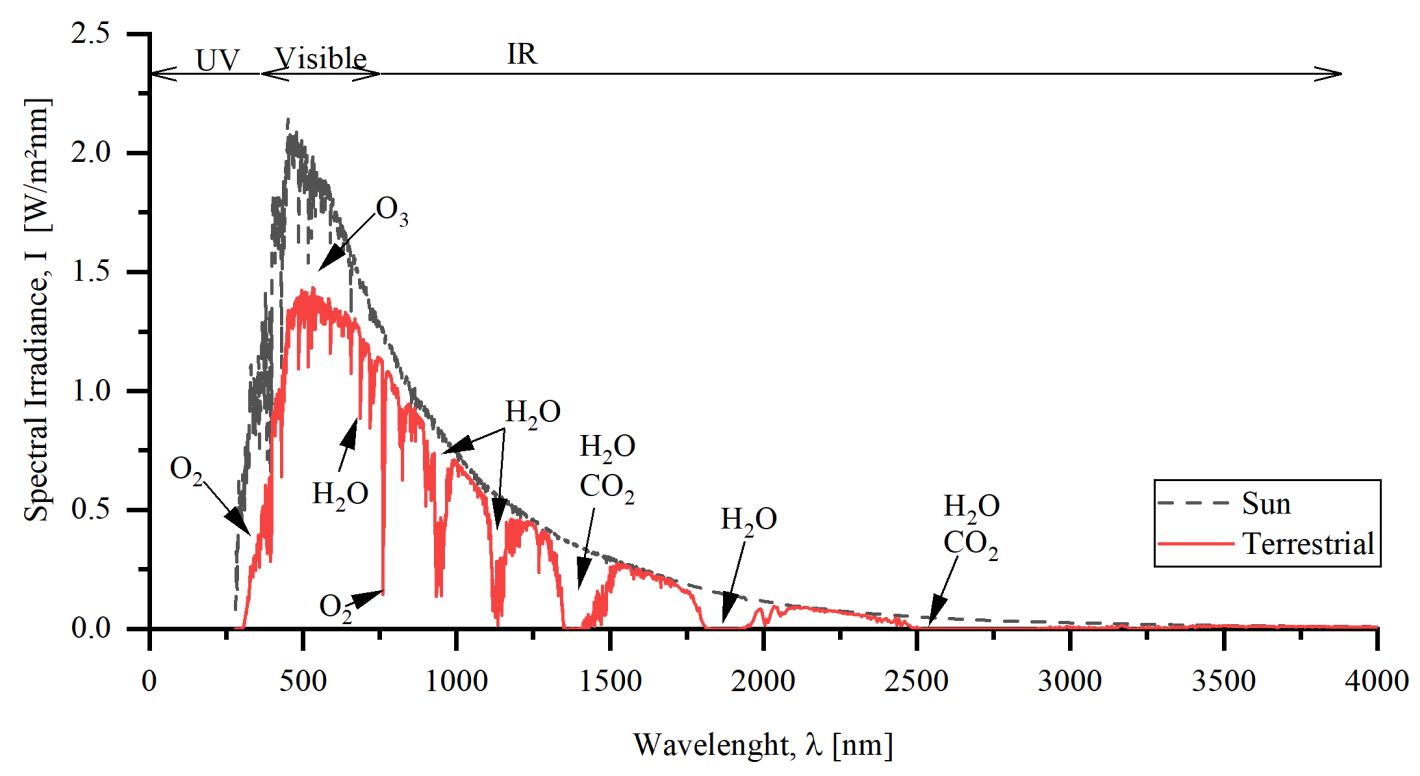

Figure 3.2. Solar spectral distribution outside and inside Eart's atmosphere at $A M=1.5$ (derivate from SMARTS v.2.9.2. ASTM G173-03).

Figure 3.2 indicates that the solar radiation is spread across many wavelengths, beginning at the ultraviolet (wavelengths shorter than $400 \mathrm{~nm}$ ), being more intense at the visible portion (from $400 \mathrm{~nm}$ to $700 \mathrm{~nm}$ ) and getting to a wide part of the infrared (wavelengths bigger than $700 \mathrm{~nm})$.

The AM (air mass) is the parameter used in the Rayleigh theory, which quantifies the irradiance amount dispersed by air molecules. This dispersion is significant only at short wavelengths. The dispersion provoked by water molecules and dust is more important, but also more challenging to quantify.

The wavelength affects absorptivity too. From the UV band up to $600 \mathrm{~nm}$, the ozone absorbs almost all solar radiation. At higher wavelengths, other chemical compounds act as absorptivity agent, as shown in Figure 3.2. This figure also shows the Rayleigh attenuation. According to Kabir et al. (2018) only $70 \%$ of the extraterrestrial solar irradiation penetrates the Earth atmosphere.

Figure 3.3 represents the influence of the Earth atmosphere on the solar irradiation and the two components that penetrates the atmosphere, which are direct and diffuse. The diffuse component is dispersed by the Earth`s atmosphere, which changes direction, and the direct is not dispersed. 


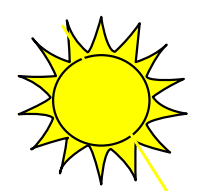

Diffuse scattered

back to space

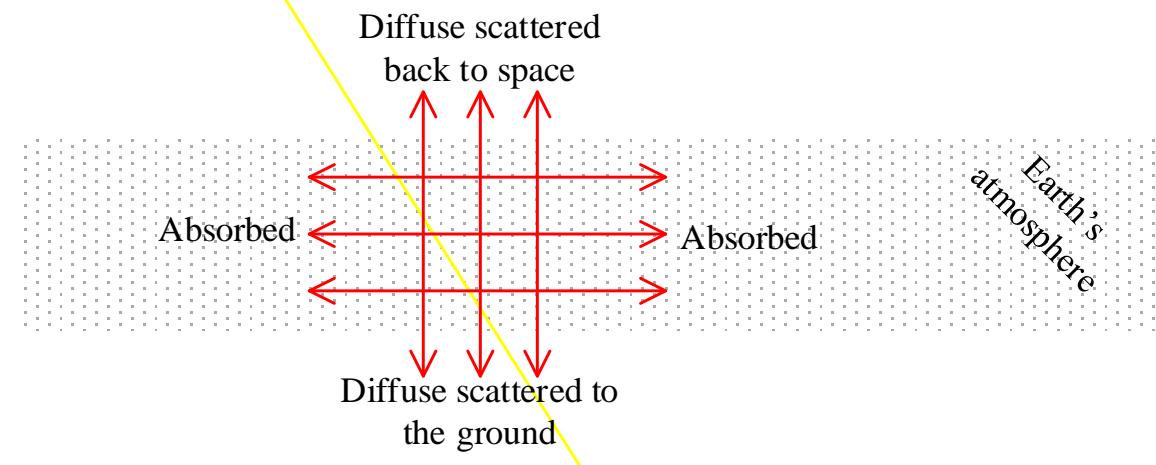

Direct or beam

radiation

Figure 3.3. Influence of the Earth atmosphere on the solar irradiation.

\subsubsection{Solar Concentrators}

The direct normal irradiation (a component of the direct irradiation normal to the surface) can be concentrated, engendering heliothermic power, also known as concentrated solar power (CSP). It can be converted directly into electric power or stored in the form of solar fuel, generated in solar thermolysis, thermochemical cycles or decarbonization processes of carbon resources.

The fundamental components of a CSP system are the collectors, which is the assemble of concentrator and a receptor; the concentrator is used to redirect the solar beams into the receptor. In electrical power plants, a thermal fluid circulates in the receptor. This fluid is either used in the thermomechanical system or is used to transfer the heat to another working fluid. In the production of solar fuels, the receptor is designed as a cavity reactor.

Collectors are made of mirrors or reflective material, which concentrates the solar energy into a small area, reaching high temperatures. The geometric concentration ratio also referred to only as concentration ratio $(C)$, is an important parameter defined as the ratio between the collector area and the receptor area.

The unity "number of Suns," equal to $1 \mathrm{~kW} / \mathrm{m}^{2}$, is usually used in this context. 
Given the wide variety of materials and geometries used to manufacture the collector, it is crucial to analyze thermal and optical properties to understand the concentration and then design the final application system. The main geometries of solar collectors are shown in Figure 3.4.

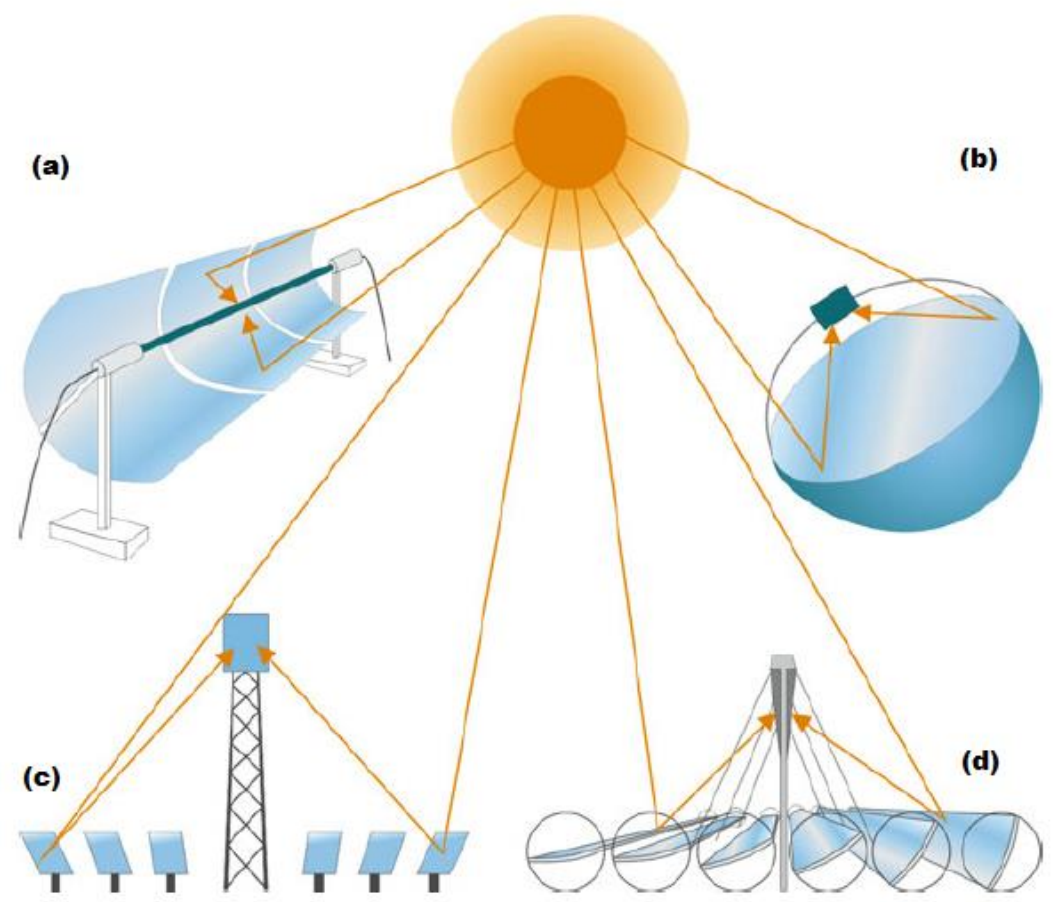

Figure 3.4. Main kinds of solar collectors: (a) parabolic trough (b) parabolic dish (c) tower (d) Fresnel mirrors (Guerrero-Lemus and Martínez-Duart, 2013).

The concentration ratio of a parabolic trough is 30 to 100 Suns (Steinfeld \& Palumbo, 2001) and the Sun beams are reflected to a line tube where the thermal fluid, which can reach up until $400{ }^{\circ} \mathrm{C}$, circulates (Kalougirou, 2014).

Given the geometrical properties of a paraboloid, all the sunbeams reflected by the parabolic dish are directed to the focal point. This way, the concentration ratio of a parabolic dish is usually between 1,000 and 10,000 Suns (Steinfeld \& Palumbo, 2001), and the temperature can reach above $1,500^{\circ} \mathrm{C}$ (Kalougirou, 2014). Due to these numbers, this kind of collector is the most used in thermochemical applications, composed of highly endothermic reactions.

The tower technology is the most used in the market (Fernández et al., 2019). Many straight tracking mirrors (heliostats) are used to reflect the sunbeams to a central tower. Just like parabolic dishes, it reaches high temperatures about $1000^{\circ} \mathrm{C}$ (Kalougirou, 2014), thus can be used to move the shovels of a turbine in a power plant. 
The mirrors used in the Fresnel linear system do not track the Sun like the heliostats, once they direct the sunbeams to the receptor independent from the incident angle although the conversion efficiency of Fresnel systems is the lowest of all four technologies presented.

Regarding Figure 3.4, it can be seen the parabolic trough and parabolic dish systems track the solar movement and its receptor moves along. The tower technology, on the other hand, works with tracking mirrors and a fixed receptor, and the Fresnel presents an all fixed apparatus. A way of grouping these devices is according to the geometry of its focus, which are a response to the geometry of the concentrator itself; the parabolic through and the Fresnel linear systems lead to linear foci and the parabolic dish and the tower present almost punctual foci.

\subsubsection{Nonimaging Solar Concentrators}

When the tracking of the sunlight is not needed or not desirable (if the CSP is used seasonally, for example), nonimaging (also called anidolics) concentrators can be used. These are apparatus without tracking systems, in which the radiant energy reaching an area is reflected to a smaller area. They are called nonimaging for they do not grant a geometric focus. On the contrary, the foci are spilled non-uniformly within all the smaller area of the concentrator, presenting random peaks of energy.

The concentration ratio, when related to nonimaging concentrators, determines the increase on power density on an absorbing blackbody, which can be purely defined as the number of rays entering a concentrator that is compressed throughout the exit.

Maximum concentration ratio for a 3D axisymmetric concentrator with circular entrance and apertures, according to Welford \& Winston (1989) is given by Equation (3.1).

$$
C_{\max }=\left(\frac{a}{a^{\prime}}\right)^{2}=\left(\frac{n^{\prime}}{n \sin \theta}\right)^{2}
$$

Where:

$a$ is the entrance diameter;

$a^{\prime}$ is the exit diameter;

$n$ is the refraction index of the entrance medium;

$n$ ' is the refraction index of the exit medium;

$\theta$ is the input semi-angle. 
To determine this ratio the ray tracing procedure is applied, investigates the multiple reflections and refractions occurring to the rays reaching the concentrator. As a major drawback to this analysis, Welford \& Winston (1989) emphasize it is a handy tool to analyze an existent optical system; however, it is less convenient when designing new systems.

Thus the method proposed in Welford \& Winston (1989) and Winston (1991) is based on the Fermat's principle, considering extreme scenarios which mean the maximum or minimum path a ray can take when traveling between two points. In this way, all the beams present the same optical path lengths no matter where they are diverging from, which is named as the edgy-ray principle or "string" method. Although, in practice, no matter how well designed the concentrator is, some rays are reflected back and never reach the exit aperture.

The simplest nonimaging concentrator on which the methods above are applied is the light cone of Figure 3.5. It is designed such as the rays of extreme input angle $\theta$ entering the concentrator of semiangle $\gamma$ either go directly to the exit aperture or are reflected only once before passing through the device. Figure 3.5 also shows that some rays undergo more than one reflection, thus do not reach the exit aperture.

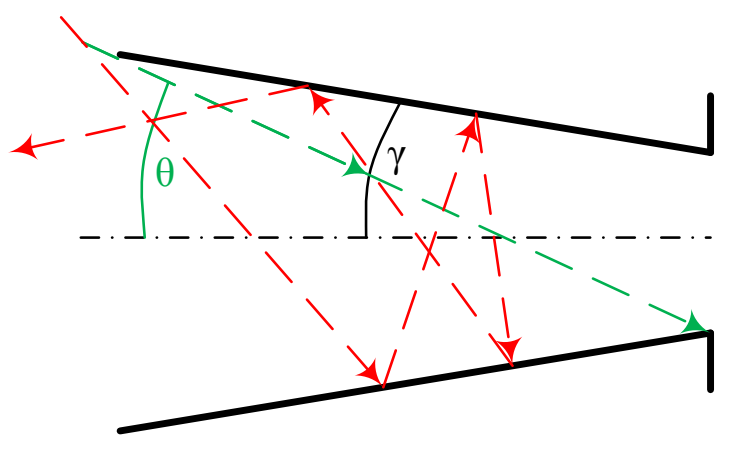

Figure 3.5. Rays reflected inside a light cone entering and those that do not enter the exit aperture.

The light cone is designed according to Equation (3.2), provided by Winston (1991), from which the relation for length can be deduced. As illustrated in Figure 3.5, $\gamma$ is the cone semiangle and $\theta$ is the maximum acceptable angle.

$$
2 \gamma=\left(\frac{\pi}{2}\right)-\theta
$$

A much more sophisticated nonimaging collector is the compound parabolic concentrator (CPC), an improvement of the light cone, presented in Figure 3.6. Starting from the fact that all rays of an extreme input angle of $\theta$ are reflected to the focus of a parabola of axis parallel to $\theta$, it is possible to establish the mathematical relations of Equations (3.3) and (3.4), brought 
by Welford \& Winston (1989), for a 3D concentrator designed from the rotation of this parabola around the concentrator axis (different from the parabola axis).

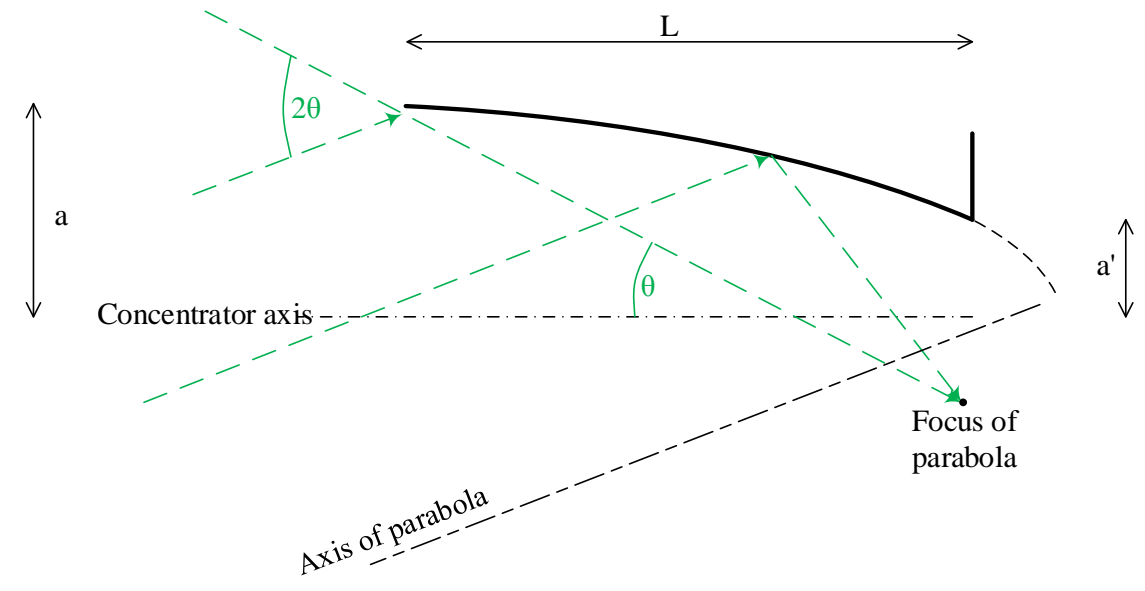

Figure 3.6. Rays reflected inside a compound parabolic concentrator reaching the parabola focus.

$$
\begin{gathered}
f=a^{\prime}(1+\sin \theta) \\
L=\left(a+a^{\prime}\right) \cot \theta
\end{gathered}
$$

Many other types of concentrators are available in the literature, but here the most significant ones have been presented.

\subsection{Chemical Reactors for Solar Fuels}

\subsubsection{Cavity Receptor and Chemical Reactors}

A cavity is a closed surface, containing a small aperture where the thermal radiation enters. It is placed at the focal point in tower or parabolic dish systems to collect heat attaining temperatures over $400^{\circ} \mathrm{C}$. It can be used both for thermal fluid circulation and as a cavity reactor for the production of solar fuels.

Conduction, convection, and radiation are thermal losses, thus how they affect the cavity's thermal equilibrium must be analyzed. Three parameters are studied, the geometry and material of the cavity and the aperture size, as a way of determining their influence in the thermal equilibrium. 
Harris \& Lenz (1985) have shown that thermal losses increase as the temperature attained by the cavity rises and that spillage and re-radiation are the most important loss mechanisms. They have also shown that the optimum aperture size decreases as the temperature rises, which increases the spillage. On this study, conduction is the least significant when the cavity is well insulated, followed by convection in a no-wind condition.

By carrying numerical work, Daabo et al. (2016a) have concluded that conical cavities present the least thermal loss, followed by cylindrical and spherical ones. However, Harris \& Lenz (1985) stand that cavity geometry is responsible for minimum influence. Daabo et al. (2016b) have numerically investigated that the larger the aperture size, the higher the heat loss.

By completely insulating and carrying the study in a no-wind condition, Steinfeld \& Schubnell (1993) have summed up that the heat absorptivity efficiency declines faster with the temperature increment, the bigger the aperture size is. Shuai et al. (2011) have indicated that the attempt to minimize the re-radiation loss by placing a quartz window in the cavity aperture is futile, but it is handy in the uniformization of the flux distribution within.

Daabo et al. (2016a) have pointed out the influence of the material in terms of absorptivity, which is related to the heat absorbed by the cavity, and reflectivity of Sunbeams. Canto \& Simões Moreira (2017) have applied the concept of effective absorptivity, showing that no matter the actual absorptivity of a given material, it assumes the behavior of a $100 \%$ absorptive material when the ratio between the cavity aperture area and the internal area is minimal.

The idea of relative heat loss has been defined by Deng et al. (2017) as the ratio between the total heat loss of a system and the energy incident on it, considering conduction negligible. In a numerical analysis, the authors have inferred that the higher the incident heat flux, the smaller the thermal losses are, thus higher is the system efficiency.

Correlations for convection in windy environments such as those where CSP systems are located have been established by Samanes et al. (2015).

\subsubsection{Thermal Equilibrium of the black body cavity}

Considering a thermally insulated hollow cavity holding a quartz window from where the light beams get inside, as shown in the schematics of Figure 3.7, its thermal equilibrium can be analyzed by verifying the heat reaching the cavity window and the losses related. Starting 
from a general analysis, all possible thermal losses have been investigated: the conduction and convection losses occurring through the window, cavity body, and insulation and the radiation losses at the window.

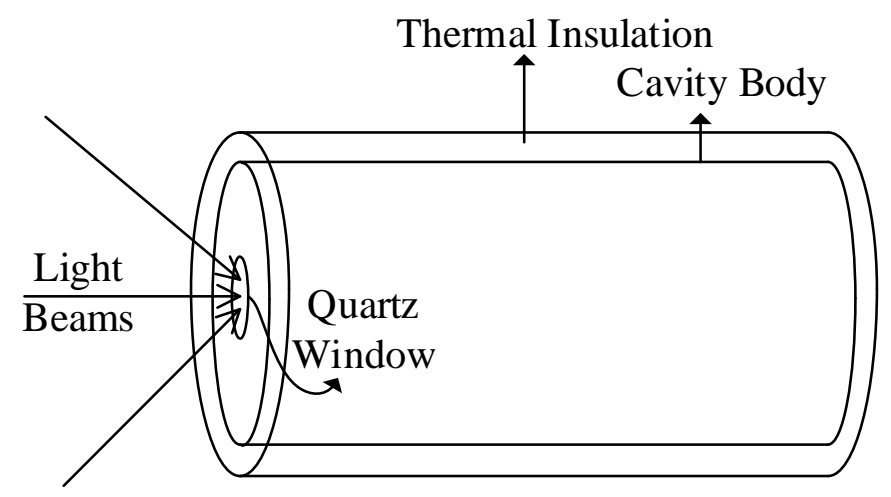

Figure 3.7. A cylindrical thermally insulated cavity.

Figure 3.8 represents the heat transfers occurring through the window and the cavity walls. The incident irradiation, $G$, enters the cavity through the window, from where the losses by re-irradiation, $Q_{\text {Reir }}$, reflection, $Q_{R e f}$, conduction and convection, $Q_{C w}$, take place. Inside the cavity, a portion of the incident heat is absorbed by the given reaction, $Q_{A b s}$. Through the cavity walls and losses by conduction and convection, $Q_{C c}$.

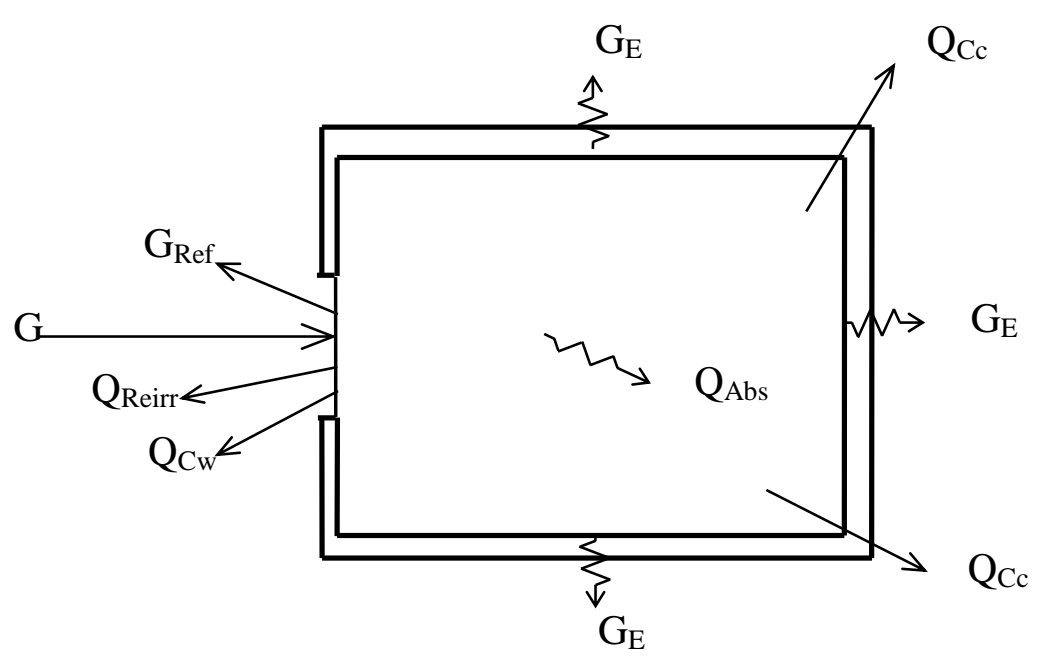

Figure 3.8. Heat transfers occurring between the light source and the cavity. 
Applying the First Law of Thermodynamics, the thermal equilibrium of the cavity can be described by Equation (3.5), where $A_{w}$ is the window area.

$$
G A_{w}=G_{R e f} A_{w}+Q_{\text {Reirr }}+Q_{C w}+Q_{C c}+Q_{A b s}
$$

To analyze the losses by re-irradiation, the analogic electric circuit of Figure 3.9 has been introduced. There are represented a "superficial resistance", associated with the cavity emissivity, $\varepsilon$, and a "spatial resistance", associated with the shape factor, $F_{w \infty}$. Also, the transmissivity of the window shown and the heat loss related to them. The temperatures $T_{c}$ and $T_{\infty}$ represent the cavity and surrounding temperatures, respectively, $E_{c}$ and $E_{\infty}$ are the cavity and surrounding radiation and $J$ is the window radiosity. Thus, Equation (3.6) and (3.7) can be written, where $A_{c}$ is the cavity walls area.

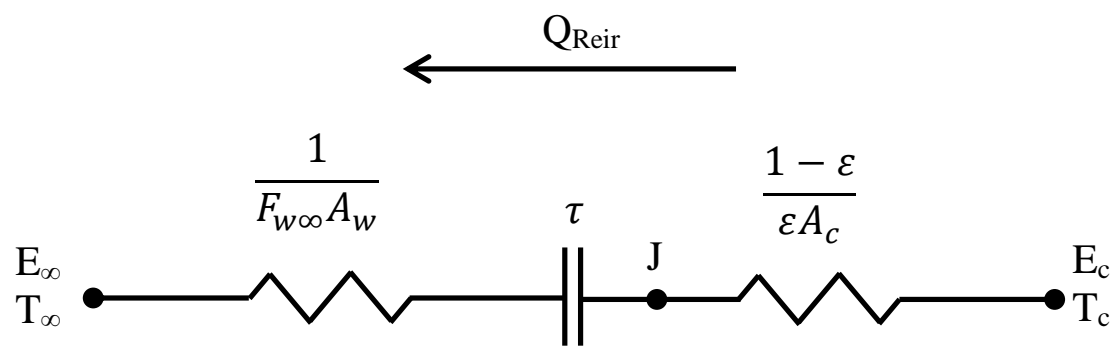

Figure 3.9. Analogic electric circuit of the losses by radiation occurring from inside the cavity to the surrounding.

$$
\begin{gathered}
Q_{\text {Reir }}=\tau \frac{E_{c}-E_{\infty}}{\frac{1}{F_{w \infty} A_{w}}+\frac{1-\varepsilon}{\varepsilon A_{c}}}=\frac{\sigma\left(T_{c}^{4}-T_{\infty}^{4}\right)}{\frac{1}{\tau} \frac{1}{F_{w \infty} A_{w}}+\frac{1-\varepsilon}{\varepsilon A_{c}}} \\
Q_{\text {Reir }}=\left[\frac{A_{w}}{\frac{1}{\tau}}\right]\left[\frac{\sigma\left(T_{c}^{4}-T_{\infty}^{4}\right)}{\frac{1}{F_{w \infty}}+\frac{1-\varepsilon}{\varepsilon_{c}} \frac{A_{w}}{A_{c}}}\right]
\end{gathered}
$$

Since the heat loss by re-irradiation can be considered as a fraction of the absorbed heat, the parameter effective absorptivity, $\alpha_{\mathrm{eff}}$, has been introduced, as shown in Equation (3.8), meaning the amount of heat that has been indeed absorbed by the cavity.

$$
Q_{\text {Reir }}=\alpha_{e f f} A_{w} \sigma\left(T_{c}^{4}-T_{\infty}^{4}\right)
$$

Given the Kirchoff law, for which the emissivity and absorptivity of a body are the same $\left(\alpha_{c}=\varepsilon_{c}\right)$, and merging Equation (3.7) and (3.8) the effective absorptivity, $\alpha_{\mathrm{eff}}$, can be written as shown in Equation (3.9). 


$$
\alpha_{e f f}=\left[\frac{1}{\tau}\left(\frac{1}{F_{w \infty}}+\frac{1-\alpha_{c}}{\alpha_{c}} \frac{A_{w}}{A_{c}}\right)\right]^{-1}
$$

Equation (3.9) demonstrates that the effective absorptivity depends on the shape factor between cavity and surrounding, the transmissivity of the window, absorptivity of the cavity and areas of the cavity and the window. On the other hand, the shape factor of the cavity is equal to unity, and if the transmissivity could be considered also equal unity, then the effective absorptivity would depend only on the cavity absorptivity and the areas of the cavity and the window.

The graphic of Figure 3.10 has been drawn for numerous imaginary materials with a variety of absorptivitys. It has been outlined in a logarithmic scale for the ratio between the window and cavity areas. It shows the influence of the ratio of the areas on the effective absorptivity of the cavity, and it can be seen that the effective absorptivity of the cavity does not actually depend on the material absorptivity if the ratio of the areas is very small, and tends to the unity on this scenario. This way, once the ratio of the areas is very small, a cavity of any given material can be analyzed as a black body cavity.

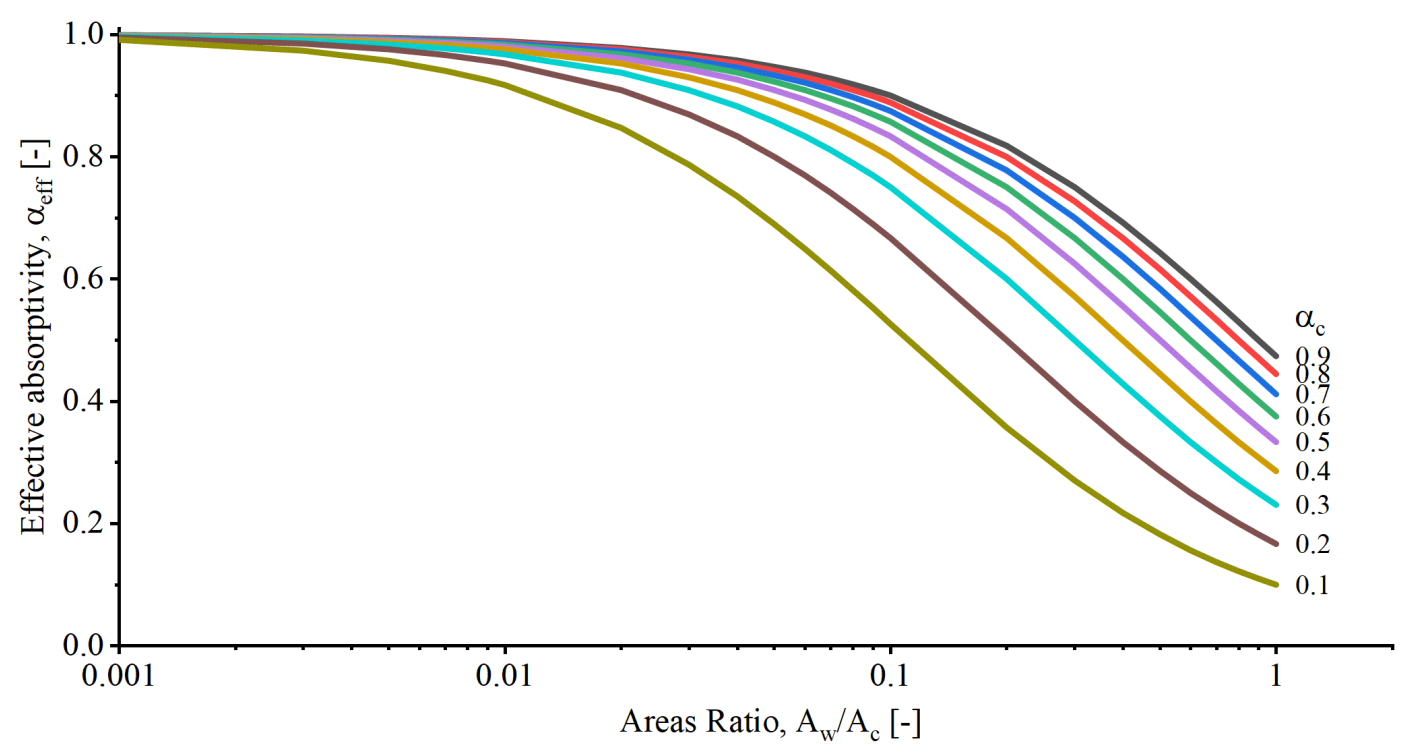

Figure 3.10. The relation between the effective absorptivity of the cavity, the cavity absorptivity and the ratio between the window and cavity areas.

Other terms of the thermal equilibrium of Equation (3.5) can also be rewritten, as shown in Equations (3.10) to (3.12), where $\rho$ is the window reflectivity and $U_{C w}$ and $U_{C c}$ are the losses by conduction and convection coefficients of the cavity and the window. The absorbed heat 
by the reaction occurring inside the cavity has been determined as a fraction, $\beta$, of the incident irradiation, as shown in Equation (3.13).

$$
\begin{gathered}
G_{\mathrm{Ref}}=\rho G \\
Q_{C w}=U_{L w} A_{w}\left(T_{c}-T_{\infty}\right) \\
Q_{C c}=U_{L c} A_{c}\left(T_{c}-T_{\infty}\right) \\
Q_{A b s}=\beta G
\end{gathered}
$$

Considering that the window does not absorb any of the incident irradiation, it can be written that $1-\rho=\tau$. Then, replacing Equation (3.8), (3.10), (3.11), (3.12), (3.12) and (3.13) in Equation (3.5) and rearranging it, the temperature of the cavity can be written as shown in Equation (3.14).

$$
T_{c}^{4}+\frac{\left(U_{C w} A_{w}+U_{C c} A_{c}\right)}{\alpha_{e f f} A_{w} \sigma} T_{c}=T_{\infty}^{4}+\frac{\left(U_{C w} A_{w}+U_{C c} A_{c}\right)}{\alpha_{e f f} A_{w} \sigma} T_{\infty}+\frac{(\tau-\beta)}{\alpha_{e f f} \sigma} G
$$

Introducing the constant $K_{1}$, present in Equation (3.15), the temperature of the cavity can be re-written as Equation (3.16). In an experimental context, it is easy to determine the coefficient $U_{c}$, by surveying the drop in the temperature of the cavity after the incident radiation ceases.

$$
\begin{gathered}
K_{1}=\frac{\left(U_{C w} A_{w}+U_{C c} A_{c}\right)}{\alpha_{e f f} A_{w} \sigma}=\frac{U_{C}\left(A_{w}+A_{c}\right)}{\alpha_{e f f} A_{w} \sigma} \\
T_{c}^{4}+K_{1} T_{c}=T_{\infty}^{4}+K_{1} T_{\infty}+\frac{(\tau-\beta)}{\alpha_{e f f} \sigma} G
\end{gathered}
$$

Considering the thermal insulation is very good, so there are no losses by conduction, the air in the surrounding is still, so there are no losses by convection, and the transmissivity of the window equal to unity, then the temperature of the cavity can be defined by Equation (3.17).

$$
T_{c}^{4}=T_{\infty}^{4}+\frac{(1-\beta)}{\alpha_{e f f} \sigma} G
$$

Figure 3.11 represents graphically, Equation (3.17), how the equilibrium temperature of the cavity works as a function of the incident irradiance and the fraction of absorptivity by the reaction, for a blackbody cavity $\left(\alpha_{\mathrm{eff}}=1\right)$. When this fraction is $100 \%$, all incident heat is absorbed by the reaction, thus the equilibrium temperature is equal to the surrounding temperature. When no heat is absorbed by the reaction, the adiabatic temperature is achieved, this means the maximum temperature the cavity is able to reach. 


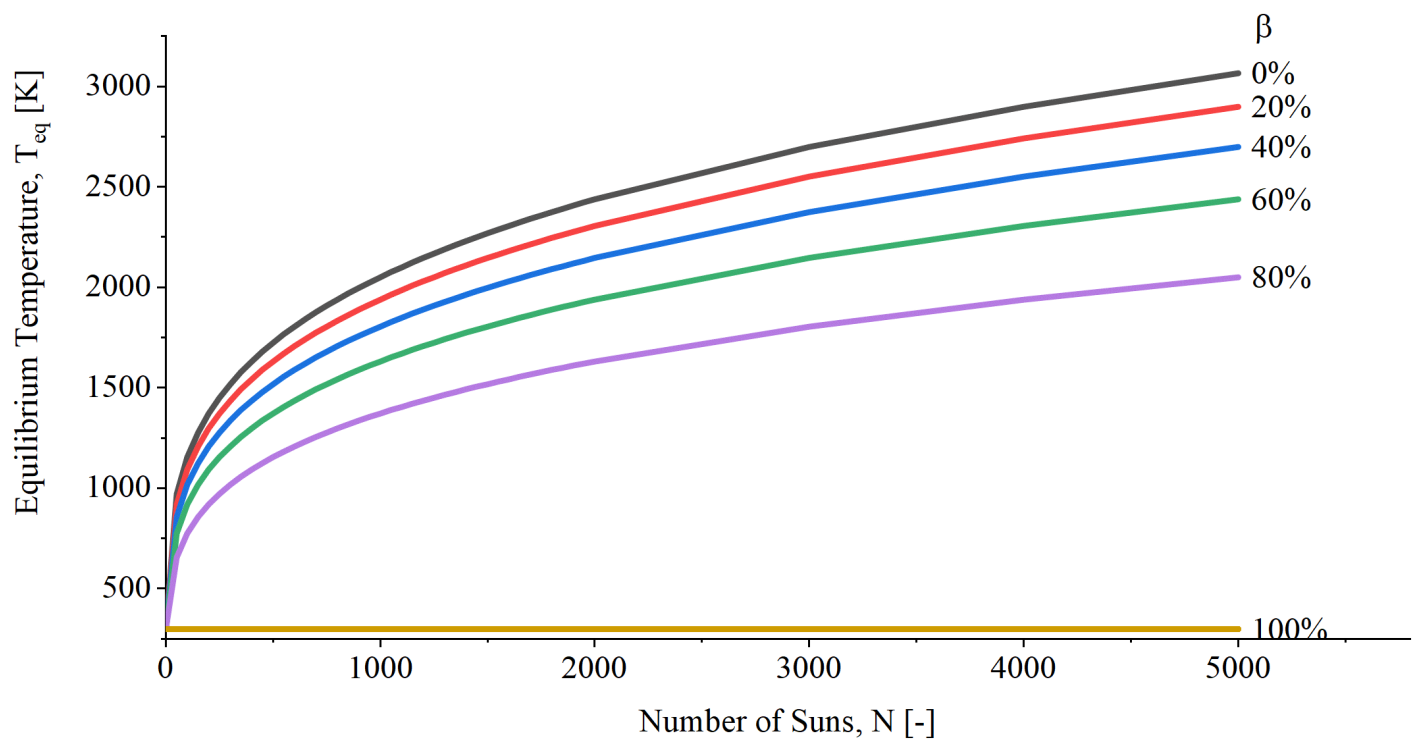

Figure 3.11. Equilibrium temperature of the cavity as a function of the incident irradiation and ratio of heat absorbed by a given reaction. 


\section{THE HIGH FLUX SOLAR SIMULATOR}

\subsection{New High Flux Solar Simulator proposed}

The HFSS proposed in this work is an off-the-shelf apparatus, primarily, composed of two HOLLE@ sky searchlights as light sources and two square paraboloid concentrators, as shown in Figure 4.1. A free space of $400 \mathrm{~mm}$, to accommodate the reactor cavity at the focal plane has been left between the two sky searchlights and 2 meters between the light sources and the concentrators.

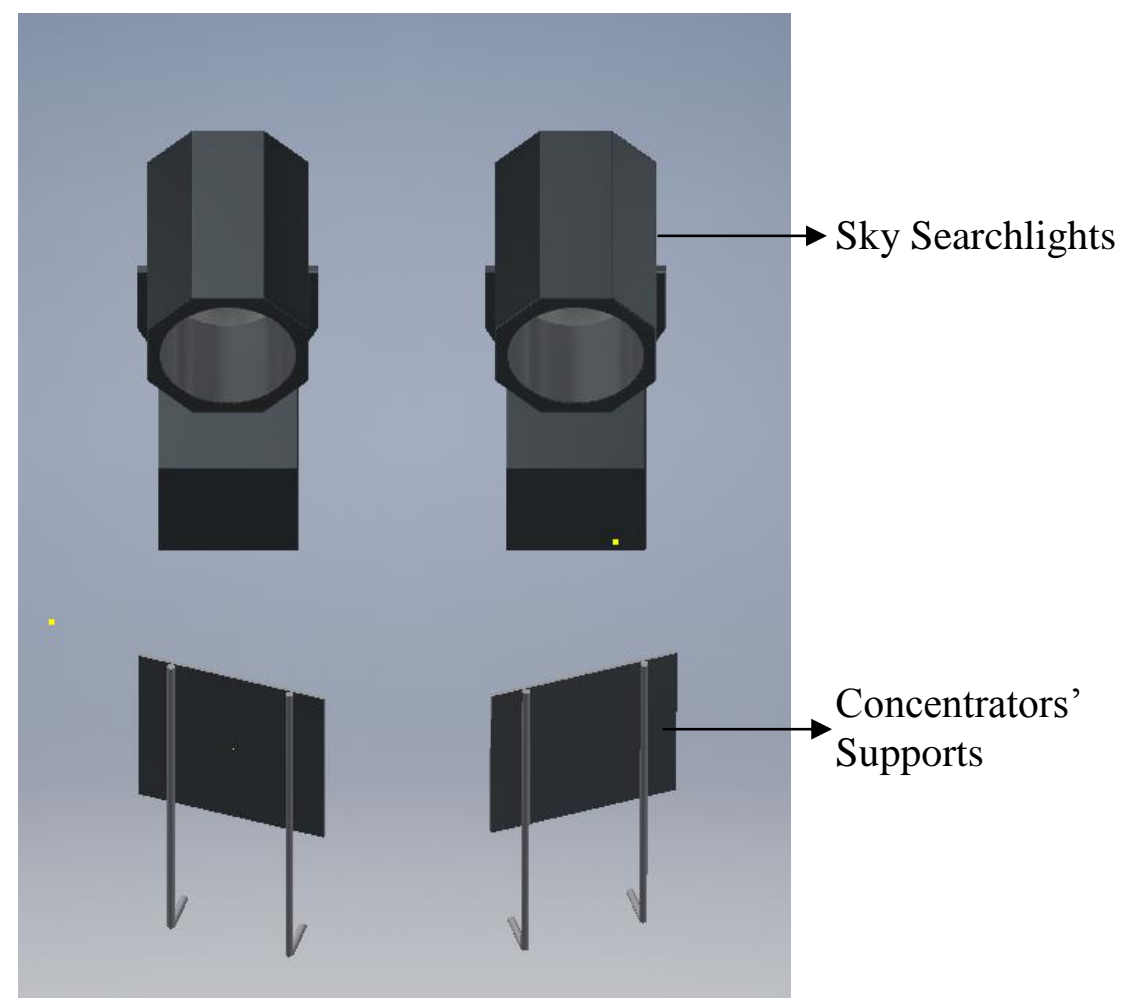

Figure 4.1. Proposed layout of the new High Flux Solar Simulator.

The sky searchlights are stadium lamps, used for light projection on the sky. They are composed by xenon short-arc lamps of $4 \mathrm{~kW}$ each, a voltage of $34 \mathrm{~V}$ and electric current of 120 A. The lamp's manual has been included in Annex A. The lamp, placed at the center of a parabolic reflector, can be moved to the paraboloid's focal point with the aid of an integrated adjusting knob. When positioned at the focal point, all light beams of the lamp become collimated. The arrangement is enclosed by a steel carcass, including a fan cooling system at the back portion - which reduces the explosion risk inherited to xenon lamps - and a glass window in the front. The light beams of the apparatus can be adjusted between $90^{\circ}$ and $120^{\circ}$ in 
the vertical. When positioned at $90^{\circ}$, the total height of the carcass is $1,090 \mathrm{~mm}$; the distance between the center of the xenon lamp to the soil is about $835 \mathrm{~mm}$ and the diameter of the glass window is $370 \mathrm{~mm}$. Figure 4.2 shows one sky searchlight used and its components.

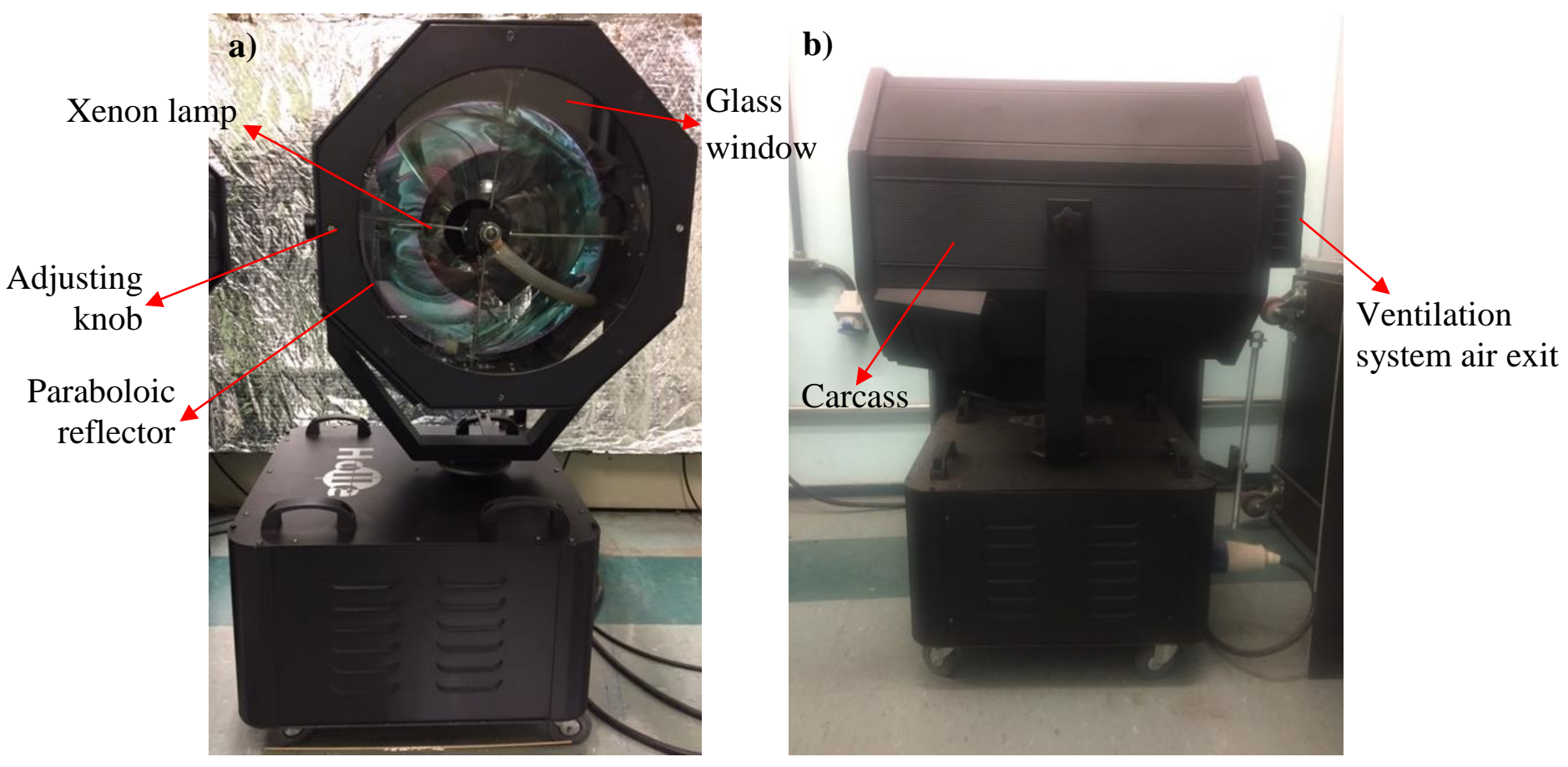

Figure 4.2. Sky Searchlight used in this work and its components. a) Frontal view; b) Side view.

As explained by Matson et al. (1984), the xenon arc lamp is an almost punctual and very bright light source, which in the case of HOLLE (c) sky searchlights lead to expected good collimation of the beams. Also, as the enclosure and integrated cooling system prevent an explosion, the use of these lamps as they come from manufacturing has revealed itself as a good option, which favors the building of the HFSS and makes a possible future expansion of the simulator by adding new lamps.

A switchboard has been developed to turn the sky searchlights on and off remotely from the test facility. The fans have to be turned on with the key indicated, in order to be possible to turn on the lamps with the aid of the other two keys. Two outstanding keys have been added to the control board for the case of system expansion.

This way, since the beams are collimated, the paraboloid geometry has been chosen for the concentrator, minding the high concentration ratio. For organizational and handling reasons, the use of a $1.6 \mathrm{~m}$ diameter concentrator, as the one employed before by Rodrigues (2016) has shown to be impractical. Thereby, two square paraboloids of $370 \mathrm{~mm}$ length (the same diameter of the sky searchlight's window) have been the solution applied. 
The manufacturing of the concentrators has been carried out using the same fiberglass parabolic master mold of $1.6 \mathrm{~m}$ diameter and focus at $643.8 \mathrm{~mm}$, which is the same as the one used by Rodrigues (2016). A fiberglass base of $370 \mathrm{~mm}$ has been fabricated, as shown Figure 4.3. A polycarbonate plate of $3 \mathrm{~mm}$ width has been fixed on this base using resin and countersunk screws; then the polycarbonate and screws have been covered by an aluminum powder coat, deposited by vacuum, resulting in the concentrator of Figure 4.4a.

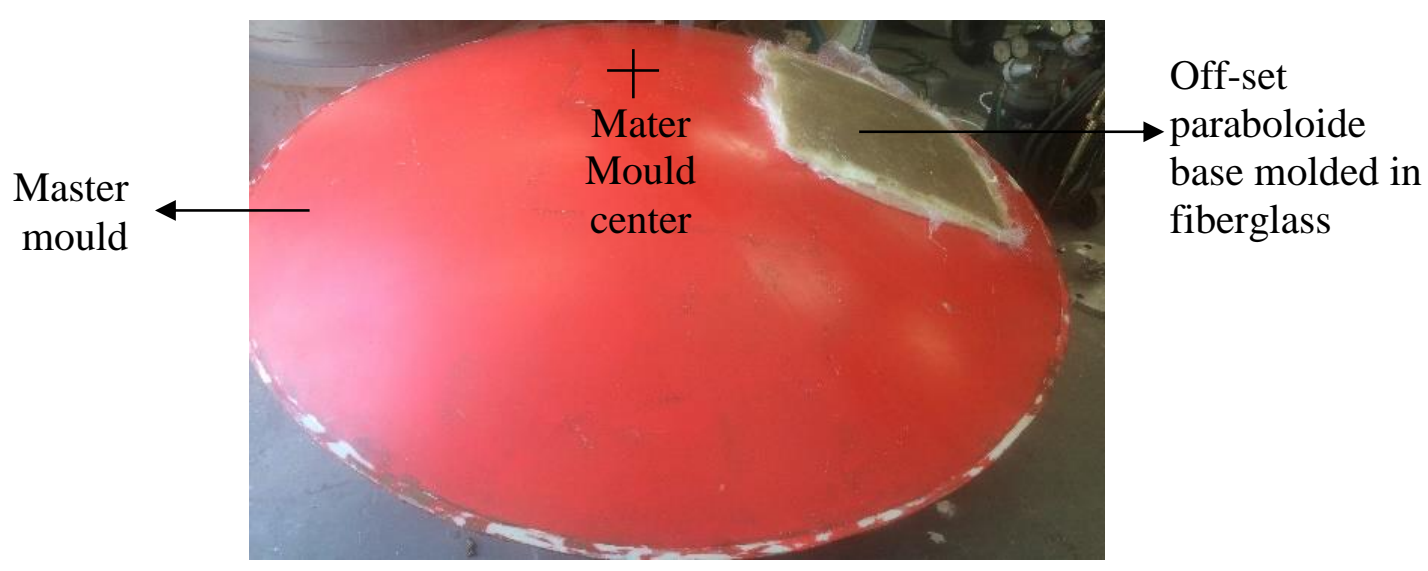

Figure 4.3. Manufacturing of the square fiber glass concentrator's base, displaced $200 \mathrm{~mm}$ from the center of the master mould.
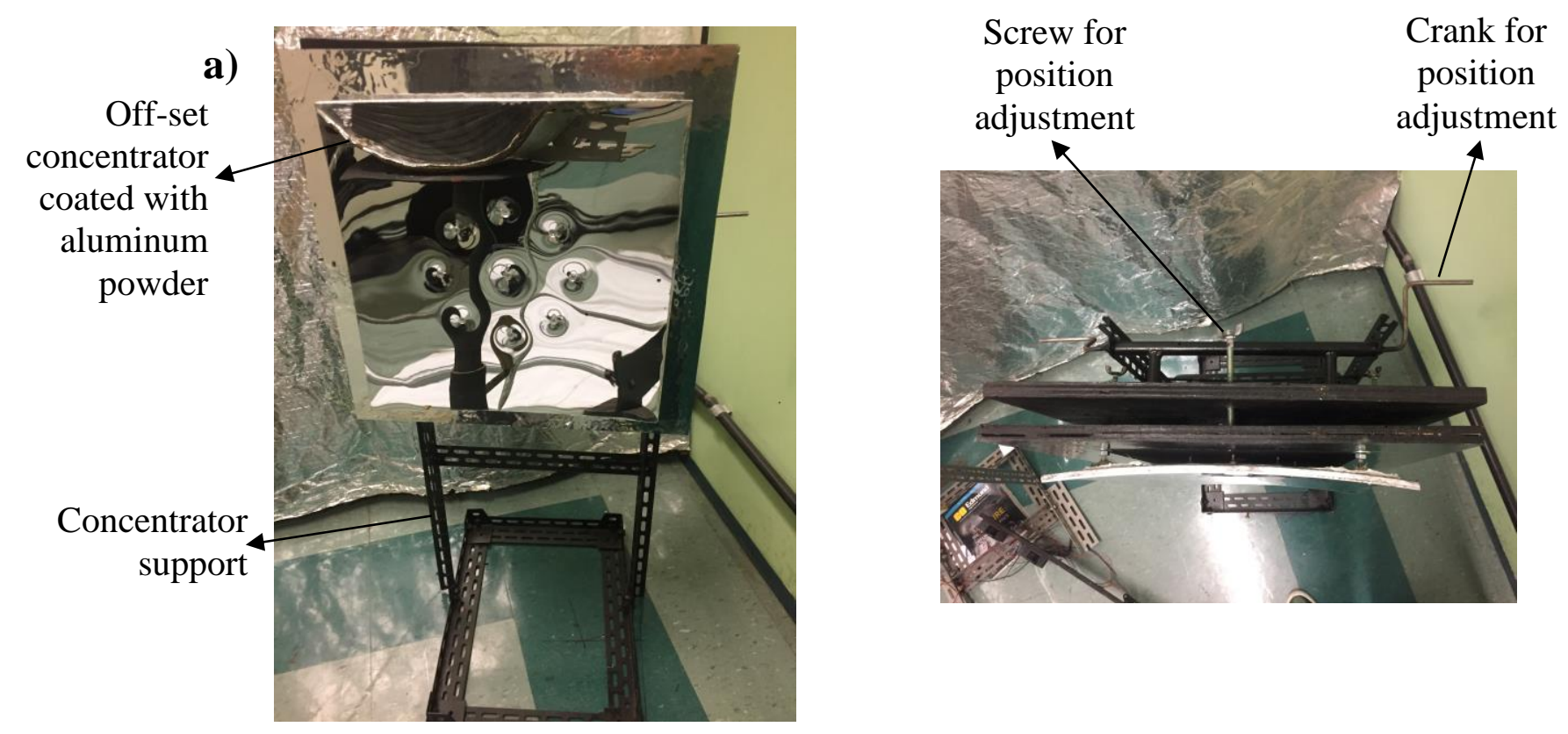

Figure 4.4. Parabolic concentrator attached to the support in a) front view; $b$ ) upper view.

The support for the concentrators has been built with perforated aluminum flat bars and two wooden plates, as show in Figure $4.4 \mathrm{~b}$ the plate's inclination can be adjusted to the support 
with the handles and adjusted to one another with screws, which contributes to a more precise system. The front of the wood has been covered with aluminum tape to avoid burning.

The analyzes of Section 3.2.2, about the thermal equilibrium of a black body cavity has led to the design of the calorimeter cavity used to study the basis on the geometry of the future reactor cavity, in investigating the actual radiant power reaching the operative fluid.

\subsection{Monte Carlo Ray Tracing method and Tonatiuh $(\subset$}

Tonatiuh(C) is open-source software, based on Monte Carlo ray tracing (MCRT) technique, used for the optical simulation of solar concentrated systems. MCRT is a statistical method used to determine the path of rays based on geometry properties and probability functions (Mecit, 2013).

Assuming that all of the solar energy reaching the Earth presents itself as electromagnetic radiation of small wavelengths, in comparison to the characteristic dimensions of the analyzed system, the software neglects the finiteness of the solar wavelength (Blanco et al., 2005). It is possible to generate real or virtual surfaces to study radiation data, such as flux distribution at a given area. It is due to a radiance function, and the probability of a bundle of photons reach an analyzed area, after following a probable path (Blanco et al., 2005).

Defining boundary volumes at each instant and considering that once a ray has left this volume, it stops interacting with the geometries within, Tonatiuh $(\subset)$ speeds up the calculation, when compared to other MCRT software, by establishing a stop criterion (Blanco, 2008).

Tonatiuh (C) has been used to analyze the optics and geometry of the HFSS proposed in this work. More precisely, the flux distribution at the focal point, and the changes when using three types of nonimaging secondary concentrators have been simulated.

\subsubsection{Off-set Concentrators}

Optical properties of the paraboloid show that when the beams reach the surface parallel to the axis, they are reflected to its focal point. On the other hand, if the beams are parallels with each other, but reach the surface with a given angle, they are not reflected to a single focal point.

To avoid the situation of the rays not being parallel to the paraboloid axis, thus not being concentrated at one single point, the alternative of off-set concentrators has been explored. It 
means that, given the master mold, the concentrator base is shaped off-set from the center. In other words, the edge of the concentrator base is placed $200 \mathrm{~mm}$ distant from the center of the master mold and bears an associated angle of about $81.5^{\circ}$ with the axis. Figure 4.5 represents the location of the off-set concentrator concerning the master mold, and the associated angle.

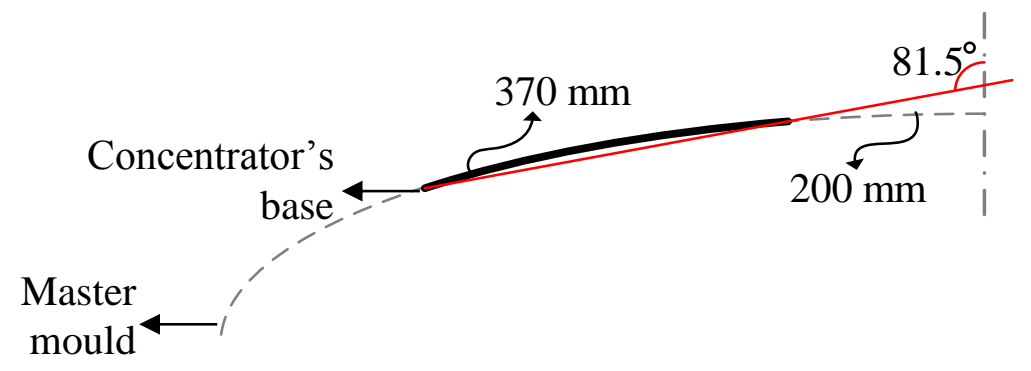

Figure 4.5. Schematics of the off-set parabolic concentrator.

Figure 4.6 represents the two off-set concentrators, designed circular to approach the area at which the beams of the sky searchlight reach, for mathematical proposes of the software, and a virtual plate positioned at the focal point of the paraboloids. The box of the figure represents the boundary volume comprising the concentrators and the plate.

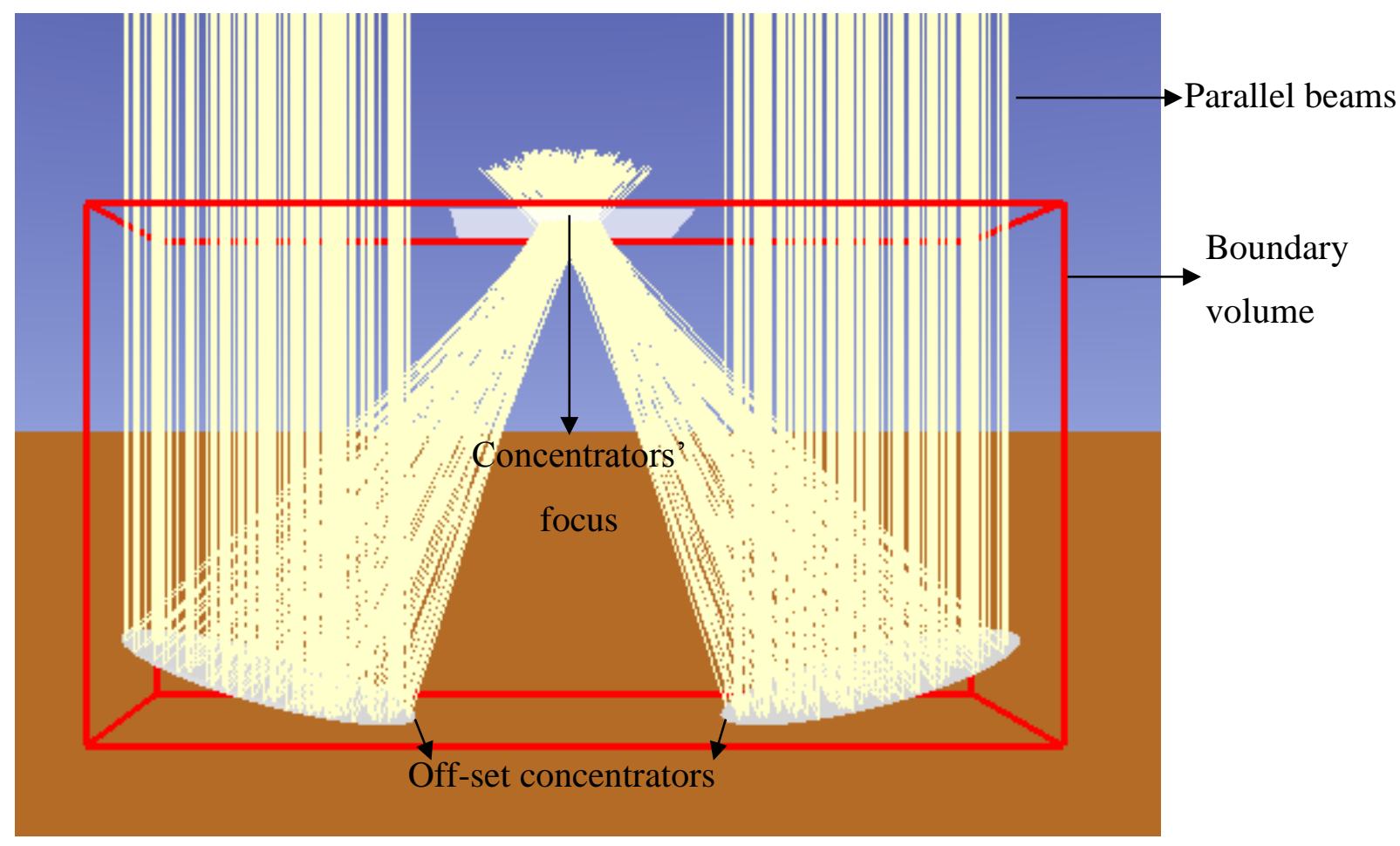

Figure 4.6. Tonatiuh simulation for parallel beams reaching the off-set concentrators, boundary volume, and a virtual plate at the focal plane of the paraboloids. 
Considering a thermal power of 1 Sun $\left(1 \mathrm{~kW} / \mathrm{m}^{2}\right)$, and reflectivity of $100 \%$ for the concentrators (meaning all rays reaching the concentrators are going to be reflected), it is possible to analyze the flux distribution at the focal plane of the paraboloids, as shown in Figure 4.7. The total thermal power has been determined by integrating the area of the concentrated heat according to the axis $\mathrm{X}$ and $\mathrm{Z}$, resulting in $228 \mathrm{~W}$. The shape of the concentrated area has proven to be very close to a circle. The total heat flux observed in the figure is 100 Suns. The average heat flux has been calculated by Tonatiuh@ as $8.9 \mathrm{~kW} / \mathrm{m}^{2}$. From the integration of the results, it has been determined that about $95 \%$ of the concentrated heat flux is located in a diameter of $80 \mathrm{~mm}$.

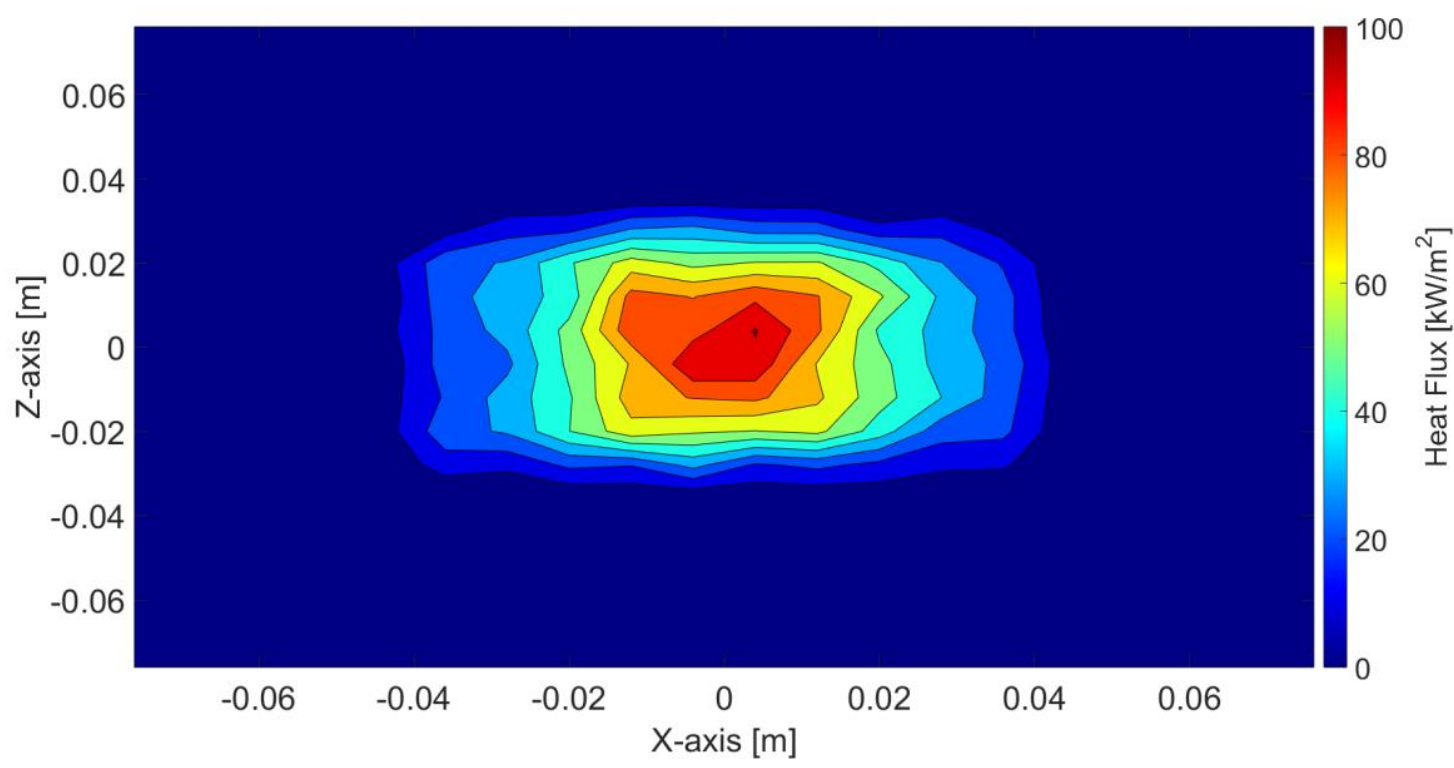

Figure 4.7. Simulation of the heat flux distribution at the focal plane of the off-set paraboloids.

The concentration ratio of the paraboloids, given by the ratio between the concentrator and the concentrated heat areas, has been estimated to be close to 43 , considering the area where $95 \%$ of the heat flux has been concentrated.

A comparison between the flux distribution using one single rotated paraboloid concentrator and an off-set concentrator has been undertaken by Canto et al. (2019a), experimentally indicating $30 \%$ improvement on the maximum heat flux attained using an off-set concentrator, compared to a central one. 


\subsubsection{Secondary Concentrators}

The secondary concentrator is a component used to concentrate the thermal energy even further. Equation (3.1) describes the maximum possible concentration ratio of a nonimaging device. Applying it for the same medium between the entrance and exit of the concentrator (same refractive index), it is reduced to Equation (4.1), where $\theta$ is the semi-angle of acceptance.

$$
C_{\max }=\frac{1}{\operatorname{sen}^{2} \theta}
$$

It is possible to define this semi-angle based on the geometry of the paraboloids as $46.5^{\circ}$, as shown in Figure 4.8. The point $\mathrm{P}$ indicated in the figure has been established using the geometry built by a commercial software; the right triangle in red has been drawn with the line starting at the edge of the $40 \mathrm{~mm}$ radius, corresponding to $95 \%$ of the concentrated power, to the point P. Applying Equation (4.1), the maximum concentration ratio for this acceptance angle has been set as 1.9 .

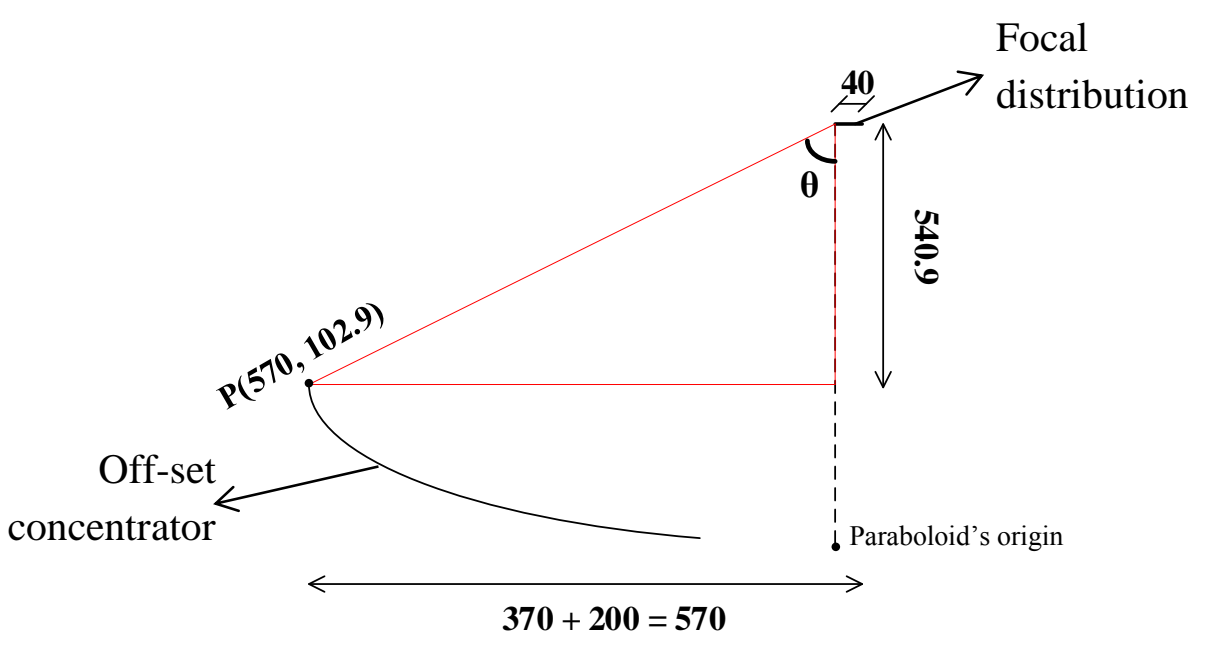

Figure 4.8. Triangle used to determine the acceptable angle in red. The dimensions are presented in $\mathrm{mm}$.

Using this configuration to design the nonimaging concentrators, since the entrance aperture of the concentrator has been established as $80 \mathrm{~mm}$ diameter, the exit aperture must be of 58 $\mathrm{mm}$. Employing the calculated information, a light cone and a CPC has been designed e their performance evaluated on Tonatiuh@

The light cone semi-angle has been determined using Equation (3.2) as $21.8^{\circ}$ and its length using Equation (4.2), which has been deduced from Equation (3.2), reaching the result of 27.5 
mm. To design the CPC, Equations (3.3) and (3.4) have been applied to determine the focus of the parabola and length of the CPC as $50.0 \mathrm{~mm}$ and $65.4 \mathrm{~mm}$, respectively.

$$
L_{\text {cone }}=\frac{a-a^{\prime}}{\tan \gamma}
$$

Placing the entrance of the concentrators at the focal plane of the offset concentrators, the heat flux distributions have been simulated, as shown in Figure 4.9 and Figure 4.10. The nominaging characteristic of these concentrators can be observed, as they have lead nor to geometric neither to well-distributed heat fluxes, in contrast to the one in Figure 4.7

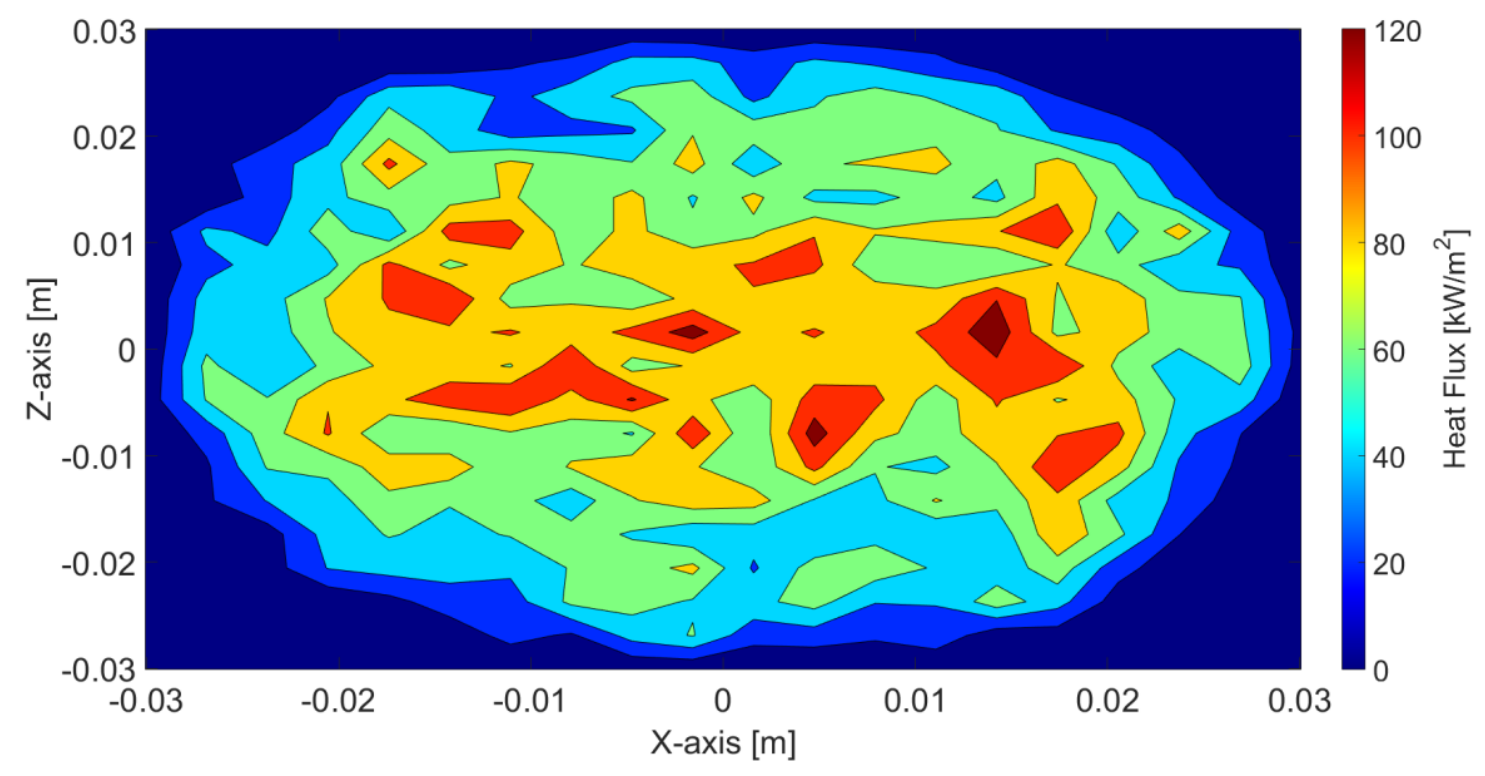

Figure 4.9. Simulated heat flux distribution at the exit of the light cone.

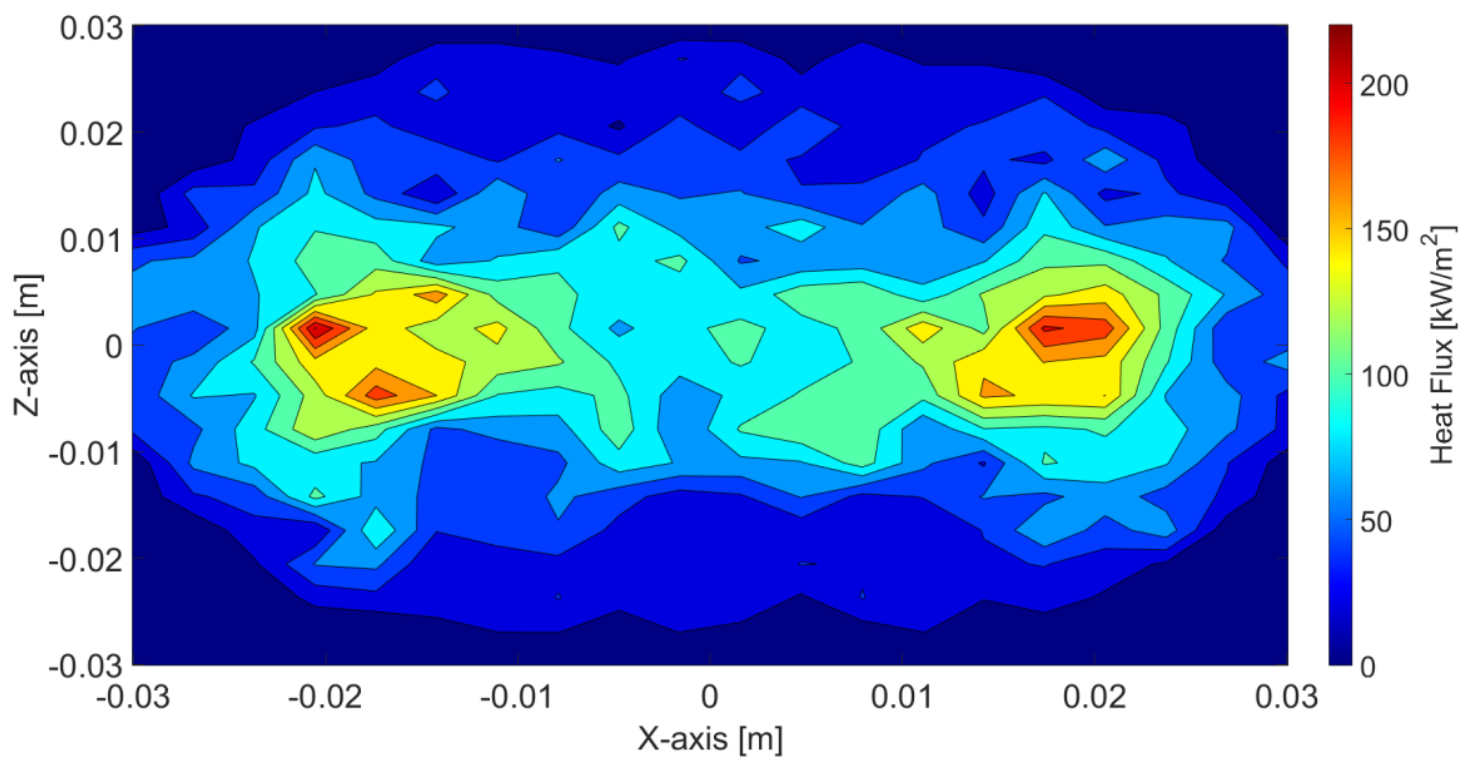

Figure 4.10. Simulated heat flux distribution at the exit of the CPC. 
The maximum (peak) and average heat flux at the exit of both apparatus, as well as the total power, have been determined as shown in Table 4.1. Defining the heat flux ratio of the secondary concentrators as the ratio between the average heat flux at the exit of the nonimaging gadget and one of the scenario when no secondary concentrator had been used, the numbers in Table 4.1 have been found. The efficiency indicated in the table has been fixed as the ratio between the total thermal power in the two scenarios mentioned above.

Table 4.1. Simulated total thermal power, maximum and average heat flux, heat flux ratio, efficiency and stagnation temperature for the use of light cone and CPC.

\begin{tabular}{l|c|c|c|c|c}
\hline & $\begin{array}{c}\text { Total thermal } \\
\text { power }\end{array}$ & $\begin{array}{c}\text { Heat flux } \\
\text { peak }\end{array}$ & $\begin{array}{c}\text { Average } \\
\text { heat flux }\end{array}$ & $\begin{array}{c}\text { Heat flux } \\
\text { ratio }\end{array}$ & Efficiency \\
\hline Unity & $\mathrm{W}$ & $\mathrm{kW} / \mathrm{m}^{2}$ & $\mathrm{~kW} / \mathrm{m}^{2}$ & - & $\%$ \\
Concentrator & 189.6 & 132.9 & 47.5 & 5.3 & 82.8 \\
Light Cone & 201.0 & 221.4 & 51.1 & 5.7 & 88.2 \\
\hline
\end{tabular}

From the results presented in Table 4.1, it is possible to infer the efficiency of both nonimaging concentrators have been simulated as above $80 \%$. The heat flux ratio indicates how many times the heat flux is further concentrated using a given device; in this case, both have concentrated about 5.5 times more than when no secondary concentrator had been used. The commercial nonimaging concentrators are designed to work well with maximum acceptance half-angle of $10^{\circ}$ (Welford and Winston, 1989), which leads to the maximum concentration ratio of 33.1. This number is about 18 times bigger than the 1.9 concentration ratio attained for the HFSS proposed. Therefore, a new way to envisage the "string" method has been suggested, at which all beams must either directly reach the exiting plane or be reflected by the same side from which it is originated, not the opposite, as shown in Figure 4.11. The beams entering the concentrator are represented by dashed lines and the rays being reflected outside are in dotted line. In consequence, Equation (4.3) has been applied for the cone semi-angle. 


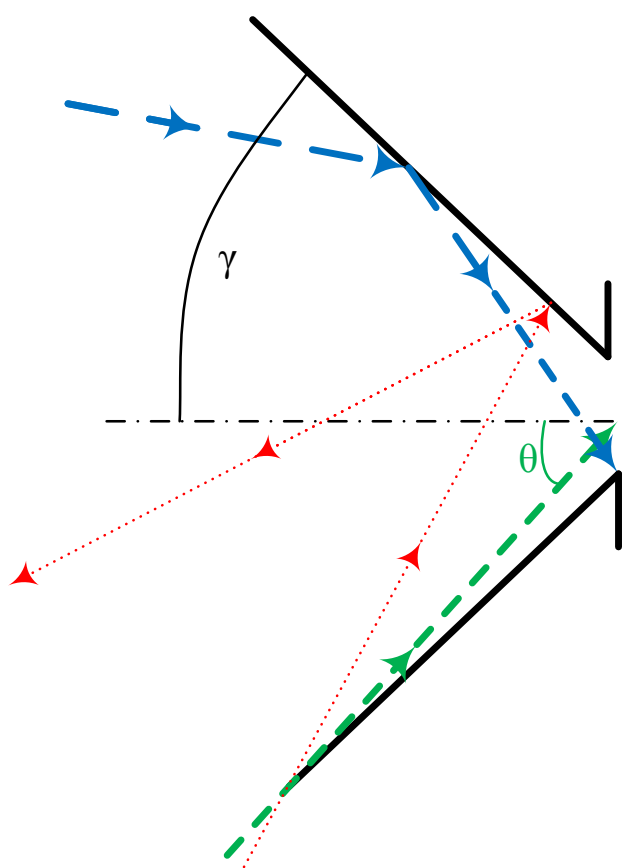

Figure 4.11. Rays reflected by the optimized cone. In red, portrayal of the rays reflected back to the entering aperture, in blue the rays reflected to the exit aperture and in green the rays reaching the exit aperture directly.

$$
\gamma=\frac{\pi}{2}-\theta
$$

Since this optimized cone does not obey the same maximum concentration ratio as the commercial ones, the exit aperture has been set as $35 \mathrm{~mm}$ diameter and its height as $100 \mathrm{~mm}$. For the cone semi-angle of $43.5^{\circ}$, calculated with Equation (4.3), the enter aperture must be $225 \mathrm{~mm}$ diameter, leading to a concentration ratio of about 6.4. The distribution heat flux at the exit of this device is shown in Figure 4.12, confirming the nonimaging characteristic of this kind of concentrator, and the results presented in Table 4.2 


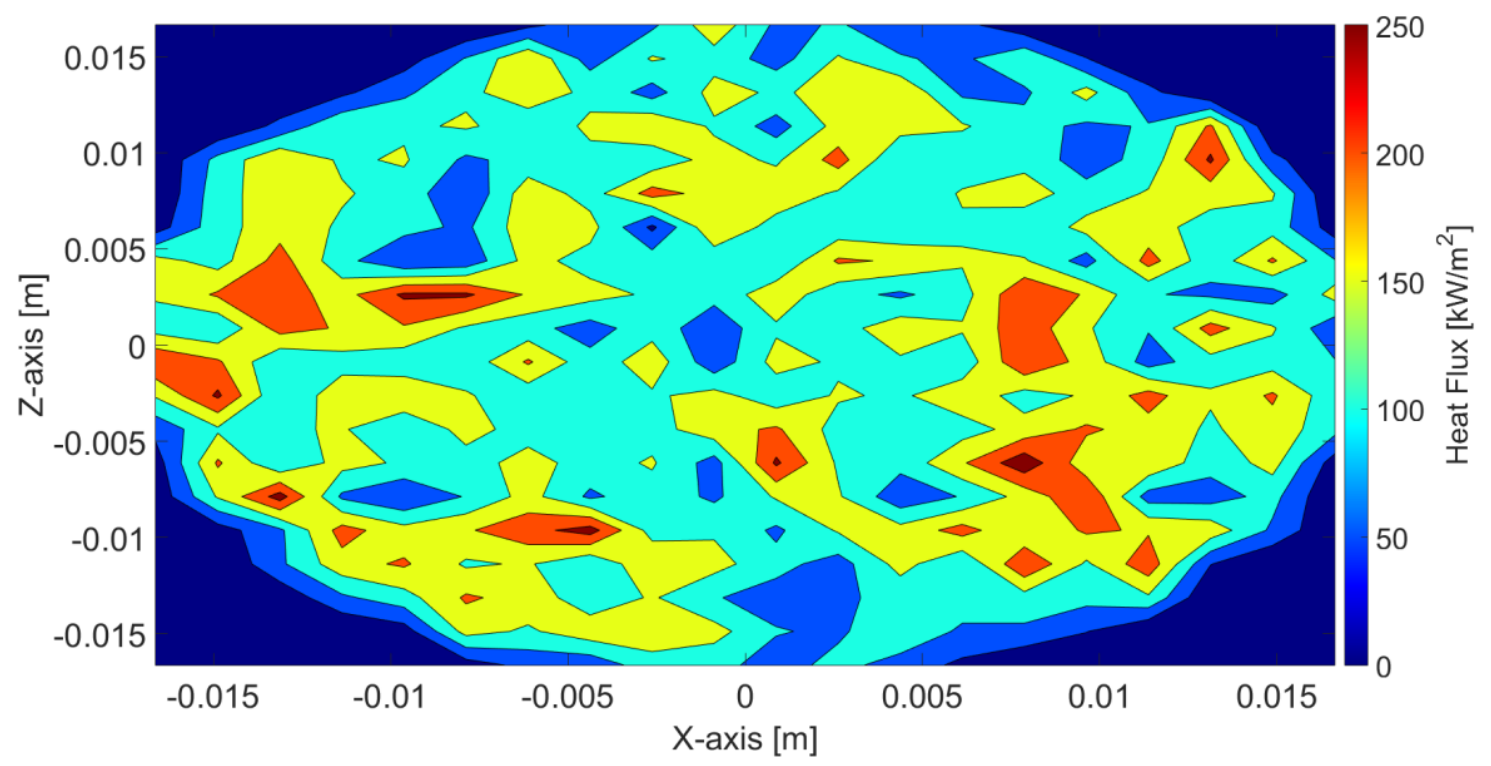

Figure 4.12. Simulated heat flux distribution at the exit of the optimized cone.

Table 4.2. Simulated total thermal power, maximum and average heat flux, heat flux ratio, efficiency using the optimized cone.

\begin{tabular}{c|c|c|c|c|c}
\hline & $\begin{array}{c}\text { Total thermal } \\
\text { power }\end{array}$ & $\begin{array}{c}\text { Heat flux } \\
\text { peak }\end{array}$ & $\begin{array}{c}\text { Average } \\
\text { heat flux }\end{array}$ & Heat flux ratio & Efficiency \\
\hline Unity & $\mathrm{W}$ & $\mathrm{kW} / \mathrm{m}^{2}$ & $\mathrm{~kW} / \mathrm{m}^{2}$ & - & $\%$ \\
Concentrator & 137.2 & 285.0 & 155.9 & 17.5 & 60.0 \\
\hline
\end{tabular}

Although the efficiency of the optimized cone has shown to be smaller than the $80 \%$ previously simulated, the coefficient of performance has been more than three times higher, with average heat flux much superior and maximum heat flux also more important. So, given the need of keeping the cavity window as small as possible, the use of the optimized cone has presented so far as the best option among the nonimaging concentrators.

Other comparisons, establishing a constant exit of $35 \mathrm{~mm}$ diameter and this time placing the exit of these devices at the focal plane of the offset concentrators can be found in Canto et al. (2019b), resulting in $49 \%$ efficiency for the optimized cone, $25 \%$ for the light cone and 86 $\%$ for the CPC. 


\subsection{Final High Flux Solar Simulator Layout}

After analyses carried out with Tonatiuh (C), the final layout of the HFSS has been designed. The distance between the light sources and the parabolic concentrators has been kept on two meters, with an imaginary axis connecting them. The support position concerning this axis has been set to $81.5^{\circ}$ and the height of the paraboloid's center has been the same as the sky search light center, this means $810 \mathrm{~mm}$. Table 4.3 resumes the layout adopted at the experimental procedure.

Table 4.3. Summary of the HFSS final layout.

\begin{tabular}{|c|c|c|}
\hline Component & Value & Additional information \\
\hline \multicolumn{3}{|l|}{ Light sources } \\
\hline Electrical power provided $[\mathrm{kW}]$ & 8 & \\
\hline Lamps & 2 & Short-arc xenon. \\
\hline Parabolic reflectors & 2 & \\
\hline Switchboard & 1 & $\begin{array}{l}\text { Lamp's turning on dependent on the } \\
\text { fan's state. }\end{array}$ \\
\hline \multicolumn{3}{|l|}{ Concentrators } \\
\hline Off-set paraboloids concentrators & 2 & $\begin{array}{l}\text { Fiberglass, polycarbonate and } \\
\text { aluminum powder. }\end{array}$ \\
\hline $\begin{array}{l}\text { Focal distance from the origin of the } \\
\text { paraboloid }[\mathrm{mm}]\end{array}$ & 643 & \\
\hline Secondary concentrator & 1 & Optimized cone. \\
\hline Supports & 2 & With improved precision. \\
\hline
\end{tabular}

\subsection{Calorimeter Cavity Design}

The calorimeter cavity has been designed to work as a black body cavity. In this sense, it is fundamental to keep the ratio between window area and the area inside the cavity as low as possible to ensure the unitary absorptivity, as proposed by Equation (3.9) and the graphic of Figure 3.10. 
Firstly, the cavity has been imagined as a cylinder, and its diameter and length have been determined setting window diameter to $35 \mathrm{~mm}$ and the ratio of areas to 0.005 . The area of the cavity walls is composed of the lateral area of the cylinder $\left(A_{\text {Lateral }}\right)$ and its bottom $\left(A_{\text {Bottom }}\right)$ and frontal $\left(A_{\text {Bottom }}-A_{\text {Window }}\right.$, where $A_{\text {Window }}$ is the area composed by the window of the cavity) areas, as shown in Equation (4.4). Table 4.4 has been presented some suited parameters for the cylinder.

$$
A_{\text {Cavity Walls }}=A_{\text {Lateral }}+2 A_{\text {Bottom }}-A_{\text {Window }}
$$

Table 4.4. Radius and corresponding lengths for a cylindrical cavity, with a $35 \mathrm{~mm}$ diameter window and areas ratio of 0.005 .

\begin{tabular}{c|c}
\hline Cylinder Radius [mm] & Cylinder length [mm] \\
\hline 27.5 & 1091.7 \\
57.5 & 477.7 \\
77.5 & 319.6 \\
\hline
\end{tabular}

From the radius and corresponding lengths of Table 4.4, the $77.5 \mathrm{~mm}$ radius and $319.6 \mathrm{~mm}$ length cavity seems the most suited geometry, presenting all dimensions in reasonable dimensions given the size of the apparatus of the HFSS. The actual cavity has been built approaching the dimensions proposed above, but also obeying the manufacture's limitations. A long copper tube of $6.35 \mathrm{~mm}$ diameter rolled up over an $80 \mathrm{~mm}$ radius billet until it had reached about $320 \mathrm{~mm}$, which corresponds to 51 spirals. The lateral area of the cavity walls has been determined applying Equation (4.5). The bottom and frontal areas have been calculated assuming $80 \mathrm{~mm}$ radius. This way, the actual areas ratio of the produced has been fixed to 0.0033 .

$$
A_{\text {LateralHelicoidal }}=2 \pi^{2} n r_{c} r_{\text {Tube }}
$$

Where:

$n$ is the number of spirals;

$r_{c}$ is the inner radius of the cavity

$r_{\text {Tube }}$ is the external radius of the copper tube. 
Figure $4.13 \mathrm{a}$ exhibits the lateral portion of the calorimeter cavity, made of welded copper spirals. And Figure 4.13b and 4.13c display the frontal and bottom parts, respectively. The pieces have been assembled by simple union. The DUXON DX7000 DuxOne black mat automotive painting of emissivity 0.88 (Henninger, 1984) has been applied to the inside and out of the whole cavity.

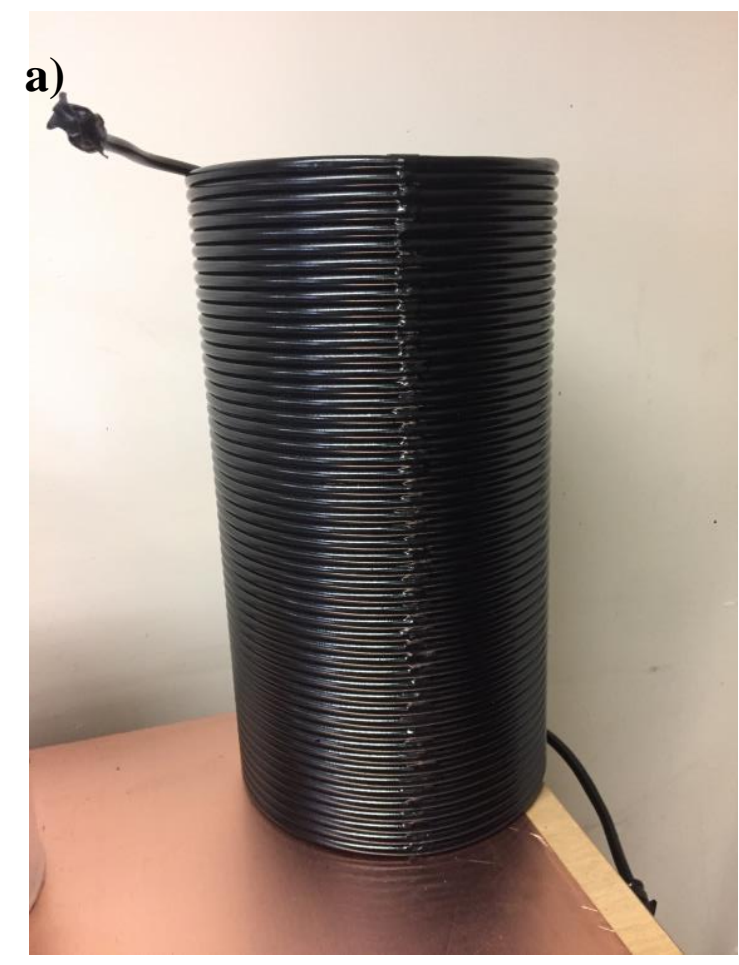

b)

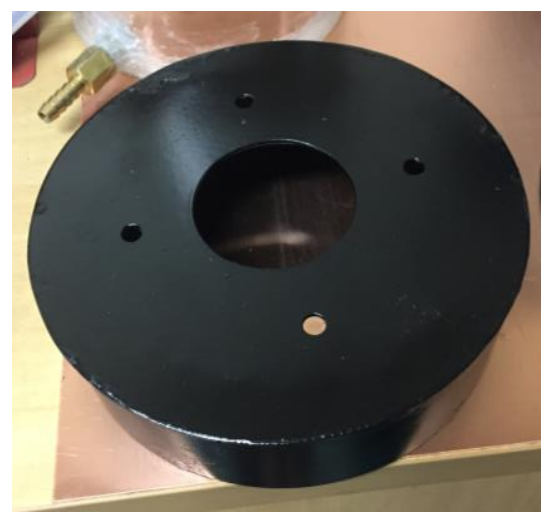

c)

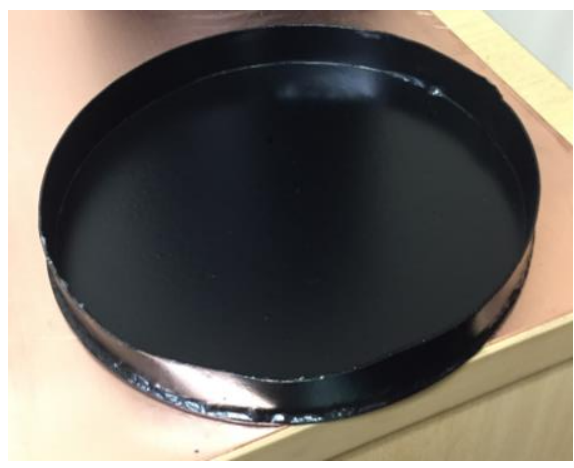

Figure 4.13. Calorimeter cavity. a) Spiral tube walls; b) Frontal part; c) Bottom part.

To minimize the losses by conduction or convection, two quartz discs have been positioned at the frontal part of the cavity, making up the window through which the radiation enters the cavity. The transmissivity of the commercial quartz shown in Figure 4.14 is about $93 \%$ between 300 and $2500 \mathrm{~nm}$. 


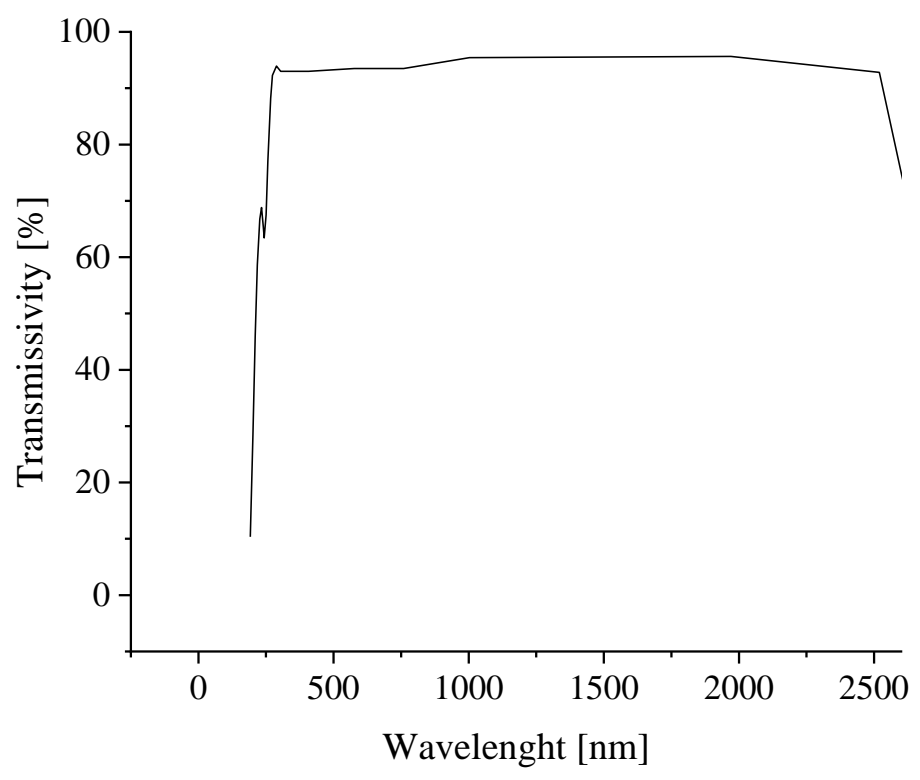

Figure 4.14. Transmissivity of a commercial quartz disc (Technical Glass Products, 2010).

Applying the information about areas ratio, paint's emissivity, and quartz transmissivity, to Equation (3.9), the effective absorptivity of the calorimeter cavity has been determined as 0.87 .

The optimized cone has been manufactured from an aluminum billet at a CNC lathe, to match the dimensions of the simulation, this means, $100 \mathrm{~mm}$ height, $225 \mathrm{~mm}$ bigger diameter and 35 $\mathrm{mm}$ smaller diameter, with a base to be pinned to the frontal part of the cavity, which can be seen in Figure 4.15a. An aluminum powder coating has been applied to the inside of the secondary concentrator to improve reflectivity, as shown in Figure 4.15b. The quartz discs have been placed between the cone and the cavity.

b)

a)
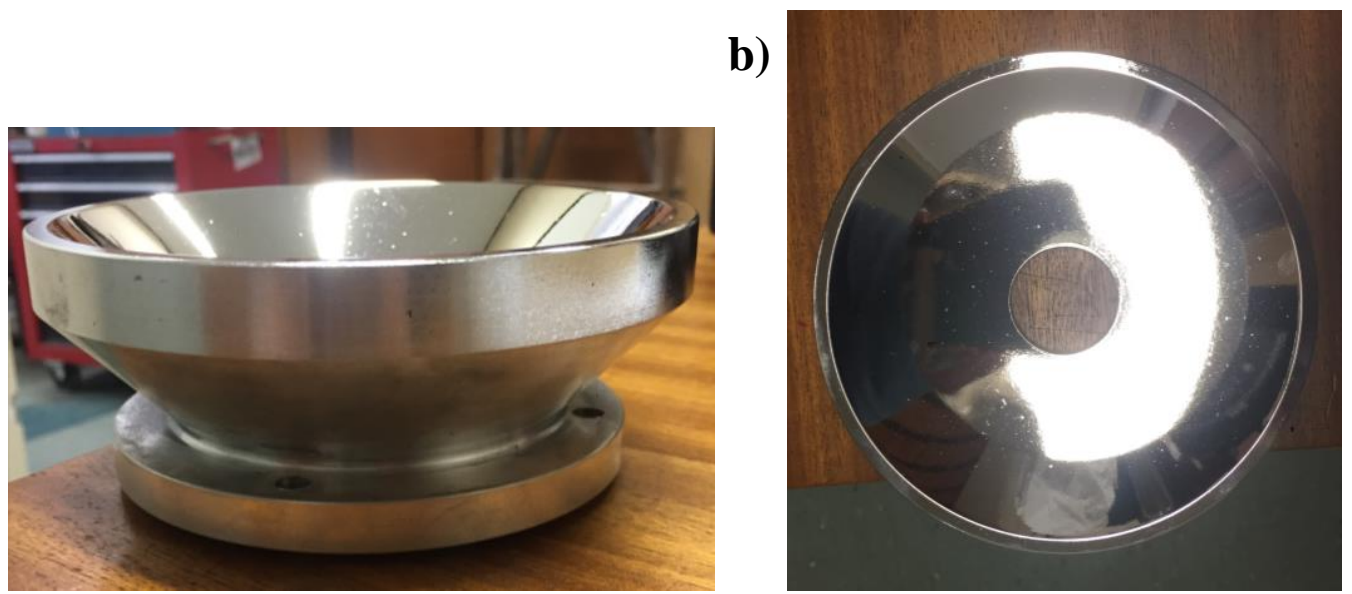

Figure 4.15. Optimized cone with a base to pin at cavity front a) side view; b) upper view. 
The whole cavity and secondary concentrator have been wrapper in glass wool insulation and aluminized tape. To prevent the burning of the insulation, an alumina plate has been placed around the cone as a shield, so side beams coming from the parabolic concentrators fail to reach the insulation surface. The insulated cavity is pictured in Figure 4.16.

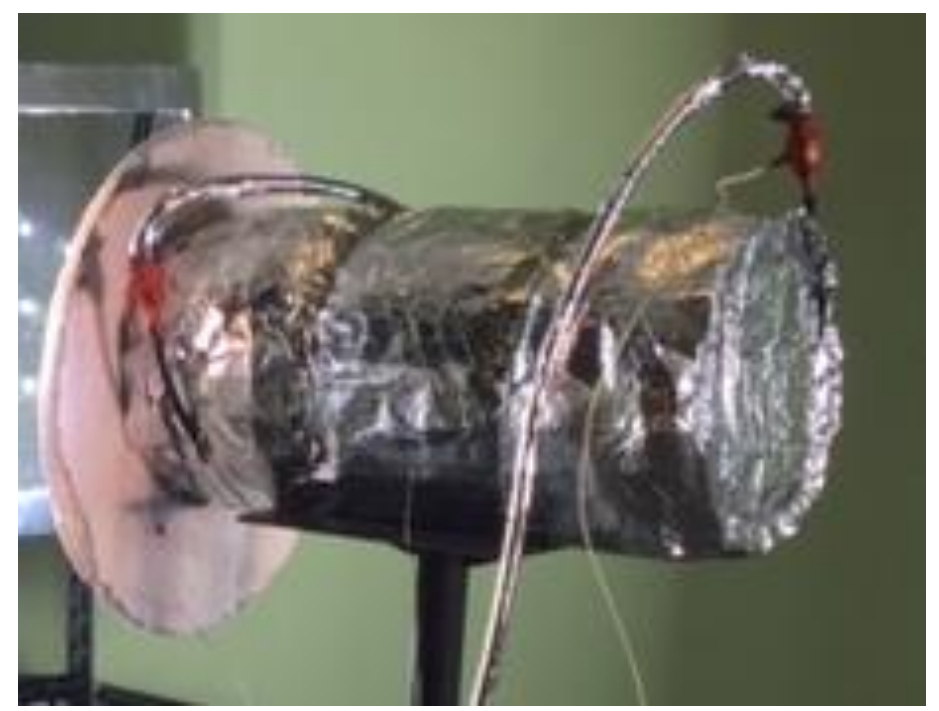

Figure 4.16. Calorimeter cavity insulated by glass wool, aluminized tape, and an alumina plate shield. 


\section{TEST RIG AND INSTRUMENTATION}

\subsection{Instrumentation}

The instruments used to perform the tests of this work have been listed, along with their limits of operation.

\subsubsection{Heat Flux Sensor}

Also known as Gardon gauge or radiometer, it is a water-cooled, circular-foil, TG-1000-0 (flanged) from Vatell Corporation Inc. (Figure 5.1), of $24.5 \mathrm{~mm}$ diameter, +/- 3\% accuracy, minimum range $5 \mathrm{~W} / \mathrm{cm}^{2}$ and maximum range $5000 \mathrm{~W} / \mathrm{cm}^{2}$ (from 50 to $50,000 \mathrm{~kW} / \mathrm{m}^{2}$ ). The data reading has been done by plugging the Gardon gauge ends to an HP 34401A multimeter, of accuracy $0.005 \%$ of the reading and $0.0035 \%$ of the range, at a range of $100 \mathrm{mV}$. It is necessary to let the multimeter turned on for at least 15 minutes before starting the tests to it to stabilize.

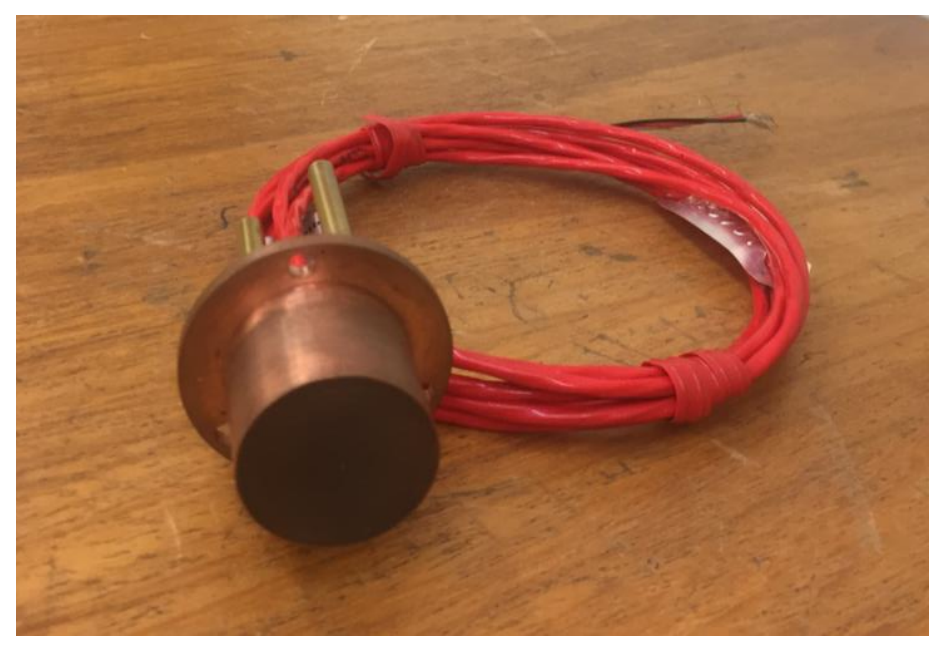

Figure 5.1. Gardon gauge from Vatell Comporation Inc.

Annex B contains the calibration curve between electric pulses and heat flux measured by the Gardon gauge used.

\subsubsection{Spectrophotometer}

The spectrophotometer used has been a USB 2000+XR1 (Figure 5.2), with an extended range. It is a modular spectrometer from the Ocean Optics, Inc., covering wavelengths from 200 to 
$1025 \mathrm{~nm}$, of 2048 pixels, and signal-to-noise (S:N) of 250:1, to which different types of fibers, calibration light sources, and other devices can be connected.

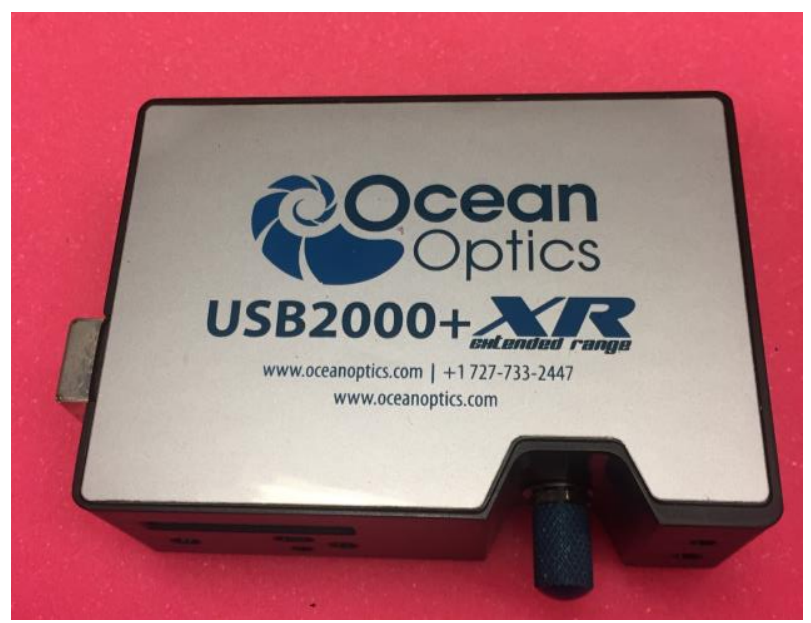

Figure 5.2. Spectrophotometer USB+XR1 from Ocean Optics Inc.

Two calibration lights have been used with the spectrometer, depending on the measurements: either an HL-3P-CAL (Figure 5.3a) or an HL-2000-LL (Figure 5.3b), both containing cooling fans. Usually, the HL-3P-CAL is used for absolute irradiance measurements. It contains a tungsten halogen lamp, calibrated from 350 to $1050 \mathrm{~nm}$, its bulb life is 10,000 hours, needing to be recalibrated every 50 hours and stabilization time of 15 minutes before operation. Its maximum uncertainty is $3 \%$. On the right side of the lights, there is the entrance for the fibers and on the left side is the entrance for the input energy.
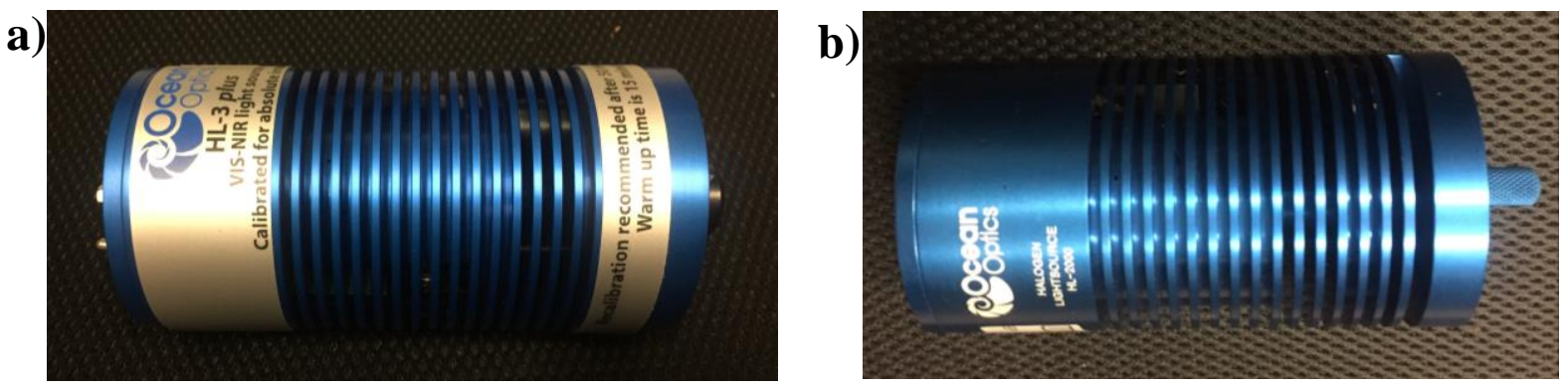

Figure 5.3. Calibration lights a) $H L-3 P-C A L$ b) $H L-2000-L L$

The HL-2000-LL contains a halogen light, which ranges from 360 to $2400 \mathrm{~nm}$ and a color temperature of $2,800 \mathrm{~K}$, and a bulb life of 10,000 hours. Ten minutes of warm-up time is needed to stabilize.

The optic fiber adopted is a path cord, used to route light from one location to another. The premium-grade fiber QP50-2-VIS-NIR (Figure 5.4a) has a fiber core of $50 \mathrm{um}$, ranges from 
400 to $2100 \mathrm{~nm}$, operates from -65 to $300^{\circ} \mathrm{C}$ and should not be bent to a radius over $2 \mathrm{~cm}$ during usage.
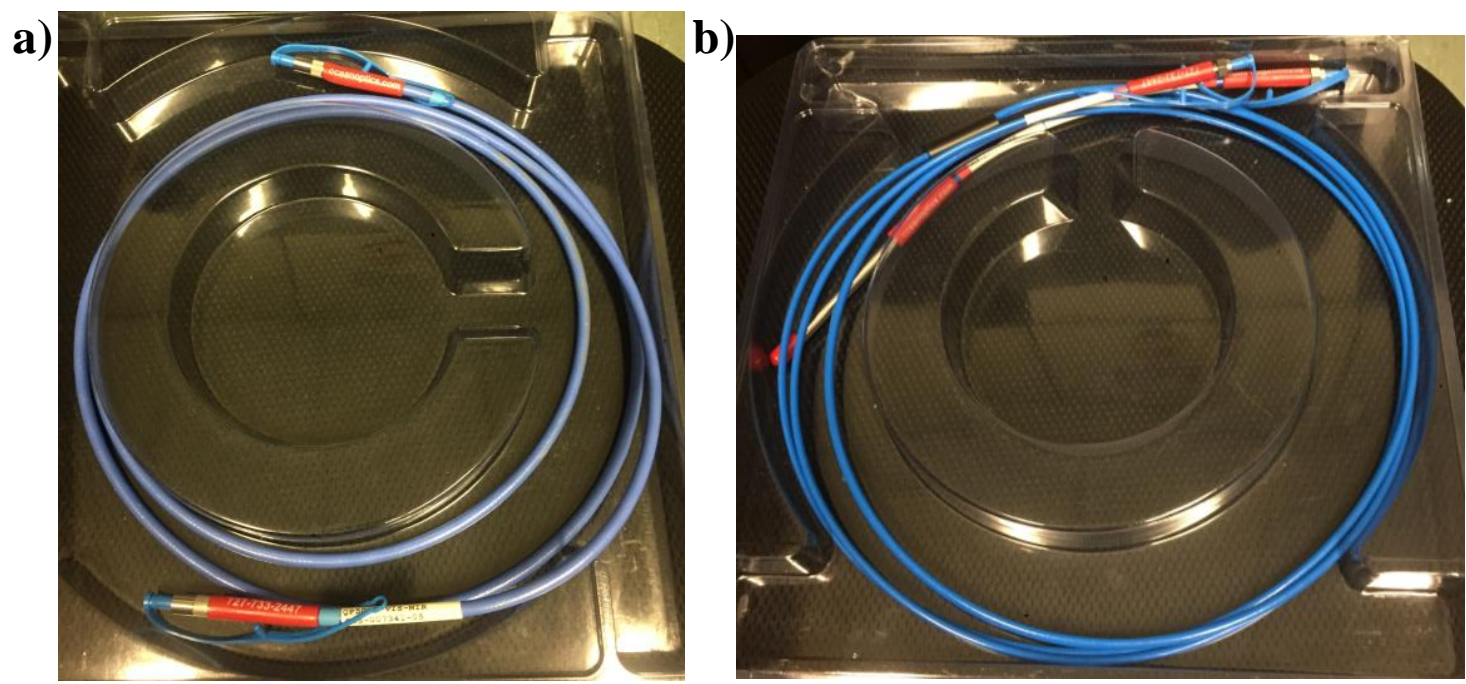

Figure 5.4. Optic fibers a) path cord QP50-2-VIS-NIR b) bifurcated fiber R400-7-VIS-NIR.

Another convenient fiber is a bifurcated one, Premium grade R400-7-VIS-NIR (Figure 5.4b), which is used to route equal amounts of light to two different locations. It has a fiber core of $400 \mu \mathrm{m}$, operating temperature ranging from $-20^{\circ} \mathrm{C}$ to $80^{\circ} \mathrm{C}$, it takes measurements from 400 to $2100 \mathrm{~nm}$ and has a bending limit of $8 \mathrm{~cm}$ radius when in use. All fibers deliver consistent results, with minimal signal variance.

Among the accessories used in particular experiments are: a cosine corrector (Figure 5.5), which is plugged at the end of a fiber to wide up the field of view up to $180^{\circ}$; a reflection probe holder (Figure 5.6), used to position the fibers of $6.35 \mathrm{~mm}$ diameter at $45^{\circ}$ or $90^{\circ}$ over flat surfaces; and a STAN-SSH specular reflectivity standard of high reflectivity (Figure 5.7), ranging wavelengths from 250 to $2500 \mathrm{~nm}$.

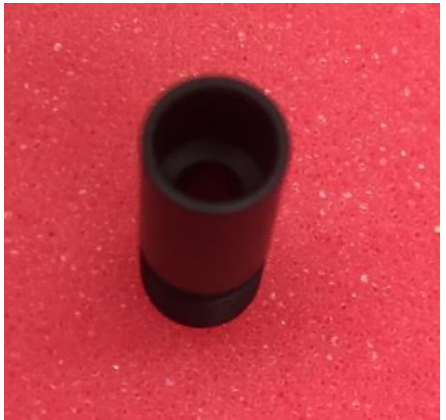

Figure 5.5. Ocean Optics' cosine corrector.

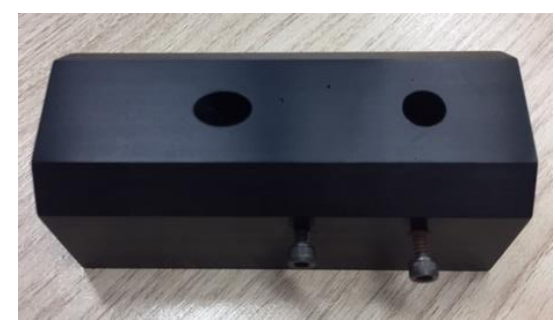

Figure 5.6. Ocean Optics' reflection probe holder.

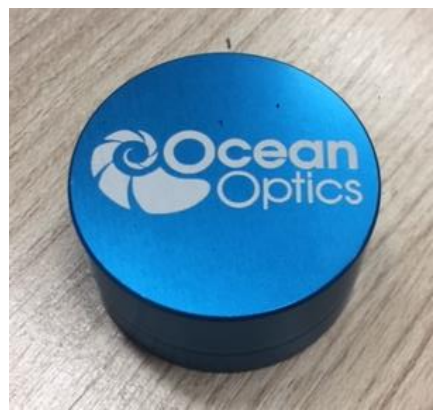

Figure 5.7. Ocean Optics' specular standard of high reflectivity. 
The software Ocean View $(\mathcal{C}$ has been provided by the manufacturer and can be used for different applications, such as absorptivity, color measurement, irradiance, reflectivity, and transmissivity. It is essential to set the parameters accordingly with the equipment in use to achieve reliable results.

\subsubsection{Near-Lambertian Plate}

A surface that has a cosine-dependent reflectivity versus a polar angle is called a Lambert one (Kienle \& Foschum, 2011), it means its radiant intensity is the same on any given direction, thus a utterly diffuse reflectivity. Substrates of little rounded alumina $\left(\mathrm{Al}_{2} \mathrm{O}_{3}\right)$ granules, of approximately $0.5 \mu \mathrm{m}$ have been used to ensure the almost total reflectivity and diffusivity of the plate (Shimokawa et al., 2001), has been chosen to match the purposes of this research for this reason.

The base of the substrate has been made out of a plate aluminum, $300 \times 300 \mathrm{~mm}$ sides and 10 $\mathrm{cm}$ width. It has been perforated at the width 7 times by an $8.4 \mathrm{~mm}$ diameter drill, and flexible aluminum tubes have been glued with resin to the holes, in the way of creating a circuit through which water has been pumped to keep the plate temperature under acceptable levels. The plate has also been perforated at its surface with a $24.5 \mathrm{~mm}$ drill, and a hole equal to the heat flux sensor has been manufactured. This way, it has been possible to use the plate with and without the radiometer coupled. Appendix A details the manufacturing process of the aluminum plate.

Afterward, the Company Castolin Eutectic has applied a $0.2 \mathrm{~mm}$ coat of the alloy Metaceram 25010 of alumina over the aluminum plate, employing the thermal sprinkler technic. The result can be verified in Figure 5.8. 


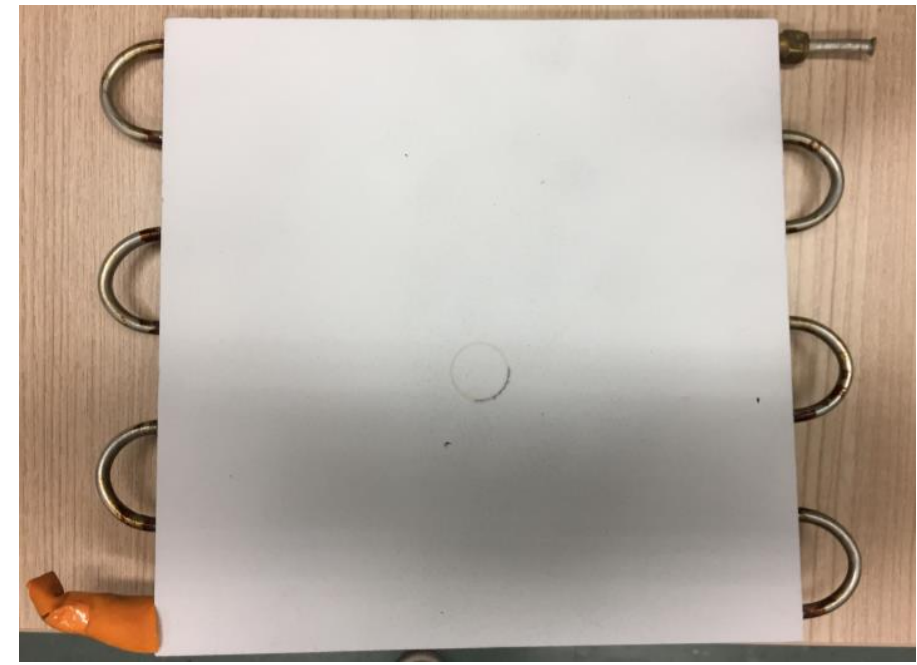

Figure 5.8. Near-lambertian plate manufactured.

\subsubsection{Other Instruments}

A coordinated table of movement in 3 axes has been used. It is composed by the mechanical structure that enables the course of $500 \mathrm{~mm}$ x $500 \mathrm{~mm}$ on the horizontal plane and $250 \mathrm{~mm}$ on the vertical plane; three Nema 23 step motors, with drives of $4.5 \mathrm{~A}$ and power supply of $36 \mathrm{~V}$ of continuous current; and a numerical controller with processor. It has been designed and manufactured by the FoxBravo Automação e Serviços Company, under the specification of the work.

A water circuit composed by the water pump Schneider BC-98 1/2 HP, a car radiator and a rotameter ranging from 60 to 600 liters of water per hour, with flexible copper and temperature resistant silicone tubes has been put to use to cool down various apparatus in different tests. Thermocouples type $\mathrm{J}$ and $\mathrm{K}$ have also been used.

Finally, the use of an 8-bit monochrome industrial camera DMK 33GP1300 has been of great importance in flux distribution analyses. It has a 1.3 MP resolution, on 1,280 x 1,024 pixels, leading to pixel sizes of $4.8 \times 4.8 \mu \mathrm{m}$, a shutter of $20 \mu \mathrm{s}$ to $10 \mathrm{~s}$ and operating temperature between $-5^{\circ} \mathrm{C}$ and $45^{\circ} \mathrm{C}$. The lens mount is of $\mathrm{C}$ or CS type. The spectral sensitivity of this camera can be found in Annex C. A lens SM25WI of adjustable focal length has been mounted to the camera. Two neutral density filters have been coupled to the lens, one of fixed 400 density and the other of variable density from 2 to 400 . Figure 5.9 shows the camera with the lens and filters mounted. To capture the images from outside the test facility, the software I.C. Capture 2.4 has been used. 


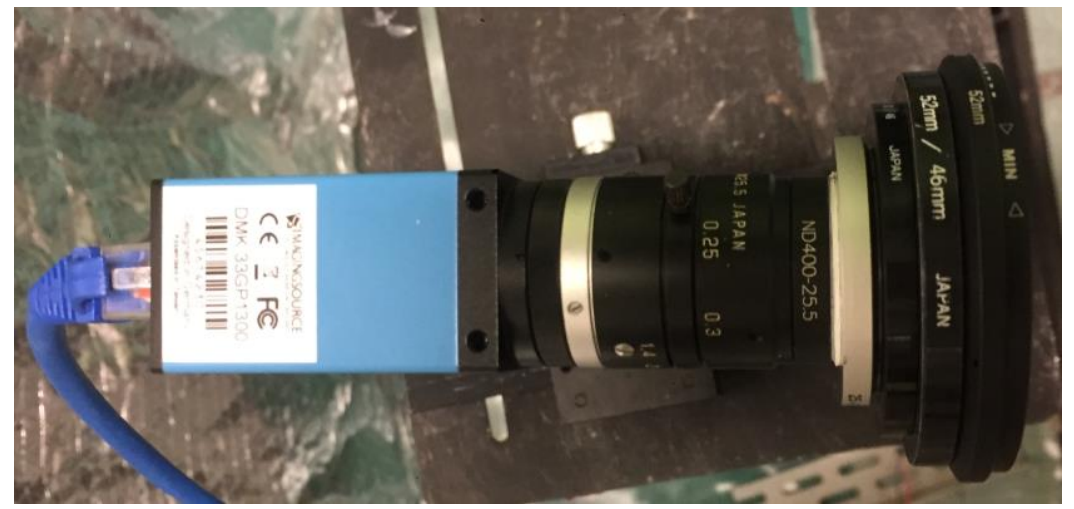

Figure 5.9. Camera DMK 33 GP1300 with the lens, neutral density filters, and adaptors mounted.

\subsection{Thermal Power of the Sky Searchlights Analyses}

The thermal radiative power is the portion of the energy of the light sources used to simulate the thermal power of the Sun on an HFSS; thus it is indispensable to distinguish the electricto-radiant efficiency of the Sky Searchlights. To do so, three techniques have been implemented: the use of the Gardon gauge, a manufactured calorimeter, and the spectrophotometer.

\subsubsection{Using the heat flux sensor}

The heat flux sensor has been mounted on the Lambertian plate, which has been used here only as support for its optical properties have not been used in any investigation. The plate has been fixed to the coordinated table and placed parallel to the sky searchlight, as shown in the layout of Figure 5.10. Horizontal and vertical sweeps of the central part of the light sources have been carried, and Equation (5.1) applied to each quadrant analyzed. The results have latter been summed and then the irradiation of the light sources determined.

$$
I(r)=\pi \int_{r_{1}}^{r_{2}} \dot{q} "(r) r d r
$$




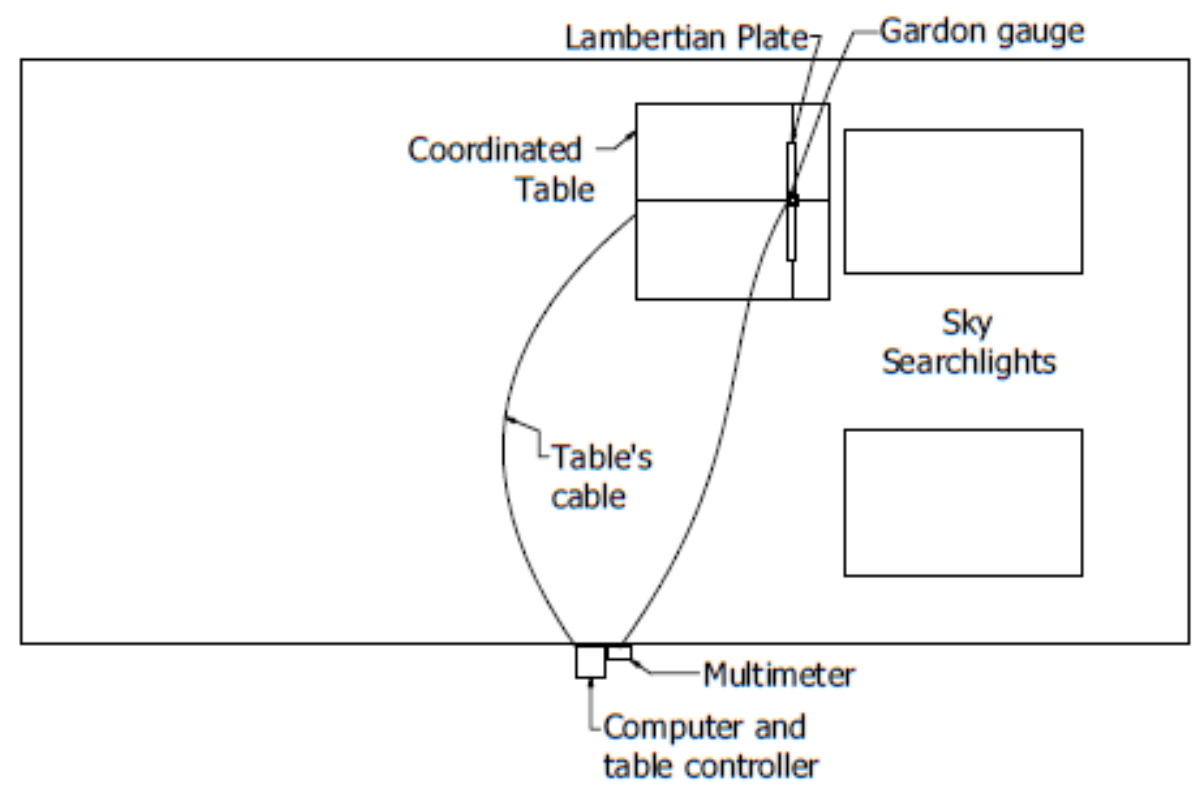

Figure 5.10. Test layout to determine the sky searchlight's irradiance using the Gardon Gauge.

The electric-to-radiant ratio of Equation (5.2), which determines how much of the input electrical power turned into radiant energy, has been defined in all three methods.

$$
R_{\text {Elec-to-Rad }}=\frac{I}{P_{\text {elec }}}
$$

\subsubsection{Using the calorimeter}

A calorimeter has been manufactured within the Sisea laboratory to compare the irradiance of the sky searchlights, using different methods. The calorimeter is made of a $6 \mathrm{~mm}$ internal diameter copper tube, spiraled until it reaches $370 \mathrm{~mm}$ diameter, which is the same as the sky searchlight window. It has been painted with black copper paint for automobile applications, of emissivity 0.88 . A commercial glass plate, of transmissivity around 0.83 from $350 \mathrm{~nm}$ to $2500 \mathrm{~nm}$ wavelength (Figure 5.11) has been placed in the front of the calorimeter to reduce losses by convection, an alumina plate has been added behind to minimize heat losses by conduction and convection, and glass wool fasted around the calorimeter diameter with an aluminum belt to prevent heat losses too. Figure 5.12 is a picture of the calorimeter manufactured. 


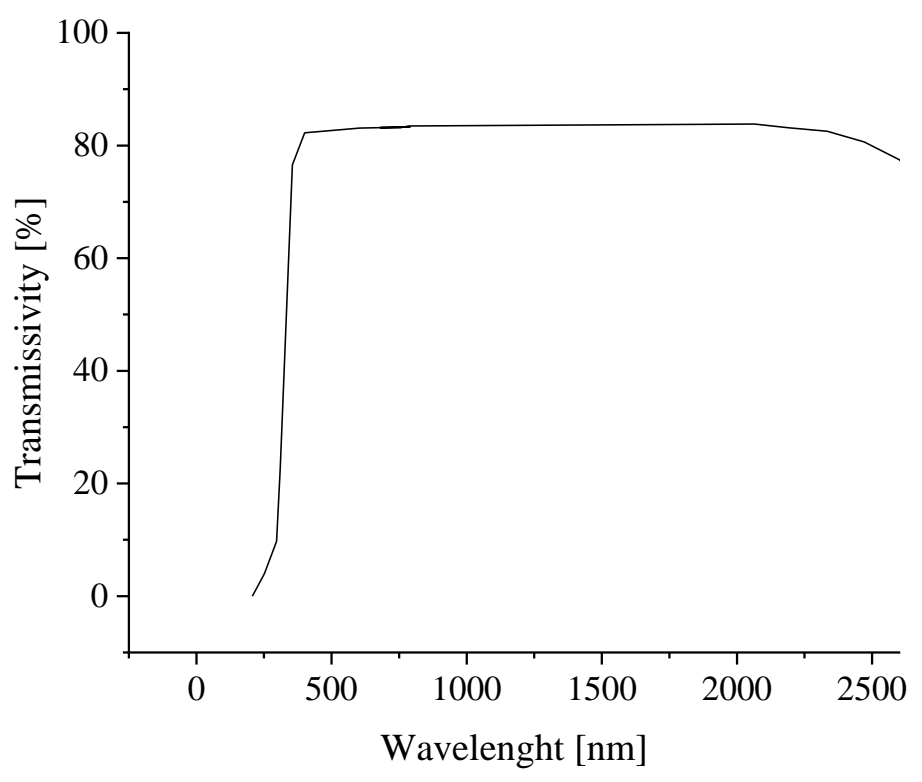

Figure 5.11. Transmissivity of a commercial glass (Tanner, 2003).

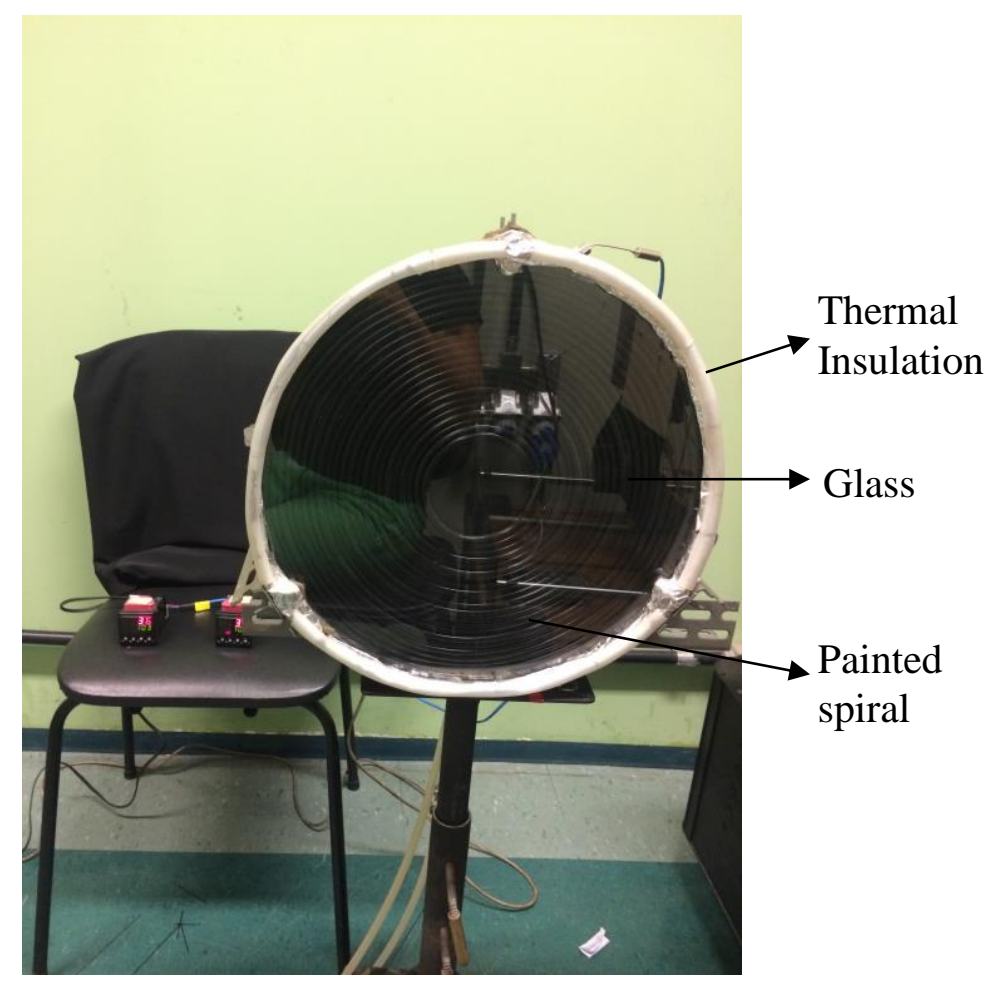

Figure 5.12. Calorimeter developed in Sisea laboratory to determine the irradiance of the sky searchlights.

The calorimeter has been positioned very close to the sky searchlight, as shown in Figure 5.13. Water has been circulated in the copper tube using the circuit previously described. A 
thermocouple has been placed at the inlet and another at the outlet of the water. The temperatures have been monitored until they had reached the steady-state.

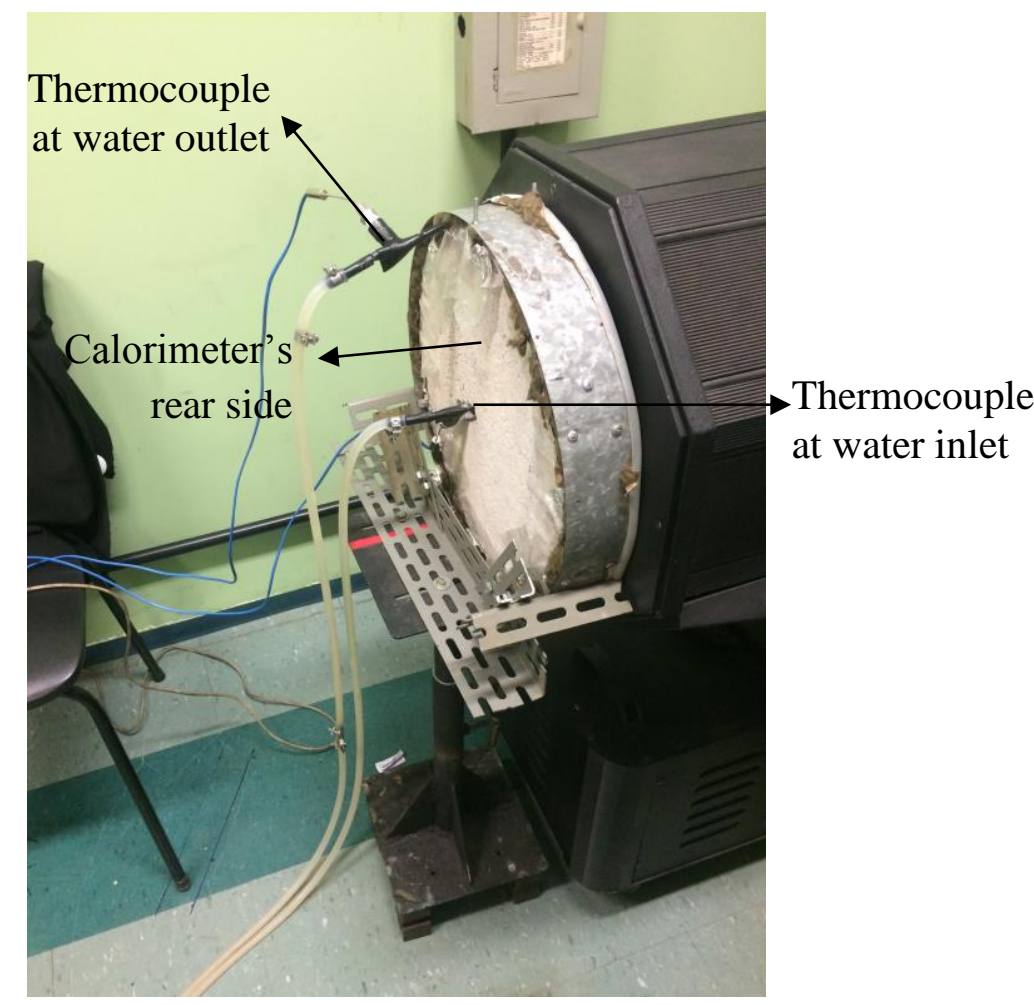

Figure 5.13. Survey to determine the irradiance of the sky searchlights. The thermocouples placed at the water inlet and exit have been indicated.

Applying the first law of thermodynamics to the calorimeter, neglecting losses by conduction and convection, Equation (5.3) has been established. Rearranging, Equation (5.4) appears to determine the irradiance of the sky searchlight. The temperature of the copper painted coil has been considered the same as the water in the outlet when steady-stead had been reached.

$$
\begin{gathered}
\eta_{\text {opt }} I_{S S L}=\dot{q}^{{ }_{\text {Ref }}}+\dot{q}^{\prime \prime}{ }_{\text {Reir }}+\dot{q}^{\prime \prime}{ }_{\text {abs }} \\
I_{S S L}=\frac{\varepsilon_{\text {paint }} \sigma\left(T_{\text {Spiral }}^{4}-T_{\infty}^{4}\right)+\dot{m}_{w} c_{P w}\left(T_{\text {out }}-T_{\text {in }}\right)}{\tau_{g} \alpha_{\text {paint }}-\left(1-\alpha_{\text {paint }}\right)}
\end{gathered}
$$

Where:

$I_{S S L}$ is the irradiance of the sky searchlight;

$\dot{q}_{R e f}$ is the heat flux per unity of area reflected by the calorimeter's glass;

$\dot{q}_{\text {Reir }}$ is the heat flux per unity of area re-irradiated by the calorimeter;

$\dot{q}_{a b s}$ is the heat flux per unity of area absorbed by the water flow;

$\eta_{\text {opt }}$ is the optical efficiency of the calorimeter front; 
$\varepsilon_{\text {paint }}$ is the black paint's emissivity (equals to the absorptivity of the paint);

$\alpha_{\text {paint }}$ is the paint's absorptivity;

$\tau_{\text {glass }}$ is the glass' transmissivity;

$\dot{m}_{w}$ is the water's mass flux;

$\mathrm{c}_{\mathrm{Pw}}$ is the water calorific power;

$T_{\text {Spiral }}$ is the tube temperature;

$T_{\text {out }}$ is the water temperature at the outlet;

$T_{\text {in }}$ is the water temperature at the inlet.

\subsubsection{Using the spectrophotometer}

Previously, the spectrometer has been calibrated using the path cord QP50-2-VIS-NIR with the cosine corrector, connected to the light source HL-3P-CAL. It is recommended by the manufacturer that the calibration is done at the same place and day as the measurement is about to take place for climate changes that can interfere. In the software, the integration time must be set in the way of the measurement reach about $80 \%$ of the limit indicated by the horizontal line and the boxcar width must not overpass 1 (one) and the fiber diameter must be set to $3,900 \mu \mathrm{m}$ when using a cosine corrector.

After the calibration has been done, the fiber end and the cosine corrector have been disconnected from the halogen lamp and placed in position for the sky searchlight measurements. As can be seen in the layout of Figure 5.14, the fiber has been mounted on the coordinated table, parallel to the sky searchlight, on a distance of $500 \mathrm{~mm}$. The other end has been connected to the calibrated spectrometer, and the data have been transmitted by a USB cable to the computer. A sweep of the horizontal central area of the sky searchlight has been carried on, and a graphics of absolute irradiance have been drawn for each point. The vertical axis has not been swept due to displacement limitations of the table. 


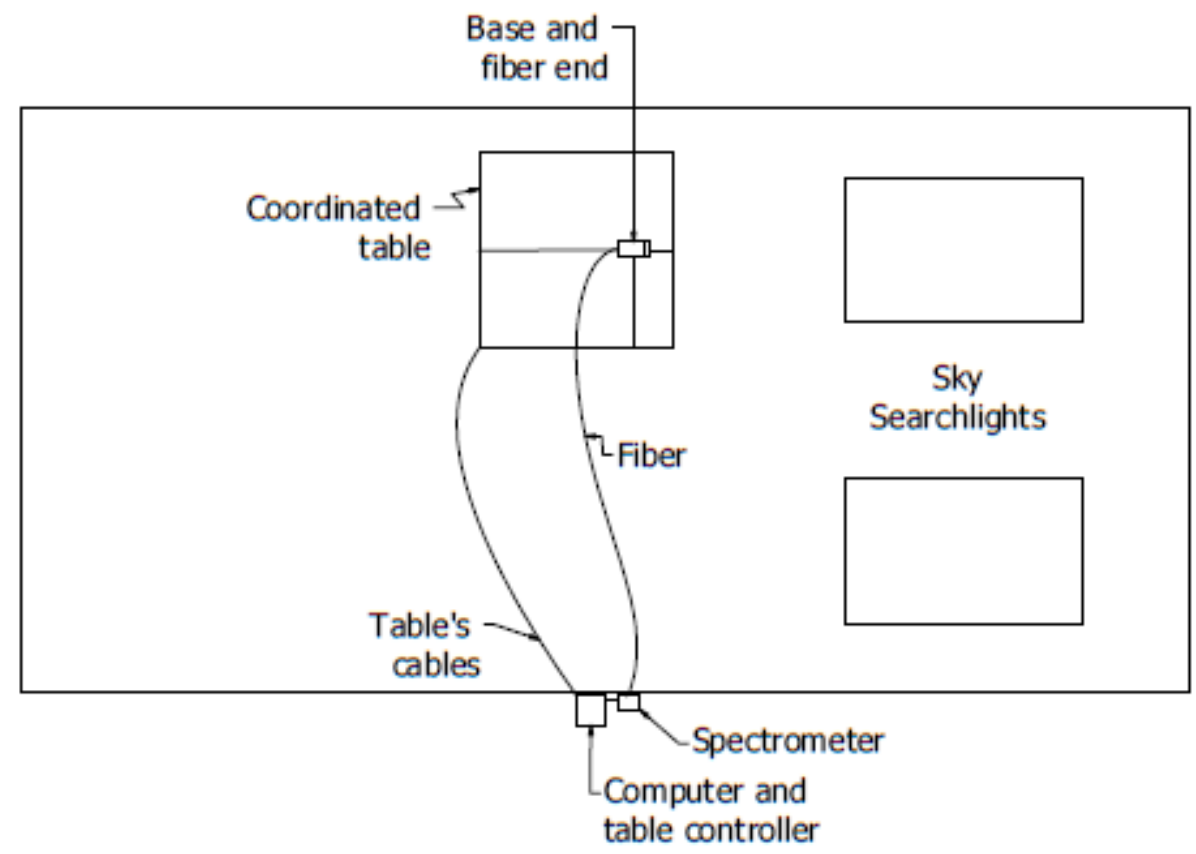

Figure 5.14. Test layout to determine the sky searchlight's irradiance using the spectrometer.

The same calibration procedure may be followed with the HL-2000 lamp to determine the relative irradiance of the sky searchlights. The maximum count of irradiation is set to 1 , and all the other counts are related to this maximum. This measurement makes possible to compare the light source used with the reference standard spectrum of the Sun. In this case, there is no need of using the cosine corrector.

The relative irradiance evaluation may be compared to the black body radiation curve calcultated with Equation (5.5) for a color temperature of 6,200 K. The point of maximum emission is calculated by the Wien's displacement law, represented by Equation (5.6).

$$
\begin{gathered}
E(\lambda)=\frac{2 \pi c^{2} h}{\lambda^{5}} \frac{1}{e^{\left(\frac{h c}{\lambda k T}\right)}-1} \\
\lambda_{\max }=\frac{2.898 * 10^{-3}}{T}
\end{gathered}
$$

Where:

$h$ equals $6.626^{*} 10^{-34} \mathrm{~J} . \mathrm{s}$ is the Planck's constant;

$c$ equals $2.999 * 10^{8} \mathrm{~m} / \mathrm{s}$ is the speed of light in vacuum;

$k$ equals $1.38 * 10^{-23} \mathrm{~J} / \mathrm{K}$ is the Boltzmann constant. 
The graphics of absolute irradiance attained in the measurements are a function of the light wavelength. To determine the irradiance of the sky searchlights at a given distance, Equation (5.7) has been applied to each measured point. Since the light obeys the inverse-square law, which states that the power of radiant energy is inversely proportional to the square of the distance of its source. Therefore, Equation (5.8) has been used to determine the irradiance of the sky searchlights. As the xenon lamp is located at $100 \mathrm{~mm}$ from the window, the distance used in this equation has been of $600 \mathrm{~mm}$.

$$
\begin{gathered}
I_{d}(r, \lambda)=\pi \int_{\lambda_{1}}^{\lambda_{2}} \int_{r_{1}}^{r_{2}} \dot{q}^{\prime \prime}(r, \lambda) r d r d \lambda \\
I=\frac{I_{d}(r, \lambda)}{d^{2}}
\end{gathered}
$$

When Equation (5.9) is applied to each point, it is possible to determine the uniformity of collimation of the sky searchlight's beams, by using Equation (5.10). The closest to the unity, the most uniform are the beams, this means, more collimated among them.

$$
\begin{gathered}
I(\lambda)=\pi \int_{\lambda_{1}}^{\lambda_{2}} \dot{q} "(\lambda) d \lambda \\
U=1-\frac{I_{\max }-I_{\text {min }}}{I_{\max }+I_{\min }}
\end{gathered}
$$

\subsection{Reflectivity of Materials}

The determination of reflectivity of materials is made using the spectrometer, the bifurcated fiber, and the HL-3P-CAL lamp. The spectrometer has been calibrated by connecting the single end of the cord to the module, one of the bifurcated terminations to the calibration light and the other has been fixed on the probe holder. The end which must be plugged to the light or the prober is indicated in the fiber. The probe holder has two holes: one positioned at $90^{\circ}$ with the horizontal plane and another at $45^{\circ}$. To make specular reflectivity measurements, the $90^{\circ}$ hole must be used. The probe holder then is placed over the specular standard of high reflectivity, to which reflectivity of $100 \%$ is set by the software.

After the calibration has been made, the probe holder has been positioned over three materials: a surface coated with aluminum powder, a highly reflective aluminum sheet, and mirror glass tape. It is fundamental that the probe does not move in relation to the probe holder to keep the results reliable. 


\subsection{Determination of the Concentrated Heat Flux}

The collimated beams reach the parabolic reflectors and are concentrated at the focal plane and studying the distribution of this concentrated flux is fundamental when designing a reactor cavity. The layout of Figure 5.15 has been implemented with this purpose. On it, the water circuit is indicated, as well as the near-Lambertian plate mounted on the coordinated table.

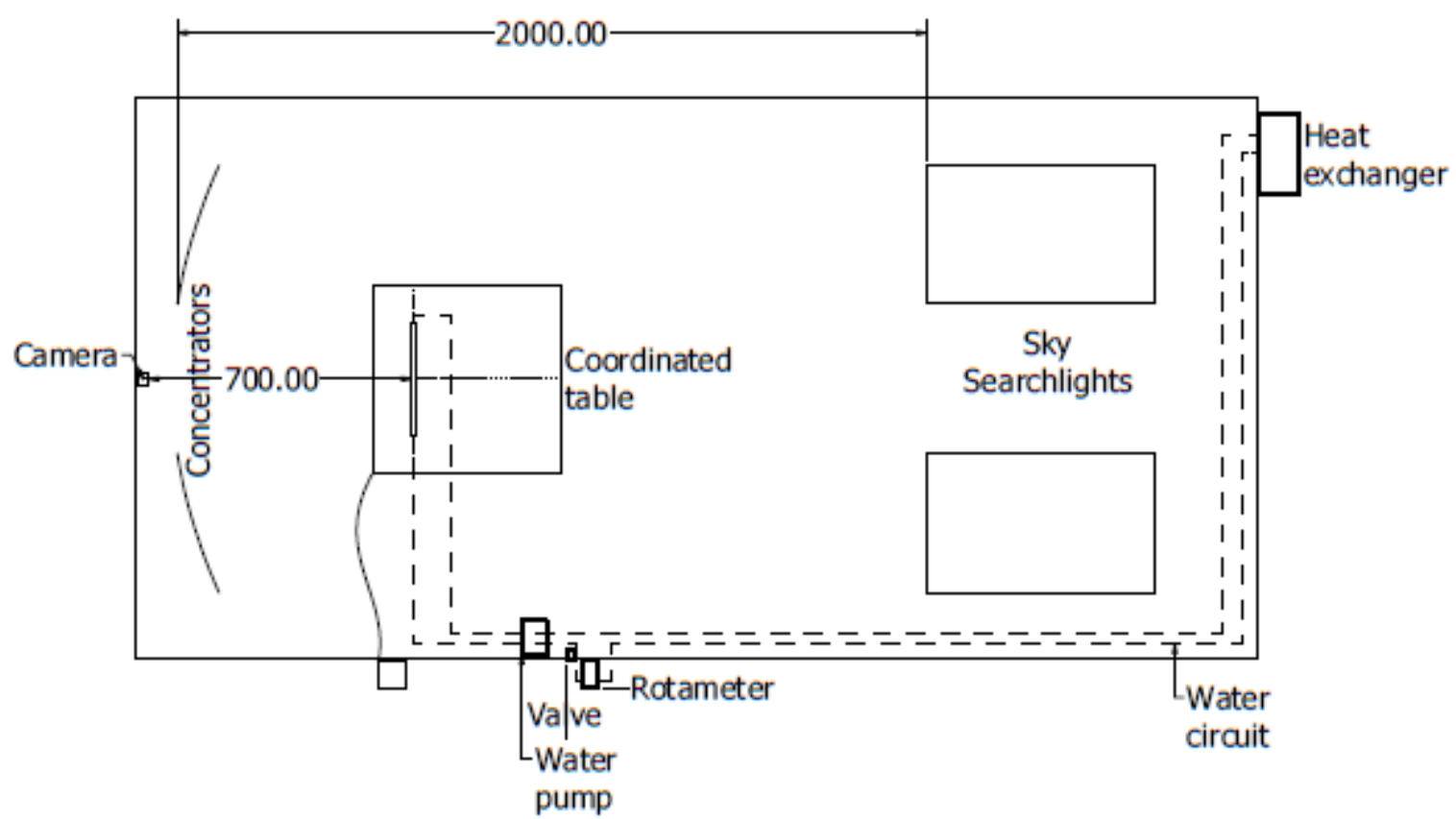

Figure 5.15. Test layout to determine the concentrated heat flux of the HFSS.

First, the radiometer has been installed to the table, and the point of maximum heat flux found, and the horizontal and vertical portions of the focal plane have been swept with the radiometer. Water flows through the near-Lambertian plate and the radiometer. Figure 5.16 represents this step of the test when the radiometer had been plugged to the near-Lambertian plate. A warm-up time of 15 minutes has been set before measurements had started. 


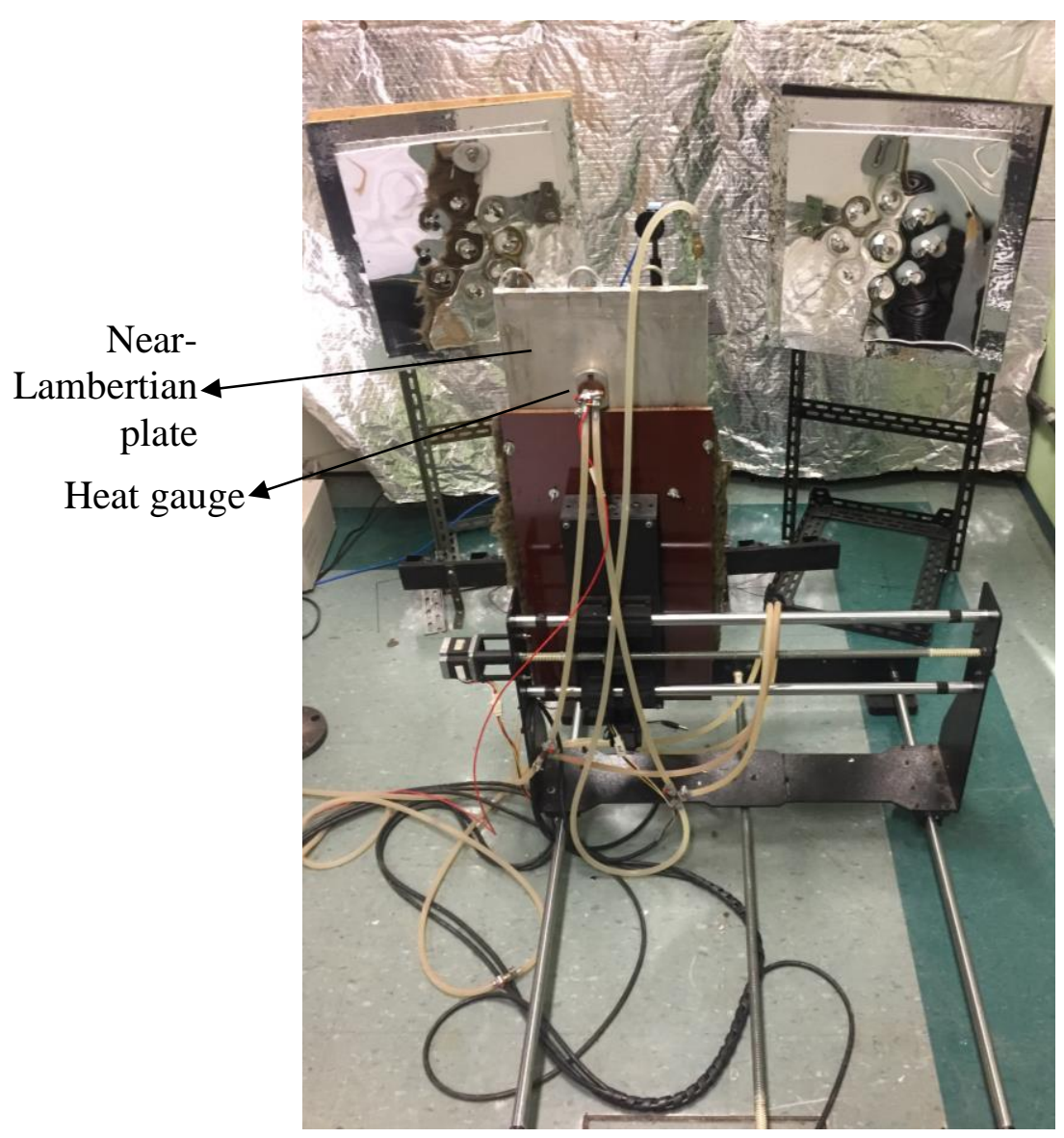

Figure 5.16. Test for determination of concentrated heat flux, with the radiometer, plugged to the nearLambertian plate, which is mounted on the coordinated table. The black and white camera is placed $700 \mathrm{~mm}$ away from the plate.

Then, the radiometer has been dismounted from the plate and the insert positioned. The black and white camera has been placed $700 \mathrm{~mm}$ away from the plate, its lens adjusted to this length, and parallel to the plate. An exposure time of $1 / 480 \mathrm{~s}$ has been set using the software, and a picture was taken.

Since this picture ranges from 0 to 255 , numbers that correspond to a gray scale, it is possible to calibrate the grayscale of the camera to the measurements surveyed with the radiometer. The picture has been resized with the aid of a component of known dimensions in another photo taken precisely at the same point as the real one.

After the relation between the grayscale and the heat flux had been determined, the black and white picture has been changed to an RGB scale, to better visualization of the heat flux distribution. This way, it is possible to analyze the concentrated heat distribution in a given area by applying Equation (5.11), on which the heat is a function of the grayscale value and $d x$ and $d y$ are the distance of the pixels. 


$$
\dot{q}^{\prime \prime}=\iint \dot{q}\left(G S_{\text {value }}\right) d x d y
$$

By integrating the whole area of the picture, the thermal efficiency of the concentrators has been determined using Equation (5.12).

$$
\eta_{\text {Thermal }}=\frac{I_{\text {concentrated }}}{2 I_{S S L}}
$$

\subsection{Calorimeter Cavity Test}

The goal of the calorimeter cavity test is to determine how much thermal energy had reached the inside of the cavity when the secondary concentrators had been used. Also, to verify if the cavity's behavior follows the mathematical approach developed.

After the heat flux distribution had been determined, the center of the cavity window has been placed at the peak flux measured with the radiometer, which means the exit of the secondary concentrator has been positioned there. Water has been pumped through the cavity, with volume flow of 70 liters of water per hour. One thermocouple type $\mathrm{J}$ has been placed at the center of the cavity, another at the water inlet and a thermocouple type $\mathrm{K}$ at the water outlet, as represented in Figure 5.17 and 5.18.

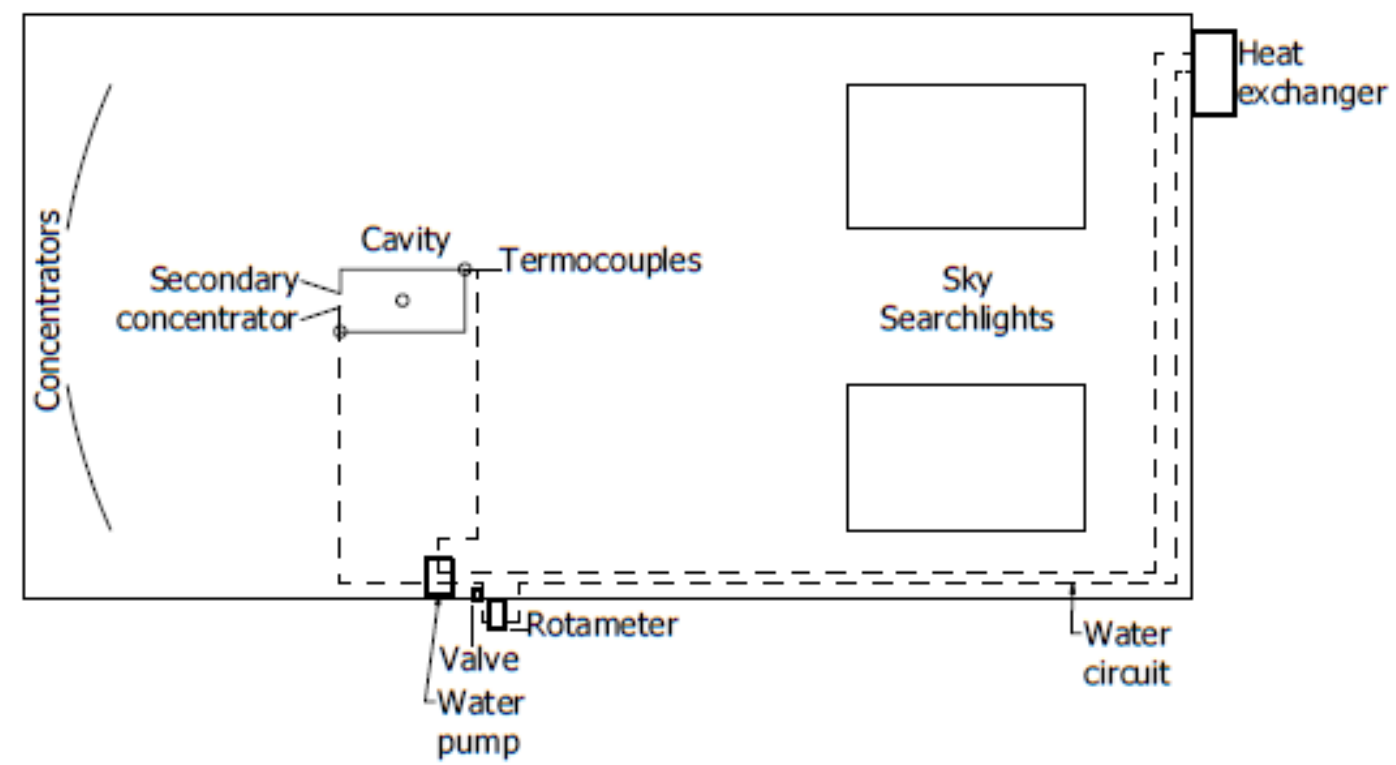

Figure 5.17. Test layout of the calorimeter cavity. 


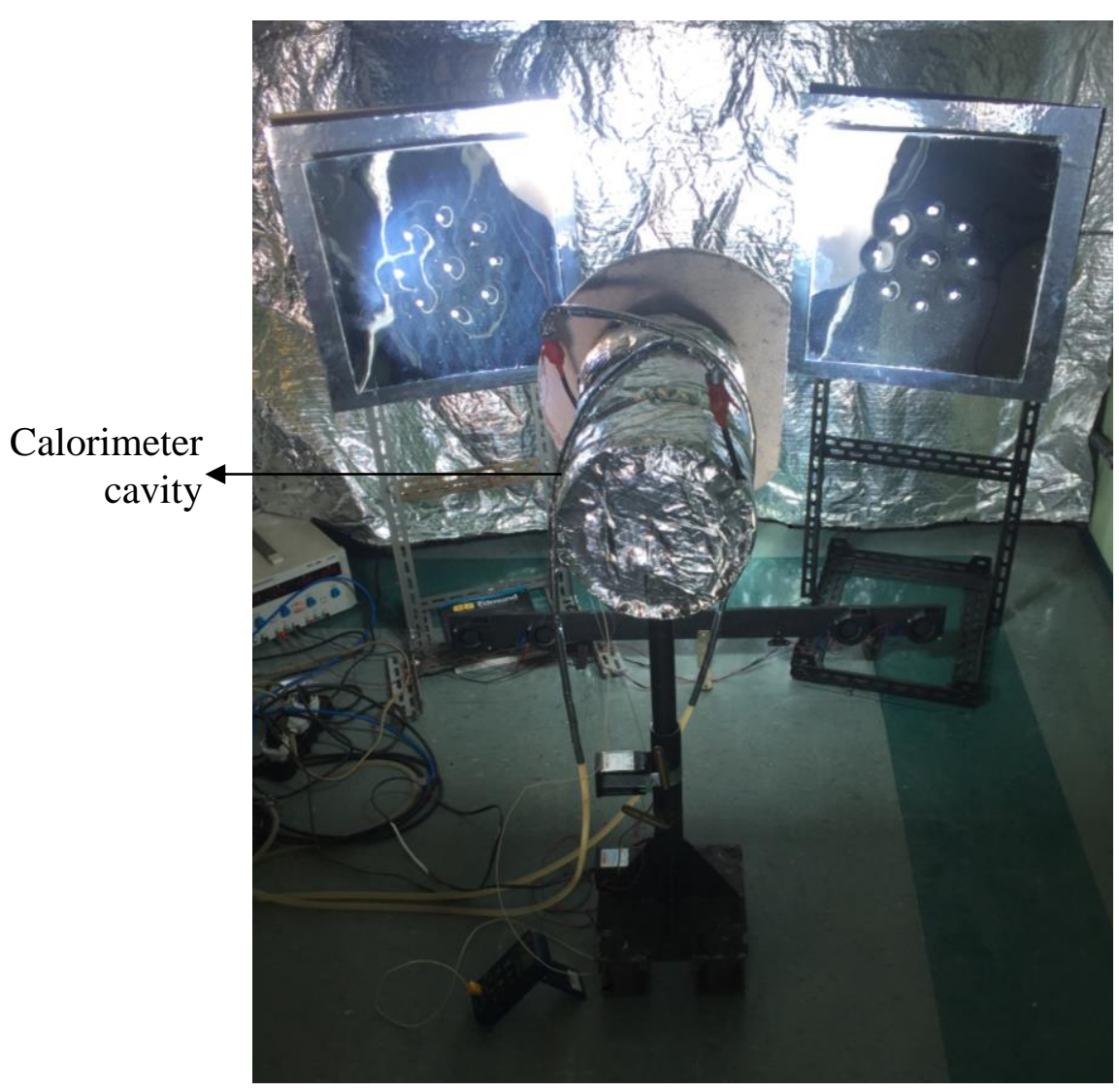

Figure 5.18. Test with the calorimeter cavity in progress.

The high flux solar simulator has been turned on and a warm-up time of 15 minutes has been set. The temperatures have been monitored for 100 minutes afterward when the cavity reached the steady-state. Since the cavity has been well thermally insulated and the tests carried out in a closed space, where the wind can be considered steady, the losses by conduction and convection have been neglected.

Applying the first law of thermodynamics for the cavity equilibrium, Equation (5.13) can be deduced; which can be expanded and re-written as Equation (5.14).

$$
\begin{gathered}
I_{\text {in }} A_{w}=\dot{q}_{\text {Abs }}^{\prime \prime} A_{c}+\dot{q}_{\text {Reir }}^{\prime \prime} A_{w}+\dot{q}_{\text {Ref }}^{\prime \prime} A_{w} \\
I_{\text {in }}=\frac{\dot{m} c_{p} A_{\text {Lat }}\left(T_{\text {out }}-T_{\text {in }}\right)+\alpha_{\text {eff }} \sigma A_{w}\left(T_{c}{ }^{4}-T_{\infty}{ }^{4}\right)}{\tau_{\text {quart }}^{2} A_{w}}
\end{gathered}
$$

Thus, the thermal efficiency of the secondary concentrator can be defined with Equation (5.15). The heat flux ratio of the CPC is calculated based on the average heat flux in the cavity's window, as shown in Equation (5.16). 


$$
\begin{gathered}
\eta_{\text {OptimizedCone }}=\frac{I_{\text {in }}}{I_{\text {Concentrated }}} \\
F R=\frac{I_{\text {in }}}{I_{\text {MeanConcentrated }}}
\end{gathered}
$$




\section{RESULTS AND ANALYSES}

In this chapter it is presented the experimental results following the procedure of Section 5.

\subsection{Thermal Characterization of the Sky Searchlights}

Analyses of relative irradiance of the sky searchlights have been carried out with the aid of the spectrometer, described in Section 5.2.3. The spectral distribution of both light sources is very close, presenting some energy peaks in the NIR (near-infrared range), contrary to the Sun's spectrum, in which the most significant amount of energy is preponderantly in the visible range, as shown in Figure 6.1. On the other hand, disregarding the near-infrared peaks, the xenon lamps have matched the black body radiation distribution proposed by the Planck's law, Equation (5.5), as can be also seen in Figure 6.1. For a color temperature of 6,200 K, the radiance peak is expected to be located at $483.9 \mathrm{~nm}$, according to the Wien's displacement law, presented in Equation (5.6), which happens for both lamps if the NIR range is not considered, as shown in Figure 6.1 as well.

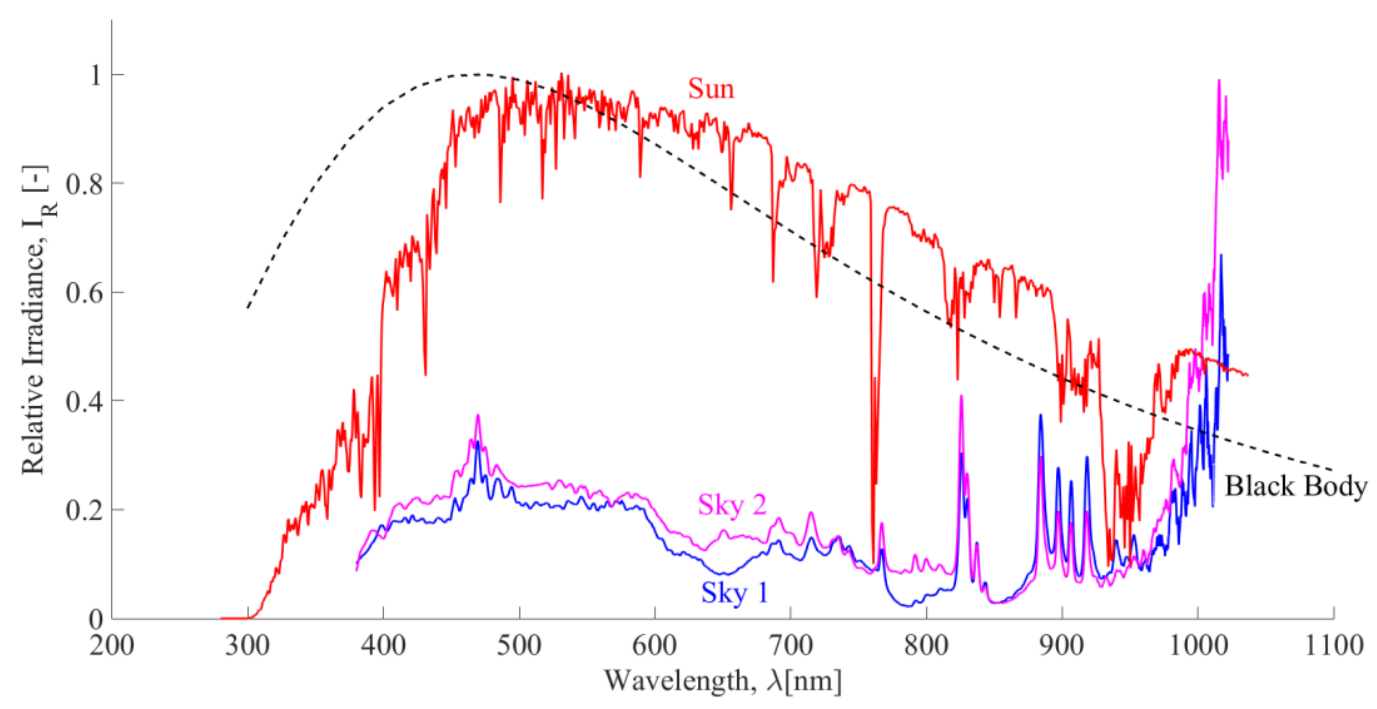

Figure 6.1. Relative irradiance of the sky searchlights, determined by experimental procedure and of the Sun, inside Earth's atmosphere via ASTM G173-03. The blue and purple lower lines correspond to the sky searchlights and the red higher to the Sun. The dotted line is the Planck's law radiation for a black body of color temperature $6200 \mathrm{~K}$.

Once the primary goal of the HFSS proposed is to be used as a "Sun' simulator apparatus in investigations related to the production of Solar Fuels, the comprehension of the thermal 
radiant energy magnitude provided by the light sources matters more than a pure resemblance with the Sun's spectrum. On the other hand, given the similarity of the spectral distribution of the sky searchlights of the same technical characteristics, it is possible to carry on the absolute irradiance measurements to one of them and extend the results to both lamps.

The absolute irradiance distribution per unit of area at wavelengths from $350 \mathrm{~nm}$ until 995 $\mathrm{nm}$, at different positions along the central horizontal line of the window, is represented in Figure 6.2. The dotted lines of the graphic represent the points on the left side of the center, and the dashed lines represent the points on the right side of the center. Other locations not represented in the figure have also been evaluated. To undertake these measurements, the fiber has been placed $500 \mathrm{~mm}$ away from window, from which the lamp is $200 \mathrm{~mm}$ apart, in such a way that the fiber has been positioned $700 \mathrm{~mm}$ away from the lamp.

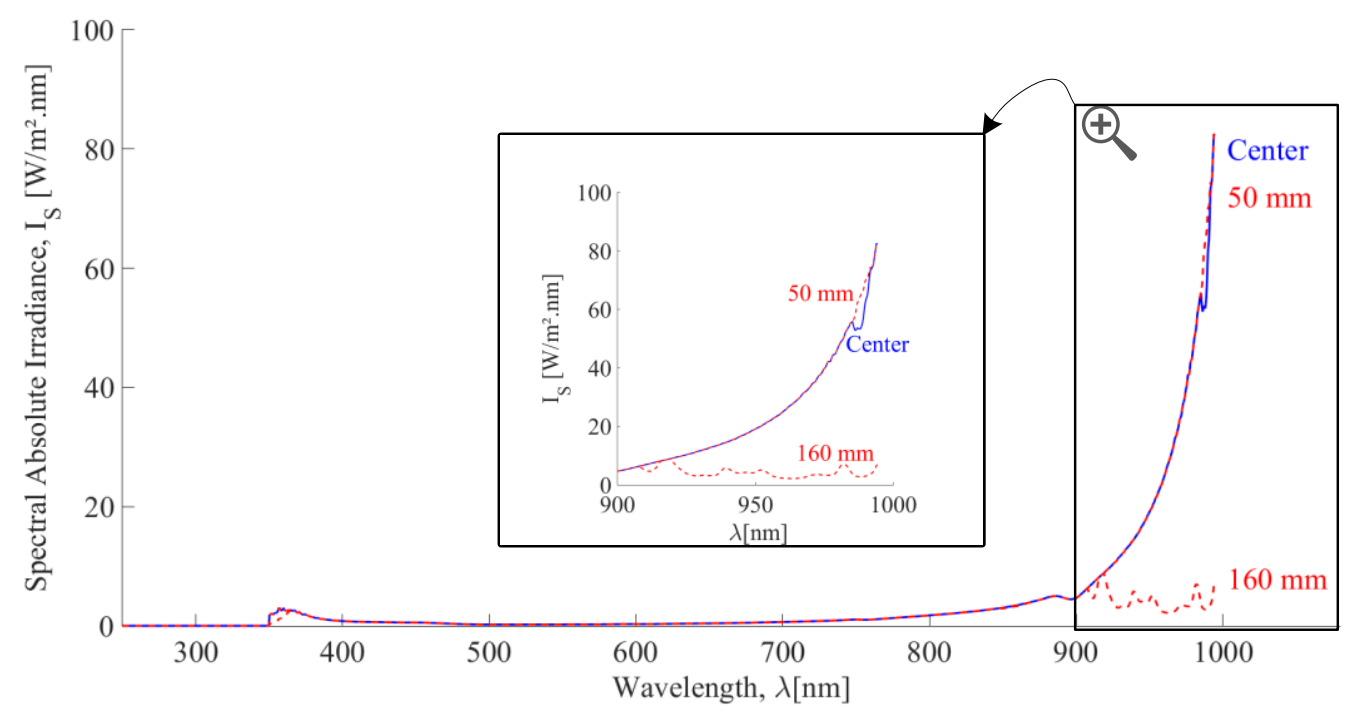

Figure 6.2. Absolute spectral irradiance at the center, $50 \mathrm{~mm}$ and $160 \mathrm{~mm}$ away from the center of the sky searchlight for a fiber located $700 \mathrm{~mm}$ away from the lamp. IR peaks in detail.

From Figure 6.2, it is noticeable that the points that are closer to the center of the light present a high peak at the near-infrared portion, while the points farther from that do not. It happens because the energy closer to the borders of the sky searchlight does not correspond to the rays specularly reflected by the paraboloid reflector, even if it still corresponds to radiant energy from the lamp. Applying Equations (5.7) and (5.8), to the curves above, a radiant thermal power of $753.9 \mathrm{~W}$ has been found, from which half $(50.1 \%)$ is provided by the visible range and another half $(49.9 \%)$ by the near-infrared.

By applying Equation (5.9), the graphic of Figure 6.3 is drawn. It represents the absolute irradiance distribution along the radius of the sky searchlight window, and therefore the 
collimation of the beams. It can be observed that the rays have not been entirely parallel, being more concentrated at the right portion of the window. It can be attributed to a slight misplacement of the reflector inside the apparatus, responsible for the collimation of the beams, and can lead to a less efficient HFSS than antecipated. The central point of the graphic carries lower energy than the ones beside it due to the paraboloid reflector's hole and mounting apparatus for the lamp present in this area.

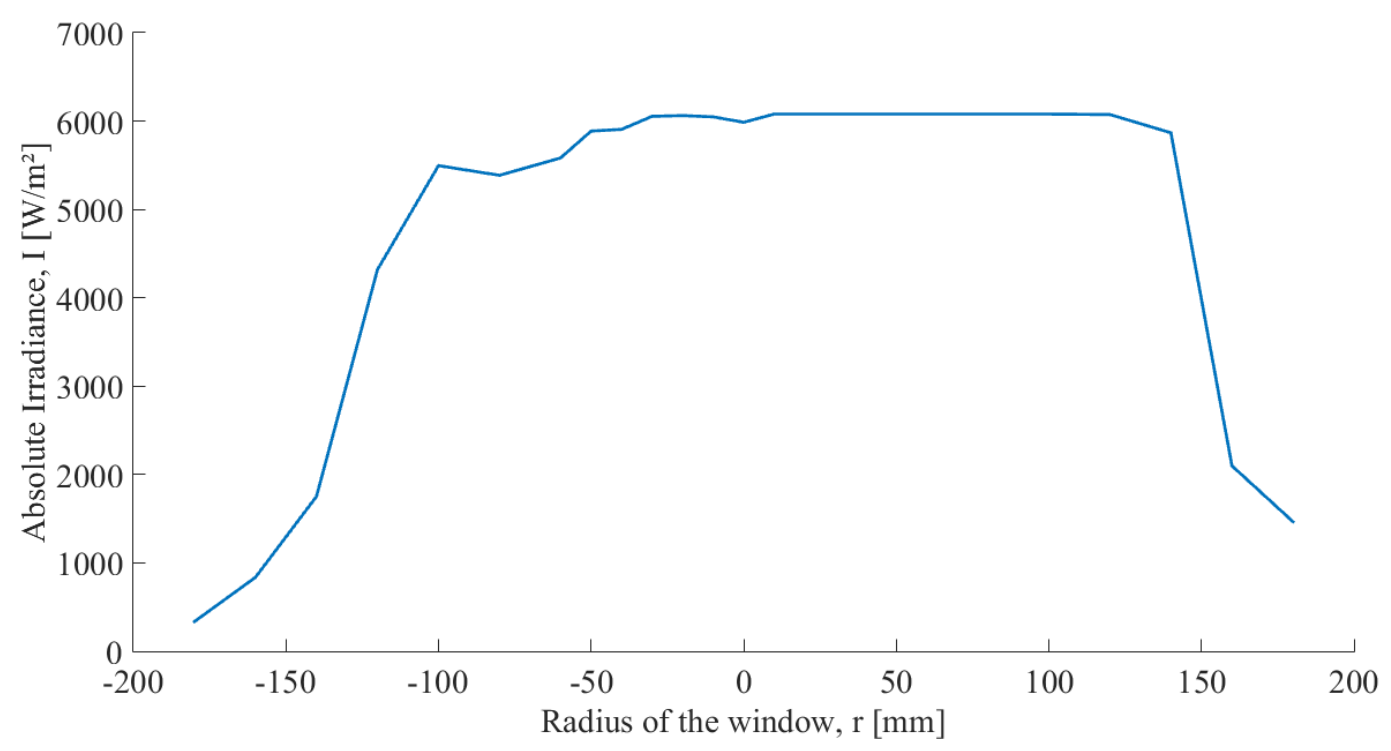

Figure 6.3. Absolute Irradiance distribution along the sky searchlight window radius.

To determine the uniformity of the beams, only the curves presenting a peak of energy in the near-infrared range have been considered. Hence, the minimum irradiance has been located at $120 \mathrm{~mm}$ to the left from the center and the maximum at $10 \mathrm{~mm}$ to the right, leading to $75.1 \%$ uniformity when using Equation (5.10). Since there is no standard regarding simulators used for CSP applications, the ASTM E927 for solar simulation for terrestrial photovoltaics test (Meng et al., 2011), has been consulted to evaluate the uniformity of the sky searchlight beams. The result attained is not good according when comparing to the maximum nominative non-uniformity of $10 \%$. It can lead to less concentrated energy, as many rays are not reaching the concentrators collimated.

The second method to assess the sky searchlights radiant thermal power has been conducted with the Gardon gauge (Section 5.2.1). Given the minimum range of $500 \mathrm{~W} / \mathrm{m}^{2}$ of the heat gauge used, it has been necessary to adjust the lamp in relation to the paraboloid reflector to concentrate the light beams in a manner that it has been possible to take a considerable 
number of measurements, as shown by the solid line of Figure 6.4. The dotted lines have been drawn by calculating the tendency line associated with the lower portion of the graphic. Equation (5.1) has been applied to the whole graphic, and the power of $726.1 \mathrm{~W}$ has been established.

This evaluation may be not very accurate since only a small portion of the sky searchlight area has been experimentally evaluated. Then, the remaining of the results have been estimated, based on the experimental results, reaching even so only $17 \%$ of the total window area, a small number even for the slightly concentrated beams formed by the placement between lamp and reflector.

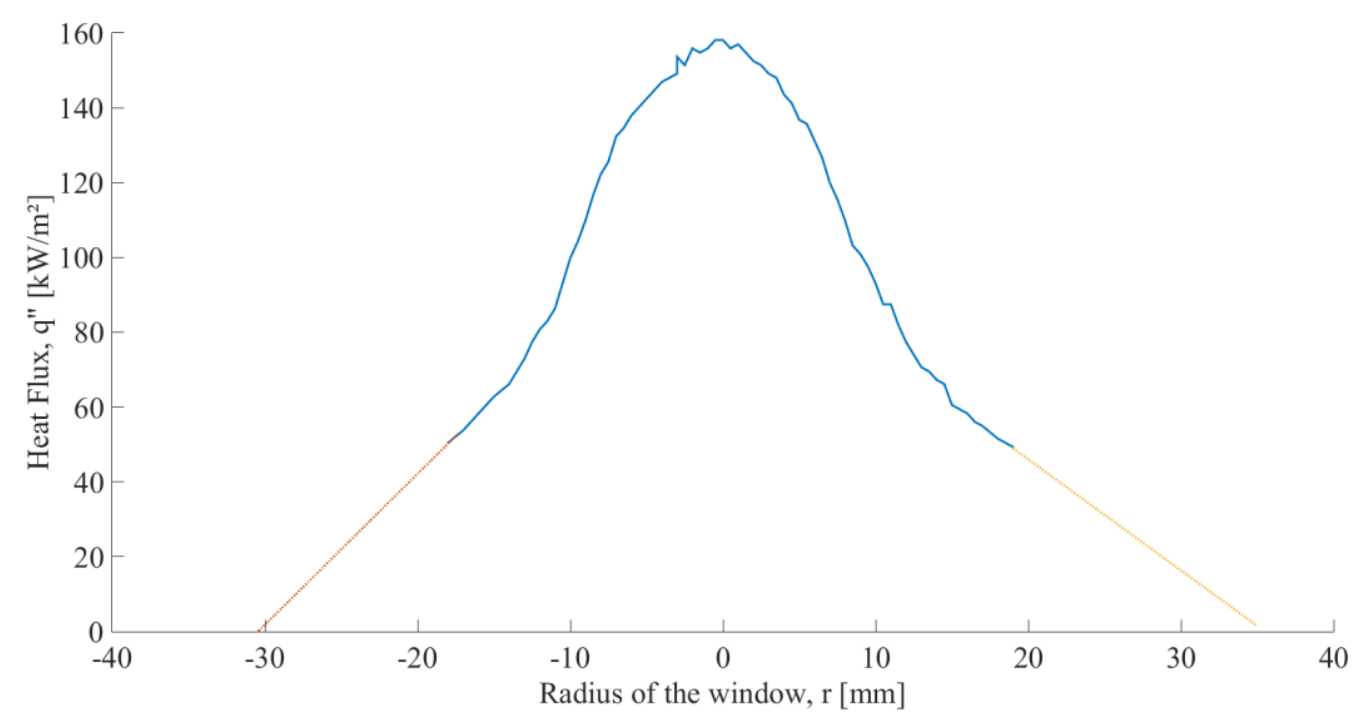

Figure 6.4. Heat flux along the horizontal radius of sky search light central line of the sky searchlight window, with lamp adjusted to the reflector to concentrate the beams. The solid line corresponds to the measurements and the dotted line to a tendency line derivated from the survey starting at $-15 \mathrm{~mm}$ to the left and $15 \mathrm{~mm}$ to the right.

Lastly, when working with the calorimeter (Section 5.2.2), after 15 minutes of warm-up, the water temperature in the outlet has remained constant in $34^{\circ} \mathrm{C}$ and the inlet in $28^{\circ} \mathrm{C}$. The surrounding temperature has been considered as $28^{\circ} \mathrm{C}$ and the spiral temperature equal to the outlet, $34^{\circ} \mathrm{C}$. So, applying Equation (5.4), the total irradiance of each sky searchlight has been estimated to be $794.1 \mathrm{~W}$.

Table 6.1 summarizes the results of thermal power radiation attained when applying each one of these methods, the error limits related to the instrumentation used and the electric-toradiant efficiency, determined by applying Equation (5.2). An average power of $758 \mathrm{~W}$ has been found, leading to an electric-to-radiant ratio of $19 \%$. 
Table 6.1. Radiation thermal power measured by three different methods, equipment error limits and electric-to-radiant efficiency.

\begin{tabular}{l|c|c|c}
\hline Method & Power [W] & $\begin{array}{c}\text { Equipment's' error } \\
\text { limit }\end{array}$ & \begin{tabular}{c} 
Eelec-to-rad [\%] \\
\hline Spectrometer
\end{tabular} \\
Gardon Gauge & 753.9 & $3 \%$ & 18.9 \\
Calorimeter & 796.1 & $0.015 \%+0.35$ & 18.2 \\
Avarage & 758.0 & $0.75 \%$ & 19.9 \\
\hline
\end{tabular}

The three methods have led to close thermal radiant power for the sky search light analyzed, with a maximum non-uniformity (calculated applying Equation (5.10)) of 2\% between them. The result attained with the calorimeter may be overestimated due to the consideration of no losses by conduction or convection, but is a great method to be applied when more sophisticated instrumentation are not available. Even if the error related to the radiometer layout is the smallest, the result achieved may be less significant than the real one due to the small area analyzed. This way, the spectrometer has been seen as the most accurate method, since the whole area of the sky searchlight has been swept in small steps and the least amount of considerations made.

The average thermal flux on the area of $370 \mathrm{~mm}$ diameter of the sky searchlight window, given the thermal power estimated by the spectrophotometer has been $7 \mathrm{~kW} / \mathrm{m}^{2}$.

\subsection{Concentrators Material}

The relationships between optical properties of a material leads to Equation (6.1), which relates absorptivity, reflectivity and transmissivity of a given material and demonstrates that the smaller the reflectivity, the more significant is the transmissivity or absorptivity of this matter.

$$
\tau+\alpha+\rho=1
$$

Thus, the concentrator's material must present high reflectivity not only because of the concentration of the beams but also due to the polycarbonate's heat distortion temperature, which is between $130^{\circ} \mathrm{C}$ and $160^{\circ} \mathrm{C}$, according to the ASTM D 648 (INCOMPLAST, n.d.) 
Three materials have been analyzed as explained in Section 5.3, in terms of reflectivity, as shown in Figure 6.5, in a range from 412 to $995 \mathrm{~nm}$. They have been: a commercial highly reflective aluminum foil, and a mirrors tape (usual in party globes) both glued to the base with resin; and aluminum powder coat, stuck to the polycarbonate by vacuum at high temperature. The aluminum powder coat has appeared to be the most suitable option for its reflectivity of about $95 \%$ at all wavelengths analyzed.

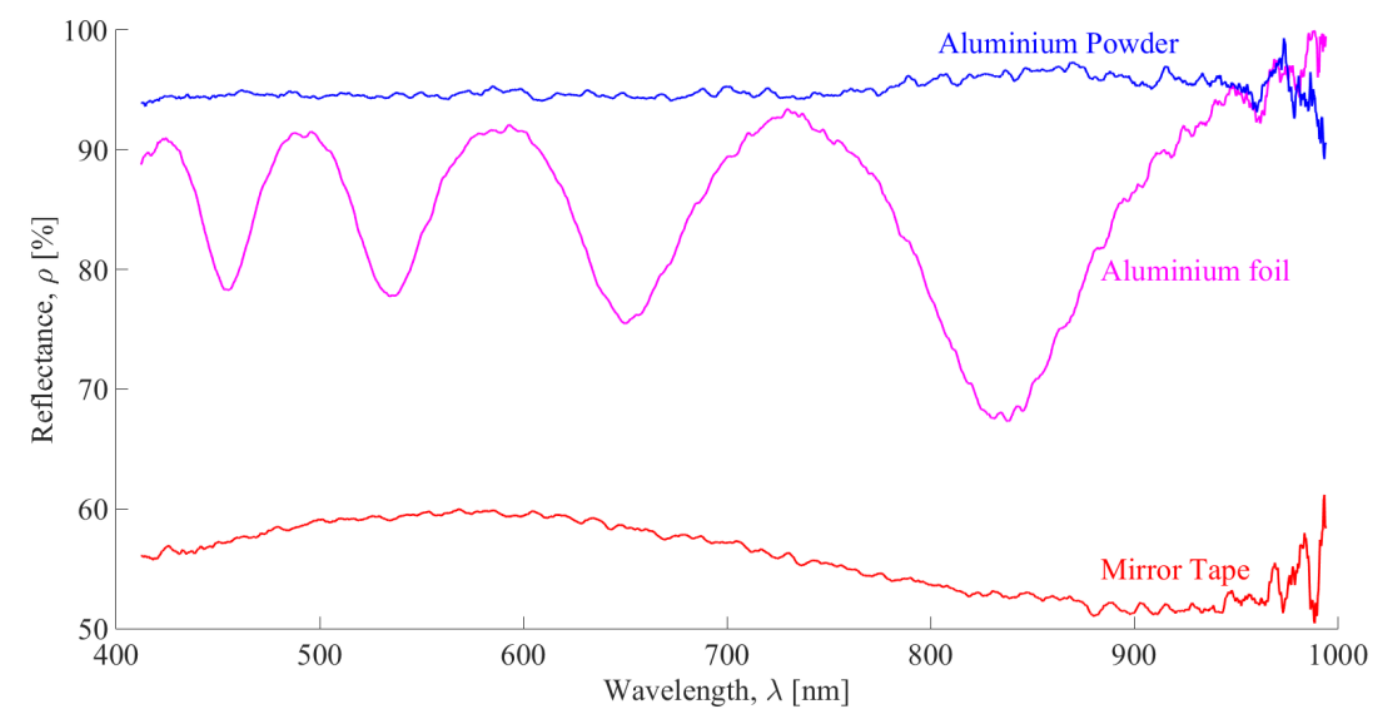

Figure 6.5. The reflectivity of different materials. Purple line in the middle corresponds to the aluminum highly reflective foil, the red lower line to the mirror tape and the blue higher line to the aluminum powder coat.

The less destructive method of manufacturing the concentrator proved to be the cold modeling of the polycarbonate to the fiberglass base, using countersunk screws, especially at the central area, ensuring the off-set geometry. Tests of heating the polycarbonate till its softening temperature has led to contaminations between the polycarbonate and the base, accountable for damaging the aluminum coat; in addition the product has not corresponded to the desired geometry.

On the other hand, the screws generate deformation on the geometry, as shown in Figure 6.6, which prejudice the concentration of the beams that are not necessarily reflected by those areas anywhere close to the focal point. Each of those nine circles corresponds to a dimeter of about $60 \mathrm{~mm}$. 


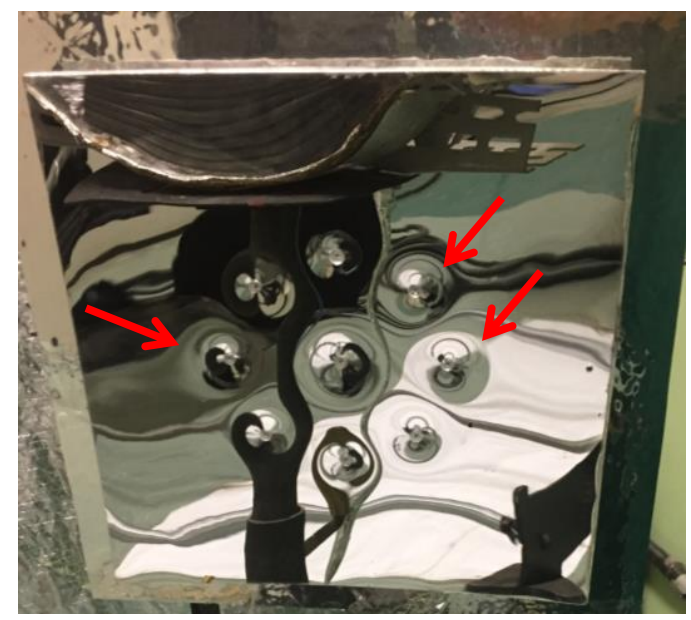

Figure 6.6. Detail for the deformations caused by the screws on the paraboloid's surface.

Thereby, given the reflectivity of $95 \%$ and subtracting the deformed area, the maximum theoretically concentrated power by the two paraboloid concentrator has been estimated applying Equation (6.2), totalizing $1.09 \mathrm{~kW}$. The input radiative thermal power has been considered equally distributed along the sky searchlight window, this implies the beams have been considered completely collimated.

$$
Q_{\max }=2 \rho \frac{I_{\text {Total }}}{A_{S S L w}}\left(A_{S S L w}-A_{\text {deformed }}\right)
$$

\subsection{High Flux Solar Simulator thermal power}

The off-set paraboloid concentrators have been positioned $400 \mathrm{~mm}$ away from each other, and the lamps in front of those two meters away. The inclination of $81.5^{\circ}$ around the vertical axis has been secured. A warm-up time of 15 minutes has been guaranteed before every test.

The thermal power of the HFSS has been determined using the radiometer the nearLambertian plate and the black and white camera. A picture of the concentrated power over the near-Lambertian plate has been taken and the grayscale of the camera has been calibrated according to the values acquired in this same area by the radiometer. Afterward, analyzes regarding the size of the focal target shaped by the concentrated power have been carried. This procedure has been proposed in Section 5.4. 


\subsubsection{Calibration of the grayscale and radiometer}

The Vatell heat gauge measures the thermal radiation flux by evaluating the difference in temperature of the water that flows within. As it has been fastened to the near-Lambertian plate, the thermal losses by conduction and convection have been estimated by keeping the radiometer still at a given point and listing the drop of heat flux measured by it in a timedependency, as show Figure 6.7. A heat loss of $1.1 \mathrm{~kW} / \mathrm{m}^{2}$.min has been quantified by drawing a tendency line of 0.81 coefficient of determination.

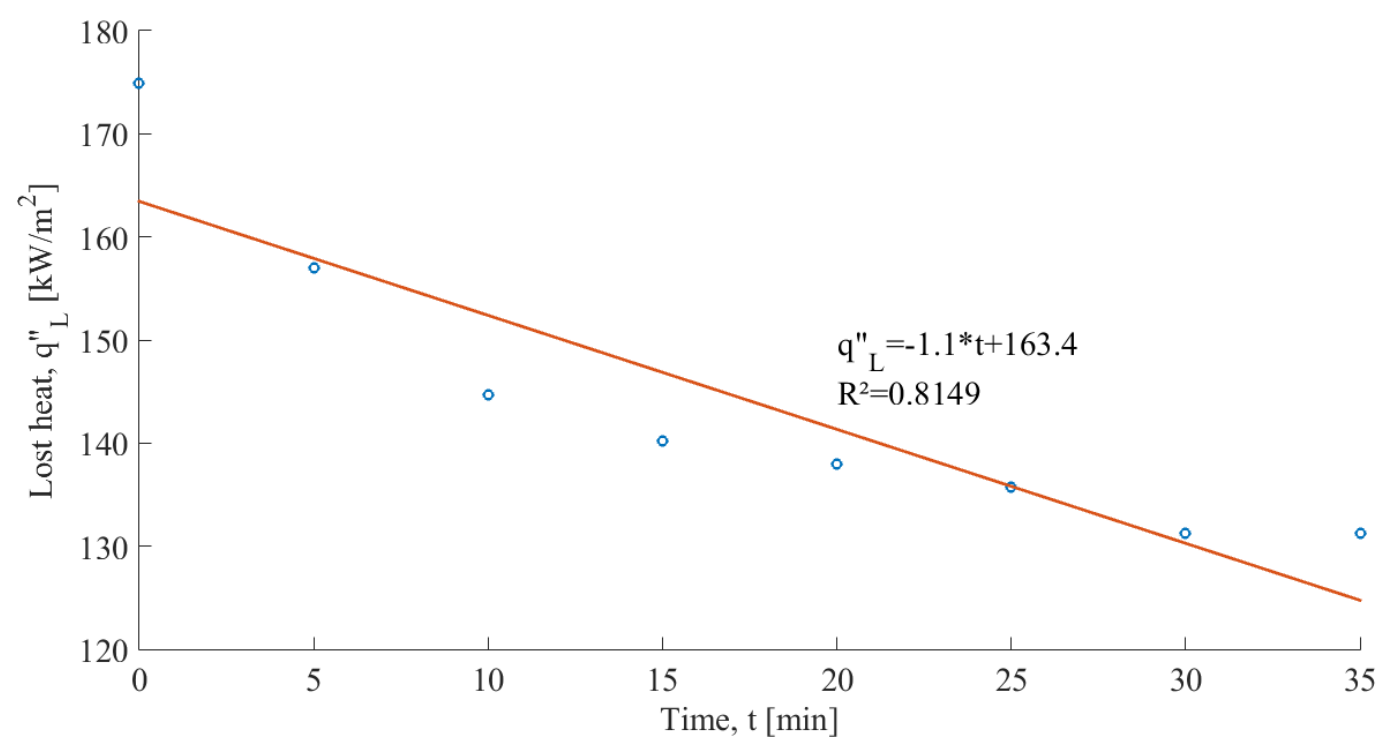

Figure 6.7. Data on the drop on the heat flux measured by the Gardon gauge with the time and tendency line, with its respective equation and $R^{2}$.

Next, the radiometer has been positioned at the theoretical point of maximum heat flux, estimated on account of the paraboloids geometry and Tonatiuh $\odot$ simulations. The actual maximum point has been located by moving the heat gauge with the aid of the coordinated table, at $870 \mathrm{~mm}$ from the floor and $66 \mathrm{~mm}$ away from the inner edge of one paraboloid and $68 \mathrm{~mm}$ from the inner corner of the other.

To capture the image of the plane of maximum heat flux, with a scale of know size, the camera has been positioned in the center of the near-Lambertian plate, $700 \mathrm{~mm}$ away and the picture of Figure 6.8 has been taken. The black circle in the center is the heat gauge of know diameter $(24.5 \mathrm{~mm})$. Then the heat gauge has been carried out and replaced by the insert, and the photograph of Figure 6.9 has been taken. It has been resized in Matlab, applying the ratio of $0.13138 \mathrm{~mm} / \mathrm{pixel}$ and the Lanczos method, which interpolate digital signals. This way, each pixel of the picture has assumed the characteristics of a step of $1 \mathrm{~mm}$. 


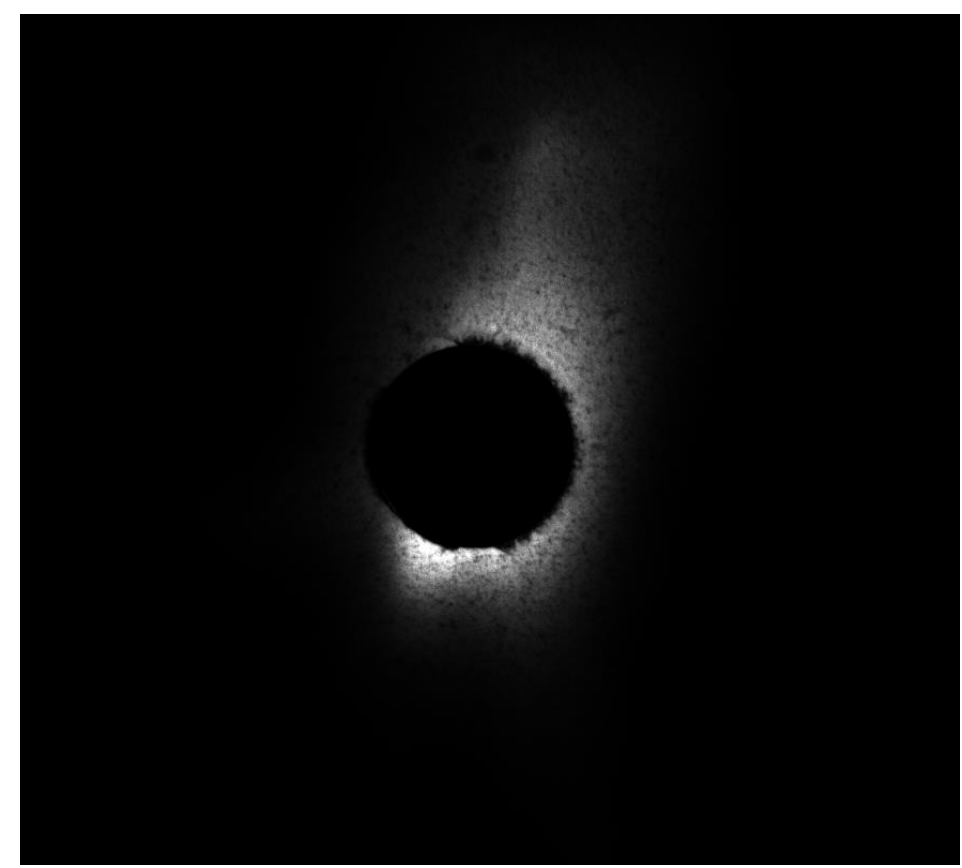

Figure 6.8. Photograph of the near-Lambertian plate containing the Gardon gauge located at the point of maximum heat flux.

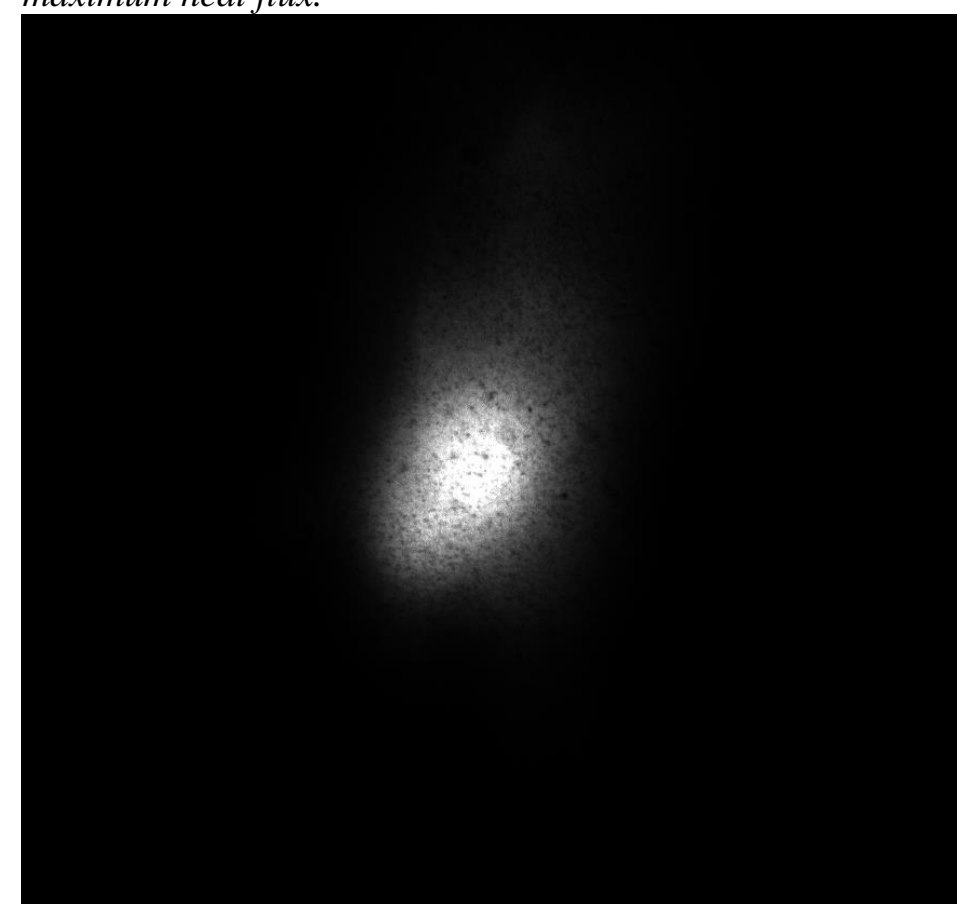

Figure 6.9. Photograph of the near-Lambertian plate without the Gardon gauge, located at the focal plane of the paraboloid concentrator, with exposure time of 1/480 s.

To calibrate the grayscale of Figure 6.9, starting at the peak flux point, the horizontal left central line, and up and down vertical central lines have been swept with the heat gauge. The time taken to each measurement has been clocked as a way of taking into account the heat 
loss in this period. Then, the grayscale of the picture has been related to the values quantified, as shown in Figure 6.10. This figure also shows the tendency lines of each set of data and the coefficient of determination. Only gray values more significant than about 25 have been considered since the resolution of the camera on darker areas may not be so precise. The maximum heat flux attained has been of $201.8 \mathrm{~kW} / \mathrm{m}^{2}$.

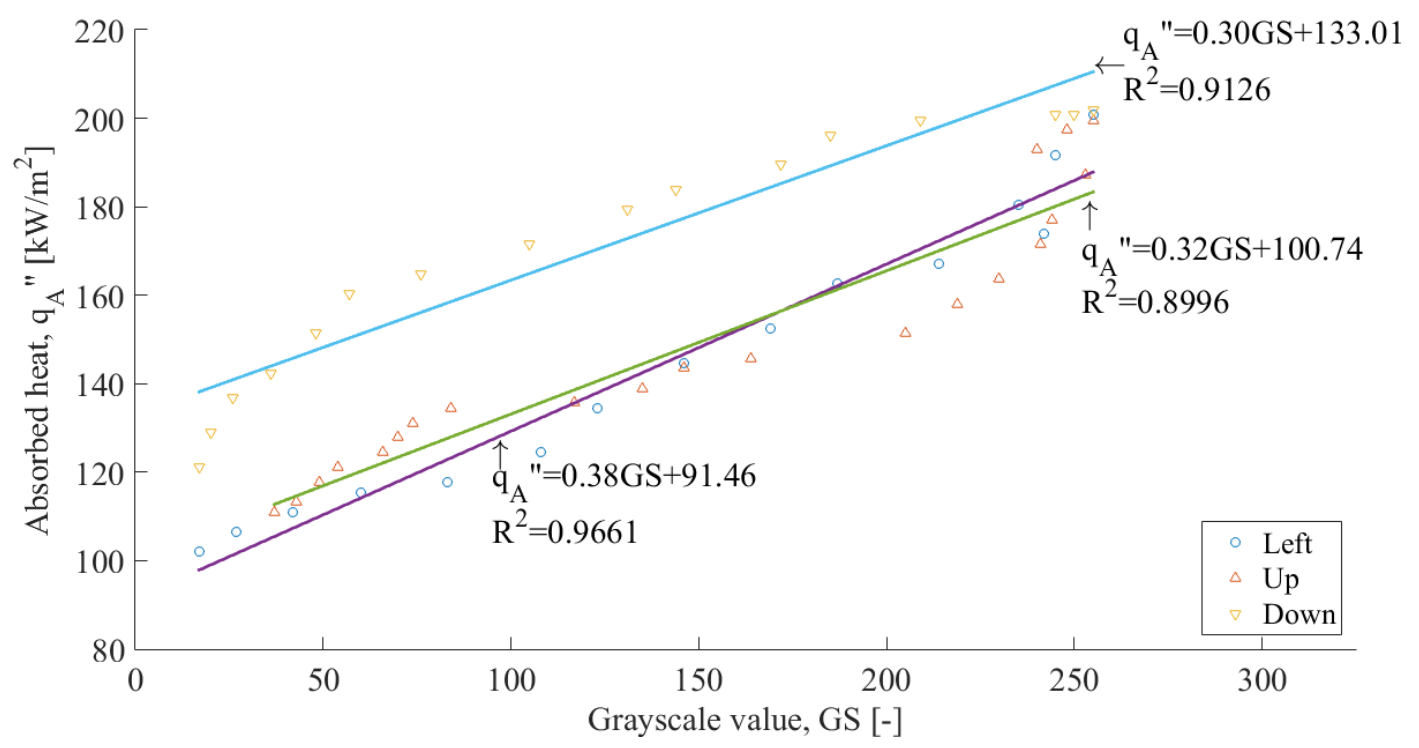

Figure 6.10. Data for calibration of the grayscale of the black and white camera and the heat gauge measurements, including tendency lines, their equations and $R^{2}$.

The calibration curve of the grayscale has been set by considering the highest $\mathrm{R}^{2}$ parameter. This way, the calibration equation may be represented by Equation (6.3).

$$
\dot{q}=0.3779 G S+91.4690
$$

\subsubsection{Near-Lambertian plate analyzes}

The calibration of the camera's grayscale has enabled to convert Figure 6.9 into the RGB picture of Figure 6.11; in which it can be seen the most concentrated area of about $5 \mathrm{~mm}$ radius in crimson, in the center, representing a concentrated heat flux of about $200 \mathrm{~kW} / \mathrm{m}^{2}$ (200 "Suns"). The decrease in the heat flux with the increase of the radius also can be seen more clearly in the colored image. In the crimson area, an almost circular shape can be noted. 


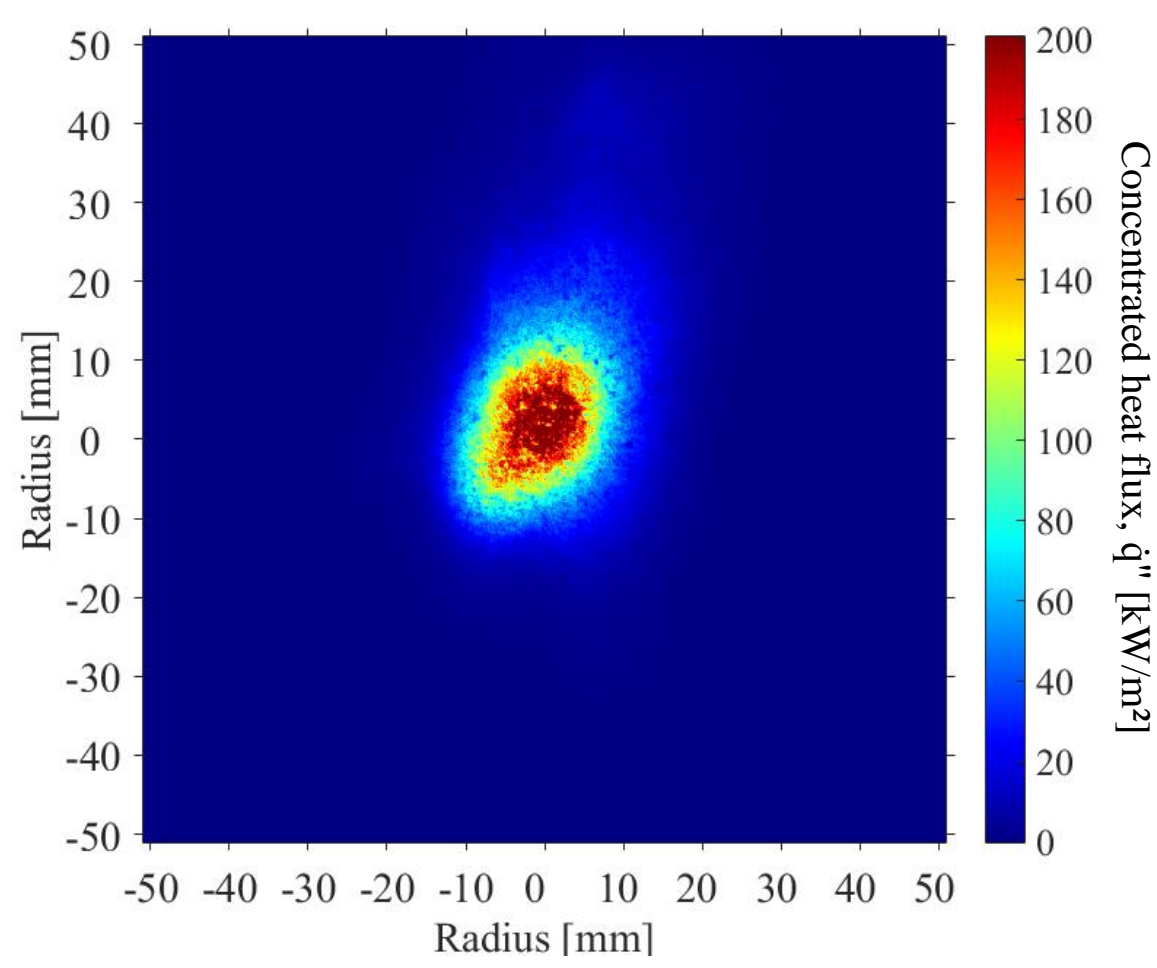

Figure 6.11. Photograph of the near-Lambertian plate located at the focal plane of the paraboloid concentrator, with an exposure time of 1/480 s converted to an $R G B$ scale.

The concentrated heat flux and the accumulated thermal power have been analyzed in terms of the radial distance from the center line, as shown in Figure 6.12. The heat flux of each step has been determined by applying Equation (6.3); thus the minimum heat flux considered in the plate has been $115.20 \mathrm{~kW} / \mathrm{m}^{2}$, which may lead to overestimated results for thermal power. The accumulated power has been calculated applying Equation (5.11), reaching a maximum of $445.3 \mathrm{~W}$ in a radius of $15 \mathrm{~mm}$.

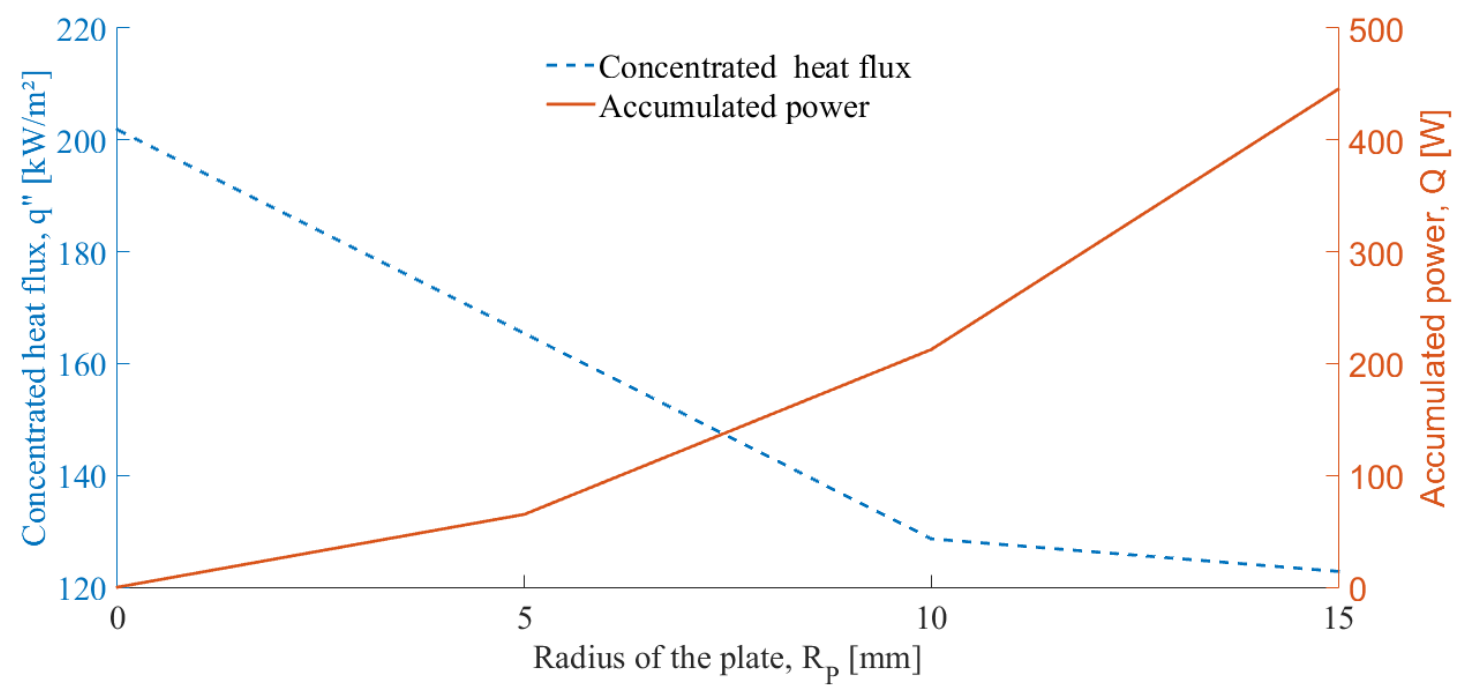

Figure 6.12. Concentrated heat flux and accumulated thermal power in terms of target radius. 
The graphic of Figure 6.13 has been drawn analyzing the central line of the near-Lambertian plate, and the accumulated power has been calculated considering the flux heat distribution as circular, as proposed in Equation (5.1); adding up to $443.1 \mathrm{~W}$ in a $15 \mathrm{~mm}$ radius. The result attained with this technic has been very close (less than $0.3 \%$ difference) to the one obtained with the anterior method; this means the heat flux distribution can be considered circular.

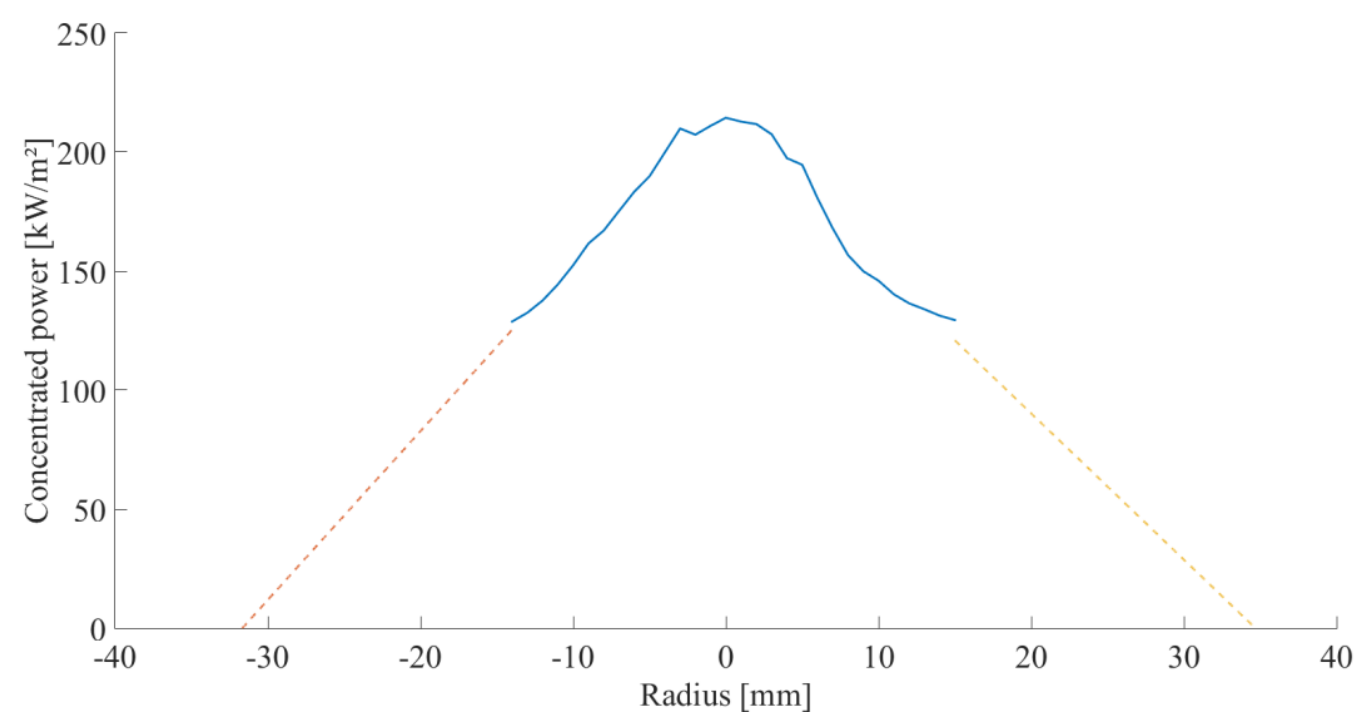

Figure 6.13. Concentrated heat flux distribution on the central horizontal line of maximum concentration on the Near-Lamberian plate. The solid line represents the values acquired with the heat gauge and the dashed lines are tendency lines starting from the last 10 measurements of each side.

As the camera resolution can be an obstacle in the estimation of the total thermal power concentrated, two tendency lines constructed with the least ten points of each side of the curve of Figure 6.13 have been assessed. Each one of these lines ends up in an approximately 30 $\mathrm{mm}$ radius, which is only a little less than the $40 \mathrm{~mm}$ radius corresponding to the concentrated power estimated with Tonatiuh $₫$ when no secondary concentrator had been in use. The total thermal energy of $668.4 \mathrm{~W}$ has been calculated in this circular area of $30 \mathrm{~mm}$ radius. The average thermal flux has been determined as $61.5 \mathrm{~kW} / \mathrm{m}^{2}$, which corresponds to a heat flux ratio of 8.8 in relation to the sky searchlight average heat flux. Applying the black body equation for this average flux, a temperature of around $750^{\circ} \mathrm{C}$ has been attained.

The total of $668.4 \mathrm{~W}$ corresponds to $61.3 \%$ of the maximum theoretically concentrated power of $1.09 \mathrm{~kW}$, calculated using Equation (6.2) and to $44.3 \%$ of the thermal energy provided by the two sky searchlights. This low thermal efficiency may be due to the difficulties to position 
correctly the concentrators, the poor collimation of the light beams or a non-unitary diffuse reflection of the near-Lambertian plate.

The results obtained in the simulation with Tonatiuh@ $\odot$ correspond to the efficiency of $100 \%$ between the input energy of $1 \mathrm{~kW} / \mathrm{m}^{2}$ and the concentrated power on the near-Lambertian plate and 8.9 heat flux ratio. Hence, the heat flux ratio attained in the experimental procedure has shown to be very close to the expected, even if the efficiency of the system is only $44.3 \%$. The calibration curve mapped can be used in many other analyzes using only the nearLambertian plate and the camera, noting that the HFSS apparatus cannot have been moved; this means the relative position between the sky searchlights and the paraboloid concentrators remain the same. This procedure saves a lot of time for there is no more need for sweeping the aimed area step by step using the radiometer.

\subsection{Calorimeter cavity analyses}

The calorimeter tests have been carried out according to Section 5.5., as the calorimeter enhance window has been adjusted at the focus of the system and cooling water has been set to run inside the device. Figure 6.14 corresponds to the cavity temperature on a time-lapse of 60 minutes. It can be seen it have reached the thermal equilibrium after 40 minutes of experiment. Figure 6.15 represents the difference of temperature between the water's inlet and outlet. After 35 minutes, when the cavity temperature reaches its maximum, the difference of water temperature have started to drop.

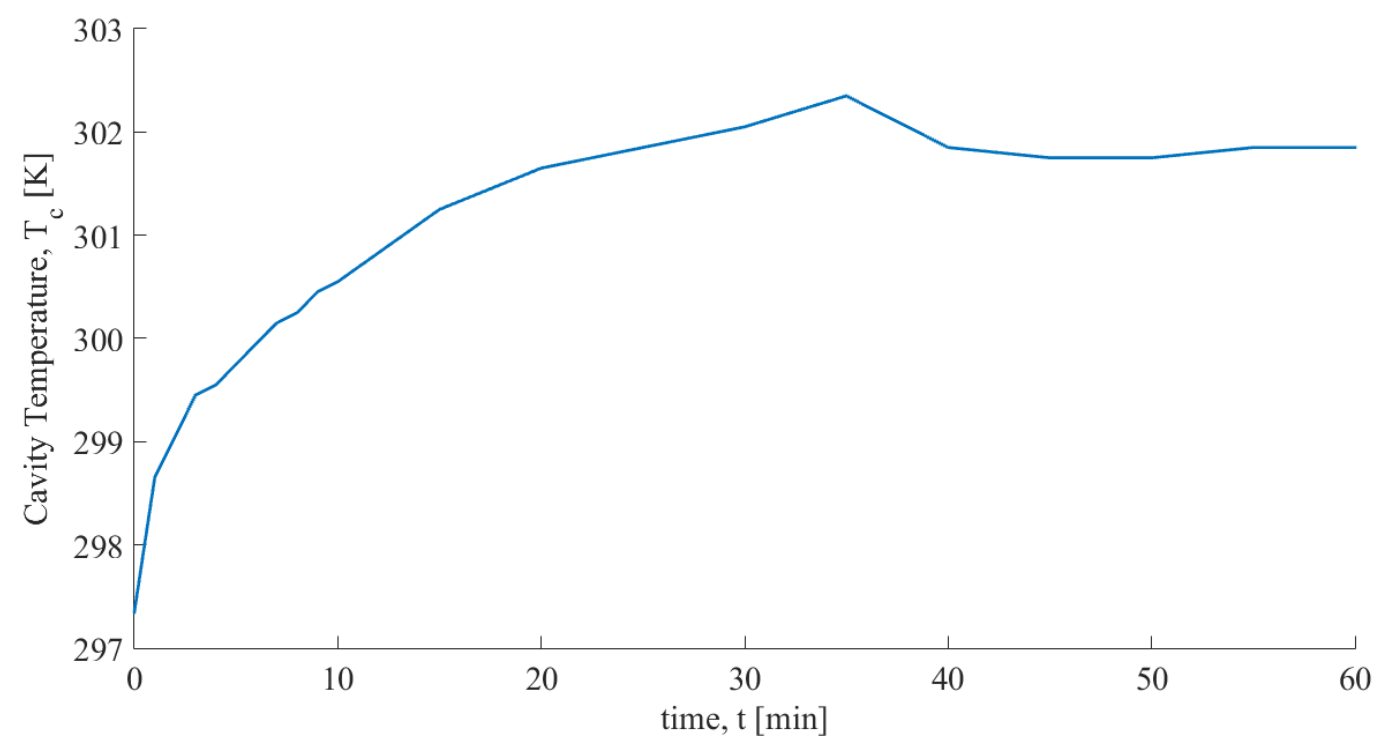

Figure 6.14. Cavity temperature on a time lapse of 60 minutes. 


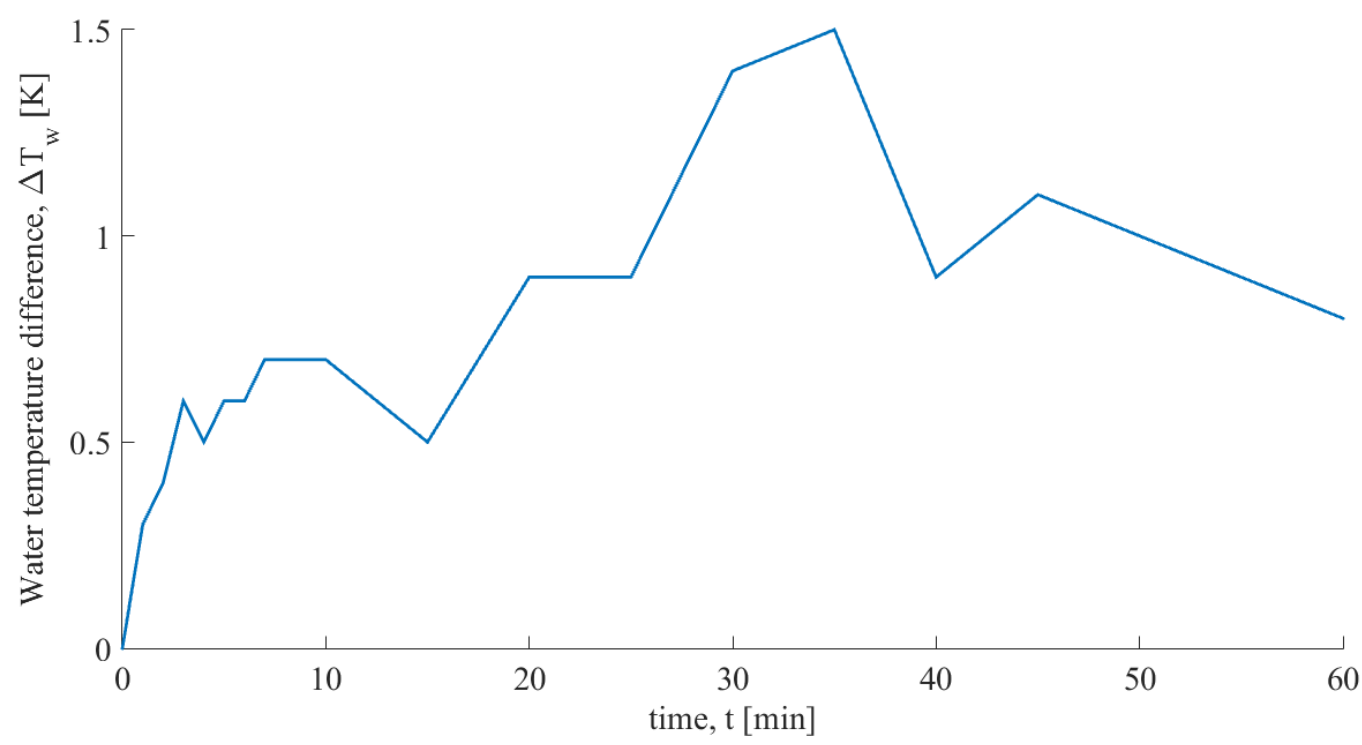

Figure 6.15. Difference of temperature of water in inlet and outlet on a time lapse of 60 minutes.

After 60 minutes of test, the lamps have been turned off and it has been noticed that the secondary concentrator's surface had been severely deteriorated, as shown in Figure 6.16. It may explain the unsteady results obtained and why the heat absorbed by the water, represented by the difference of temperature, have started to decline after a while.

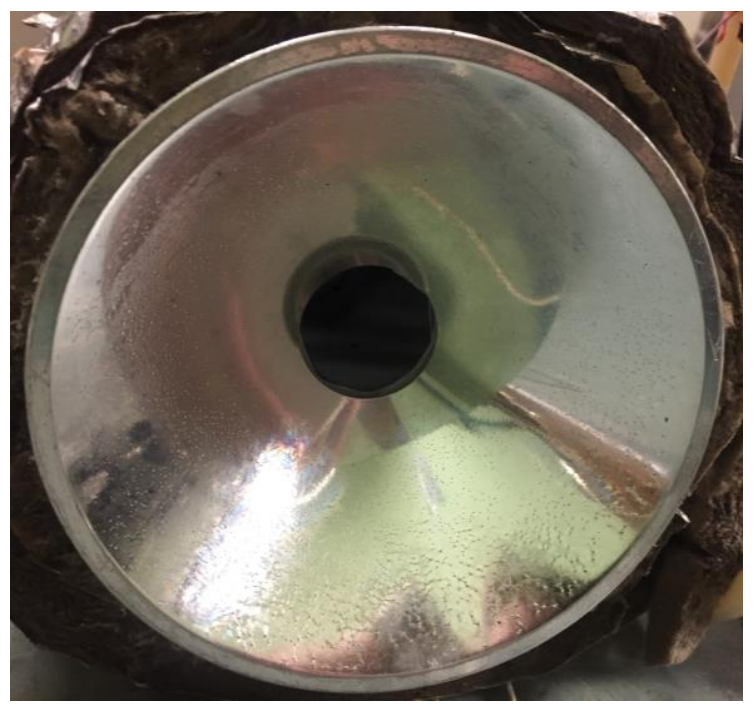

Figure 6.16. Photograph of the deterioration of the secondary concentrator after the experiment. 
By applying Equation (5.14), the graphic of Figure 6.17 has been drawn. The first 15 minutes of experiment correspond to the warm-up time of the apparatus. The evaluations have been carried out at 35 minutes, when both the temperature cavity and the difference in temperature of the water reach the maximum.

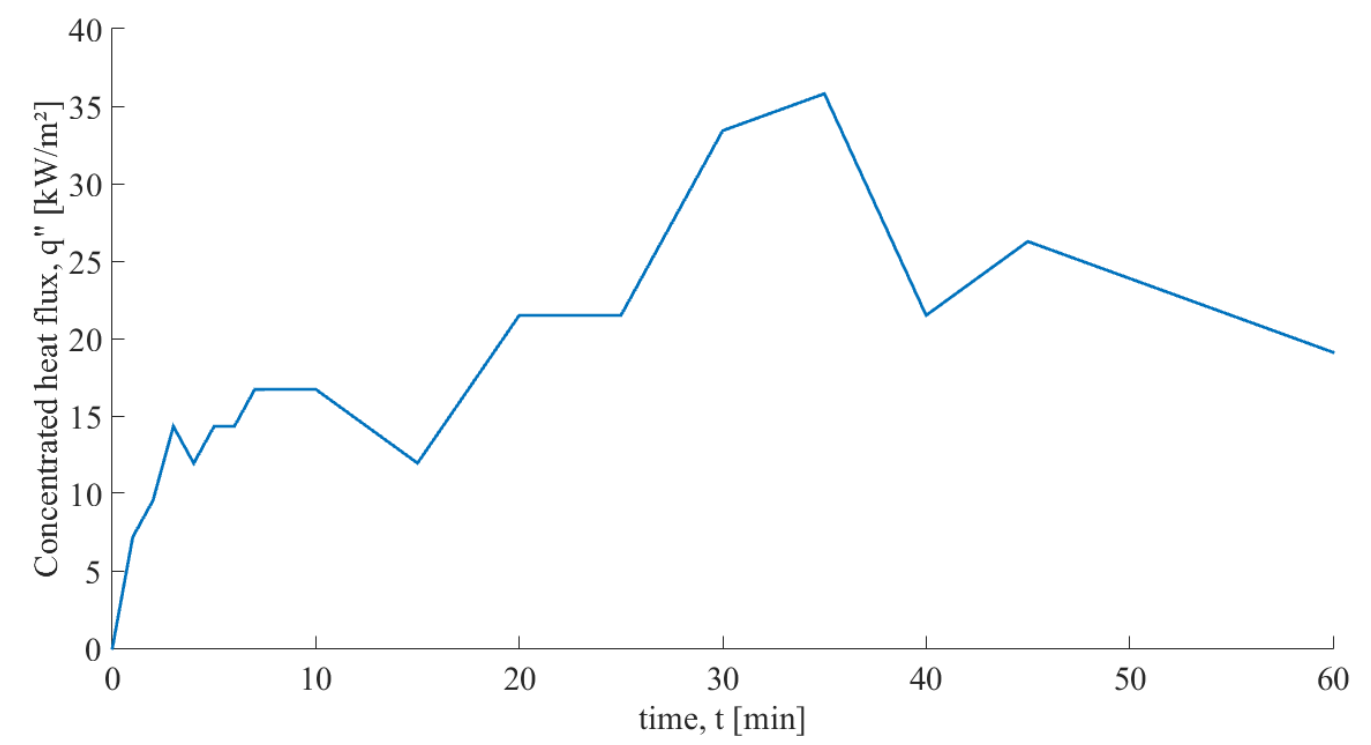

Figure 6.17. Concentrated heat flux on the cavity calorimeter window on a time lapse of 60 minutes.

At 35 minutes, an average incident thermal flux of $35 \mathrm{~kW} / \mathrm{m}^{2}$ has been achieved, corresponding to a thermal power of $34.5 \mathrm{~W}$. From this total, only $0.2 \mathrm{~W}$ correspond to reradiated energy and $31.0 \mathrm{~W}$ to the absorbed heat, which matches $90 \%$ of the incident thermal power.

Applying Equations (5.15) and (5.16), thermal efficiency of 5.15\% and a heat flux ratio of 0.58 have been achieved. The experimental results have been very different from the expected by the Tonatiuh $\odot$ simulation, in which a ratio of performance of 17.5 and an efficiency of $60 \%$ had been achieved. Some reasons for that can be appointed, such as:

- Poor thermal insulation, leading to high conduction losses which have not been taken into account;

- Wrong positioning of the cavity;

- The fact that the experiment has not been performed until the thermal equilibrium had been achieved due to the secondary concentrator deterioration. 


\section{CONCLUSIONS}

High Flux Solar Simulators, which are apparatus used to emulate the high thermal energy of the Sun radiation are applied to improve the research of Solar fuels, being reliable and constant, highly energetic light sources. Many HFSS have been developed in first world countries such as Switerzland, Germany and United States since 2003, but none has been drawn up before in Brazil, except in Sisea group.

Initially, a careful up-to-date literature review of existent HFSS around the world and on the theoretical background supporting this study have been carried out. Then, MCRT simulation has been performed using the Tonatiuh $(\mathcal{C}$ software to determine the design of the primary and secondary concentrators. The theory of black body cavity has endorsed the sketch of the calorimeter cavity. Subsequently, experimental procedures have been adopted and the parts built and positioned. Xenon light sources have been used in packs commercially known as "sky searchlights", which provide stable, punctual light along with the electrical control system and optical features, creating a parallel light beam that had been concentrated in offset paraboloid mirrors to a focus.

The thermal radiant energy to electric power rate of the sky searchlights has been determined by three methods, namely: (1) spectrophotometer, (2) heat Gardon gauge and (3) the calorimeter built within the SISEA laboratory. This analysis has established the output thermal energy of the system to $758 \mathrm{~W}$, obtaining an average thermal radiant energy to electric power ratio of $19 \%$. This helped determining the paraboloid concentrator mirrors flux ratio, leading to the choice of the off-set configuration.

Three surface coatings of the off-set paraboloid concentrators have been studied in means of reflectivity, and the $95 \%$ reflectivity of the aluminum powder has proved to be the best option for this parameter. On the other hand, the cold molding technic of the polycarbonates over the fiberglass, using screws on the center of the paraboloid geometry has represented a loss of predictable reflective area and leading to a $20 \%$ difference between the actual and the expected efficiencies of the concentrators.

The concentrated heat flux distribution on the experimental rig has lead to a smaller area than the expected on the simulation (around $30 \mathrm{~mm}$ radius for the first, versus $40 \mathrm{~mm}$ radius for the later). The total thermal power experimentally found corresponds to an efficiency of $44.3 \%$, but the average heat flux of $61.5 \mathrm{~kW} / \mathrm{m}^{2}$ and the peak heat flux of about $200 \mathrm{~kW} / \mathrm{m}^{2}$ have turned out to almost equal heat flux ratios between the simulation and the experiment, 
considering the input divergence of $1 \mathrm{~kW} / \mathrm{m}^{2}$ on the Tonatiuh $\odot$ model and about $7 \mathrm{~kW} / \mathrm{m}^{2}$ of the real one. This may be explained for the best concentration area of the test rig concerning the MCRT method.

The results attained for the secondary concentrator and, thus, for the calorimeter cavity have not been nearly good. The thermal efficiency of this concentrator is less than $10 \%$, and the flux ratio, expected to be 17.5 has been less than 1 . The main reason for that may be indicated to be the difficulty of positioning of the cavity on the right spot found with the heat gauge and a possible poor thermal insulation. This can be verified by the fact that the secondary concentrator surface has been deteriorated, even though the aluminum powder coating presents an operation temperature of $120^{\circ} \mathrm{C}$. Further tests could not be carried out due to the degradation of the aluminum powder layer.

Thus, the primary and specific objectives proposed at the beginning of this work have been achieved. Once an appropriate secondary concentrator and reactor cavity have been designed and built, the HFSS developed can be effectively used to activate reaction occurring under $750^{\circ} \mathrm{C}$. For reactions occurring under temperatures higher than that, an enlargement of this HFSS is suggested. On the other hand, a larger HFSS may be easily characterized in means of thermal flux, given the near-Lambertian plate and black and white camera calibration.

\subsection{Suggestions for future work}

- To build a new High Flux Solar Simulator at higher power to increase the temperatures and radiation heat fluxes;

- Design and construction of a commercial secondary concentrator, in which the entrance aperture may be placed at the point of maximum heat flux of the concentrators, favoring the positioning. Ideally, it is going to have a focus as narrow as possible to avoid the concentrated radiation spread.

- Once the new apparatus has been built, carrying out high temperature experiments, such as that involved in solar fuels, is suggested. 


\section{REFERENCES}

Aichmayer, L., Garrido, J., Laumert, B., 2017. Performance improvements of the KTH highflux solar simulator. AIP Conf. Proc. 1850. https://doi.org/10.1063/1.4984530

Aichmayer, L., Wang, W., Garrido, J., Laumert, B., 2016. Experimental flux measurement of a high-flux solar simulator using a Lambertian target and a thermopile flux sensor. AIP Conf. Proc. 1734. https://doi.org/10.1063/1.4949211

ASTM E927-19. Standard Classification for Solar Simulators for Electrical Performance Testing of Photovoltaic Devices.

Alxneit, I., Schmit, H., 2011. Spectral Characterization of PSI's High-Flux Solar Simulator. J. Solar Energy Engineering, 134, 011013. https://doi.org/10.1115/1.4005249

Blanco, M.J., 2008. Tonatiuh: An object oriented, distributed computing, Monte-Carlo ray tracer for the design and simulation of solar concentrating systems. $16^{\text {th }}$ Workshop on Crystalline Silicon Solar Cells \& Modules, August 6-9, Denver, CO.

Blanco, M.J., Amieva, J.M., Mancilla, A., 2005. The Tonatiuh Software Development Project: An Open Source Approach to the Simulation of Solar Concentrating Systems, in: International Mechanical Engineering Congress and Exposition. ASME, Orlando, pp. $1-8$.

Boubault, A., Yellowhair, J., Ho, C.K., 2015. Design and Characterization of a 7.2 KW Solar Simulator. Vol. 1 Adv. Sol. Build. Conserv. Clim. Control Environ. Altern. Fuels Infrastructure; ARPA-E; Comb. Energy Cycles, CHP, CCHP, Smart Grids; Conc. Sol. Power; Econ. Environ. Policy Asp 139, V001T05A017. https://doi.org/10.1115/ES201549472

Canto, L., Varon, L., Barreto, G.A., Simões-Moreira, J.R., 2019a. Comparison of Concentrators for an Off the Shelf High Flux Solar Simulator, in: IAPE Innovative Applied Energy. Oxford.

Canto, L., Varon, L.M., Simões-moreira, J.R., 2019b. Design of a Secondary Concentrator For High Flux Solar Simulators, in: 1st Franco-AMSUD Energy and Environment Meeting. Marseille.

Canto, L., Simões Moreira, J.R., 2017. Thermal modeling of cavity-receiver for concentrated solar energy, in: 24th ABCM International Congress of Mechanical Engineering. ABCM, Curitiba, p. 10. https://doi.org/10.26678/ABCM.COBEM2017.COB17-0861

Chu, S., Cui, Y., Liu, N., 2016. The path towards sustainable energy. Nat. Mater. 16, 16-22. 
https://doi.org/10.1038/nmat4834

Codd, D.S., Carlson, A., Rees, J., Slocum, A.H., 2010. A low cost high flux solar simulator. Sol. Energy 84, 2202-2212. https://doi.org/10.1016/j.solener.2010.08.007

Daabo, A.M., Mahmoud, S., Al-Dadah, R.K., 2016a. The effect of receiver geometry on the optical performance of a small-scale solar cavity receiver for parabolic dish applications. Energy 114, 513-525. https://doi.org/10.1016/j.energy.2016.08.025

Daabo, A.M., Mahmoud, S., Al-Dadah, R.K., 2016b. The optical efficiency of three different geometries of a small scale cavity receiver for concentrated solar applications. Appl. Energy 179, 1081-1096. https://doi.org/10.1016/j.apenergy.2016.07.064

Deng, Q., Xiao, X., Hao, Y., Wang, Q., Hu, T., Wang, Y., 2017. Heat transfer performance evaluation of a large-size cavity receiver in the solar power tower plant based on angle factors. Sol. Energy 148, 78-86. https://doi.org/10.1016/j.solener.2017.03.067

Detz, R.J., Reek, J.N.H., Van Der Zwaan, B.C.C., 2018. The future of solar fuels: When could they become competitive? Energy Environ. Sci. 11, 1653-1669. https://doi.org/10.1039/c8ee00111a

Dong, X., Sun, Z., Nathan, G.J., Ashman, P.J., Gu, D., 2015. Time-resolved spectra of solar simulators employing metal halide and xenon arc lamps. Sol. Energy 115, 613-620. https://doi.org/10.1016/j.solener.2015.03.017

Duffie, J.A., Beckman, W.A. Solar Engineering of Thermal Processes. 4 ed. New Jersey: John Wiley \& Sons, 2013.

Egan, M., 2017. Solar jobs growing 17 times faster than US economy. CNN. Available at http://money.cnn.com/2017/05/24/news/economy/solar-jobs-us-coal/index.html. Acessed in October $4^{\text {th }}, 2018$

Ekman, B.M., Brooks, G., Rhamdhani, M.A., 2015. Development of high flux solar simulators for solar thermal research. Sol. Energy Mater. Sol. Cells 436-446. https://doi.org/10.1007/978-3-319-48220-0_17

Esen, V., Sağlam, Ş., Oral, B., 2017. Light sources of solar simulators for photovoltaic devices: A review. Renew. Sustain. Energy Rev. 77, 1240-1250. https://doi.org/10.1016/j.rser.2017.03.062

Fernández, A.G., Gomez-Vidal, J., Oró, E., Kruizenga, A., Solé, A., Cabeza, L.F., 2019. Mainstreaming commercial CSP systems: A technology review. Renewable Energy 140, 152 - 176. https://doi.org/10.1016/j.renene.2019.03.049

Gallo, A., Marzo, A., Fuentealba, E., Alonso, E., 2017. High flux solar simulators for 
concentrated solar thermal research: A review. Renew. Sustain. Energy Rev. 77, 13851402. https://doi.org/10.1016/j.rser.2017.01.056

Garrido, J., Aichmayer, L., Wang, W., Laumert, B., 2017. Characterization of the KTH highflux solar simulator combining three measurement methods. Energy 141, 2091-2099. https://doi.org/10.1016/j.energy.2017.11.067

Guerrero-Lemus, R., Martínez-Duart, J.M., 2013. Chapter 7: Concentrated Solar Power, in: Lecture Notes in Energy: Renewable Energies and CO2. Springer, London, pp. 135-151. https://doi.org/10.1007/978-1-4471-4385-7

Harris, J.A., Lenz, T.G., 1985. Thermal performance of solar concentrator/cavity receiver systems. Sol. Energy 34, 135-142. https://doi.org/10.1016/0038-092X(85)90170-7

Henninger, J.H., 1984. Solar Absorptivity and Thermal of Some Common Spacecraft Thermal-Control Coatings, NASA Reference Publication. https://doi.org/10.1017/CBO9781107415324.004

Hirsch, D., Zedtwitz, P. V., Osinga, T., Kinamore, J., Steinfeld, a., 2003. A New 75 kW High-Flux Solar Simulator for High-Temperature Thermal and Thermochemical Research. J. Sol. Energy Eng. 125, 117. https://doi.org/10.1115/1.1528922

IEA, 2019. Tracking Clean Energy Progress Sol. PV. Available at https://www.iea.org/tcep/power/renewables/solar/. Accessed May 1 ${ }^{\text {st }}, 2019$.

INCOMPLAST, n.d. Policarbonato. Available at: https://incomplast.com.br/policarbonato/. Accessed in December $1^{\text {st }}, 2018$.

Iqbal, M., 1983. An Introduction to Solar Radiation, An Introduction to Solar Radiation. https://doi.org/10.1016/B978-0-12-373750-2.50017-3

Jin, J., Hao, Y., Jin, H., 2019. A universal solar simulator for focused and collimated beams. Appl. Energy. https://doi.org/10.1016/j.apenergy.2018.09.223

Jungcurt, S., 2019. Global Energy Demand in 2018 Grew at Fastest Pace in a Decade [WWW Document]. SDG Knowl. Hub. Available at https://sdg.iisd.org/news/global-energydemand-in-2018-grew-at-fastest-pace-in-a-decade/. Accessed in September $15^{\text {th }}, 2019$.

Kabir, E., Kumar, P., Kumar, S., Adelodun, A.A., Kim, K.H., 2018. Solar energy: Potential and future prospects. Renew. Sustain. Energy Rev. 82, 894-900. https://doi.org/10.1016/j.rser.2017.09.094

Kalogirou, S. Solar Energy Engineering. 2 ed. San Diego: Elsevier Inc, 2014.

Khan, J., Arsalan, M.H., 2016. Solar power technologies for sustainable electricity generation 
- A review. Renew. Sustain. Energy Rev. 55, 414-425. https://doi.org/10.1016/j.rser.2015.10.135

Kienle, A., Foschum, F., 2011. 250 years Lambert surface: does it really exist? Opt. Express 19, 3881. https://doi.org/10.1364/OE.19.003881

Krueger, K.R., 2012. Design and Characterization of a Concentrating Solar Simulator. Master Dissertation presented to the Faculty of the Gradual School of the University of Minnesota.

Krueger, K.R., Davidson, J.H., Lipiński, W., 2011. Design of a New 45 kW[sub e] High-Flux Solar Simulator for High-Temperature Solar Thermal and Thermochemical Research. J. Sol. Energy Eng. 133, 011013. https://doi.org/10.1115/1.4003298

Krueger, K.R., Lipiński, W., Davidson, J.H., 2013. Operational Performance of the University of Minnesota 45 kW e High-Flux Solar Simulator. J. Sol. Energy Eng. 135, 044501. https://doi.org/10.1115/1.4023595

Leary, G., Switzer, G., Kuntz, G., Kaiser, T., 2016. Comparison of xenon lamp-based and ledbased solar simulators, in: 43rd IEEE Photovoltaic Specialists Conference. IEEE, Portland, pp. 3062-3067. https://doi.org/10.1109/PVSC.2016.7750227

Li, J., Gonzalez-Aguilar, J., Pérez-Rábago, C., Zeaiter, H., Romero, M., 2014. Optical analysis of a hexagonal 42k we high-flux solar simulator. Energy Procedia 57, 590-596. https://doi.org/10.1016/j.egypro.2014.10.213

Li, J., Gonzalez-Aguilar, J., Romero, M., 2015. Line-concentrating Flux Analysis of 42kWe $\begin{array}{llllll}\text { High-flux Solar Simulator. Energy } & \text { Procedia }\end{array}$ https://doi.org/10.1016/j.egypro.2015.03.016

Malagueta, D., Szklo, A., Soria, R., Dutra, R., Schaeffer, R., Moreira Cesar Borba, B.S., 2014. Potential and impacts of Concentrated Solar Power (CSP) integration in the Brazilian electric power system. Renew. Energy 68, 223-235. https://doi.org/10.1016/j.renene.2014.01.050

Matson, R.J., Emery, K.A., Bird, R.E., 1984. Terrestrial solar spectra, solar simulation and solar cell short-circuit current calibration: A review. Sol. Cells 11, 105-145. https://doi.org/10.1016/0379-6787(84)90022-X

Mecit, A.M., 2013. Optical Analysis and Modeling of a Window for Small Particle Receiver Using the Monte Carlo Ray Trace Method. Master Dissertation presented to the Faculty of Mechanical Engineering of San Diego State University.

Meng, Q., Wang, Y., Zhang, L., 2011. Irradiance characteristics and optimization design of a 
large-scale solar simulator. Sol. Energy 85, 1758-1767. https://doi.org/10.1016/j.solener.2011.04.014

Moyo, J.M., Fund, I.M., Wachenfelt, A. Von, 2017. Concentrated Solar Power ( CSP ) and Photovoltaic ( PV ): Has time come for solar energy in Africa? Fond. pour les études Rech. sur le développment Int. 187.

Myers, D.R., 2010. Comparison of direct normal irradiance derived from silicon and thermopile global hemispherical radiation detectors $77730 \mathrm{G}$. https://doi.org/10.1117/12.859732

Pape, B., Batlles, J., Geuder, N., Piñero, R.Z., Adan, F., Pulvermüller, B., 2009. Soiling impact and correction formulas in solar measurements for CSP projects. 15th SolarPaces Conf. https://doi.org/10.13140/2.1.4355.0406

Pelay, U., Luo, L., Fan, Y., Stitou, D., Rood, M., 2017. Thermal energy storage systems for concentrated solar power plants. Renew. Sustain. Energy Rev. 79, 82-100. https://doi.org/10.1016/j.rser.2017.03.139

Peters, A., 2017. Solar Now Provides Twice as Many Jobs as the Coal Industry. Fast Co. Available at: https://www.fastcompany.com/3068125/solar-now-provides-twice-asmany-jobs-as-the-coal-industry. Accessed in April, 10 ${ }^{\text {th }}, 2018$.

Petrasch, J., Coray, P., Meier, A., Brack, M., Haberling, P., Wuillemin, D., Steinfeld, A., 2007. A novel $50 \mathrm{~kW} 11,000$ suns high-flux solar simulator based on an array of xenon arc lamps. J. Sol. Energy Eng. Asme 129, 405-411. https://doi.org/10.1115/1.2769701

Petrasch, J., Steinfeld, A., 2005. A Novel High-flux Solar Simulator Based on an Array of Xenon Arc Lamps - Optimization of the Ellipsoidal Reflector and Optical Configuration, in: 2005 International Solar Energy Conference. ASME, Orlando. https://doi.org/10.1115/1.2769701

Polito, R. Demanda de energia no Brasil deve crescer 4\% em 2019, segundo EPE, 2019. Polito, R. Available at: http://www.valor.globo.com/brasil/noticia/2019/02/15/demandade-energia-no-brasil-deve-crescer-em-4-em-2019-segundo-epe.htlm. Accessed in May, $7^{\text {th }}, 2019$.

Rodrigues, J. da R.H., 2016. Projeto e construção de um simulador solar concentrador. Universidade de São Paulo, São Paulo. Master dissertation presented to the Escola Politécnica of the Universidade de São Paulo.

Samanes, J., García-Barberena, J., Zaversky, F., 2015. Modeling Solar Cavity Receivers: A Review and Comparison of Natural Convection Heat Loss Correlations. Energy Procedia 
69, 543-552. https://doi.org/10.1016/j.egypro.2015.03.063

Shimokawa, R., Takahashi, T., Takato, H., Ozaki, A., Takano, Y., 2001. $2 \mathrm{~m}$ thin film c-Si cells on near-Lambertian Al O substrates. Sol. Energy Mater. 65, 593-598.

Shuai, Y., Wang, F.Q., Xia, X.L., Tan, H.P., Liang, Y.C., 2011. Radiative properties of a solar cavity receiver/reactor with quartz window. Int. J. Hydrogen Energy 36, 12148 12158. https://doi.org/10.1016/j.ijhydene.2011.07.013

Simões-Moreira, J.R., Rodrigues, J.R., Goto, T. G., Ribas, V.E. Economia do Hidrogênio. In: Simões-Moreira, J.R. (Org.). Energias Renováveis, Geração Distribuida e Eficiência Energética. São Paulo: Gen, 2017. p. 296-306.

Solargis, 2019a. Direct Normal Irradiation.

Solargis, 2019b. Solar Resource Map for Brazil.

Steinfeld, A., Palumbo, R., 2001. Solar Thermochemical Process Technology. Encycl. Phys. Sci. Technol. 15, 237-256. https://doi.org/10.1016/B0-12-227410-5/00698-0

Steinfeld, A., Schubnell, M., 1993. Optimum aperture size and operating temperature of a solar cavity-receiver. Sol. Energy 50, 19-25. https://doi.org/10.1016/0038092X(93)90004-8

Sun at the push of a button, 2017. . Ger. Aerosp. Cent. URL Available at http://www.dlr.de/dlr/en/desktopdefault.aspx/tabid-10080/150_read21807/\#/gallery/26633. Accessed in: April, 15 ${ }^{\text {th }}, 2018$.

Tanner, M., 2003. Nitrogen in Co-compost, and other chemical compost analyses. Report of a field study in Kumasi, Ghana, from March to November 2003.

Technical Glass Products, 2010. Fused Quartz/Fused Silica Average Transmissivity Curves. $\begin{array}{llll}\text { Available } \quad \text { at: } & \text { The W.Wallace Co.,Inc. URL }\end{array}$ http://www.technicalglass.com/fused_quartz_transmission.html. Accessed in April, $5^{\text {th }}$, 2018.

Wang, W., 2014. Simulate a 'Sun' for Solar Research: A Literature Review of Solar Simulator Technology. Presented to the Dept of Energy Technology of the Royal Institute of Technology. Stockholm.

Wang, W., Aichmayer, L., Laumert, B., Fransson, T., 2014. Design and validation of a lowcost high-flux solar simulator using Fresnel lens concentrators. Energy Procedia 49, 2221-2230. https://doi.org/10.1016/j.egypro.2014.03.235

Welford, W.T., Winston, R., 1989. High collection Nonimaging optics. Academic Press, San 
Diego. https://doi.org/10.1016/0165-1633(90)90058-9

Wieghardt, K., Funken, K.H., Dibowski, G., Hoffschmidt, B., Laaber, D., Hilger, P., Eßer, K.P., 2016. SynLight - The world's largest artificial sun. AIP Conf. Proc. 1734. https://doi.org/10.1063/1.4949090

Wieghardt, K., Laaber, D., Dohmen, V., Hilger, P., Korber, D., Funken, K.H., Hoffschmidt, B., 2018. Synlight - A new facility for large-scale testing in CSP and solar chemistry. AIP Conf. Proc. 2033. https://doi.org/10.1063/1.5067078

Wieghardt, K., Laaber, D., Hilger, P., Dohmen, V., Funken, K.H., Hoffschmidt, B., 2017. Engineering and erection of a 300kW high-flux solar simulator. AIP Conf. Proc. 1850. https://doi.org/10.1063/1.4984507

Winston, R., 1991. Nonimaging optics, Scientific American. https://doi.org/10.1038/scientificamerican0391-76

Writer, S., 2019. One of South Africa's biggest renewable energy projects - a R12 billion solar farm - is now live. Bus. Tech. Available at: https://businesstech.co.za/news/energy/298018/one-of-south-africas-biggest-renewableenergy-projects-a-r12-billion-solar-farm-is-now-live/. Accessed in January, $5^{\text {th }}, 2019$.

Yadav, D., Banerjee, R., 2016. A review of solar thermochemical processes. Renew. Sustain. Energy Rev. 54, 497-532. https://doi.org/10.1016/j.rser.2015.10.026 
APPENDICES 


\section{APPENDIX A - MANUFACTURING OF THE NEAR-LAMBERTIAN PLATE.}

An aluminum plate has been perforated lengthwise in the depth as show Figure A.1. Aluminum flexible tubes have been added to water to flow inside the holes, as shows Figure A.2.

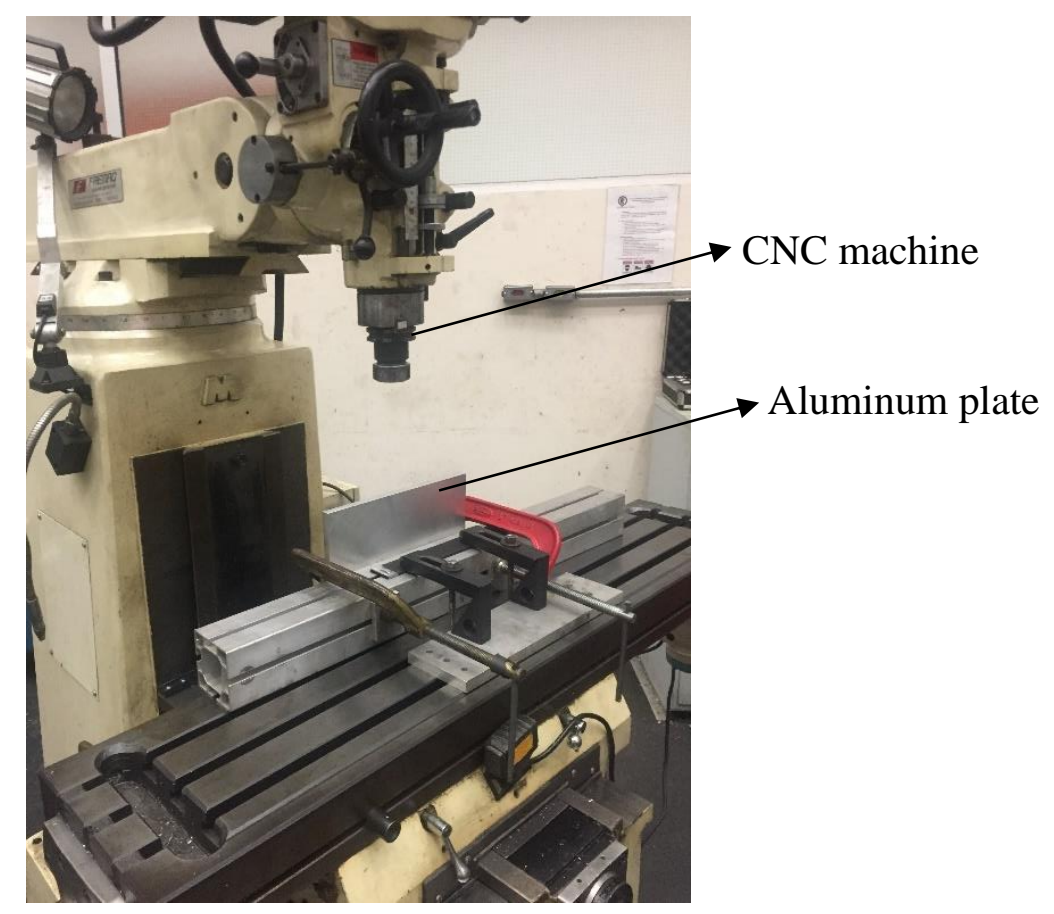

Figure A.1. Perforation of the plate by a CNC machine.

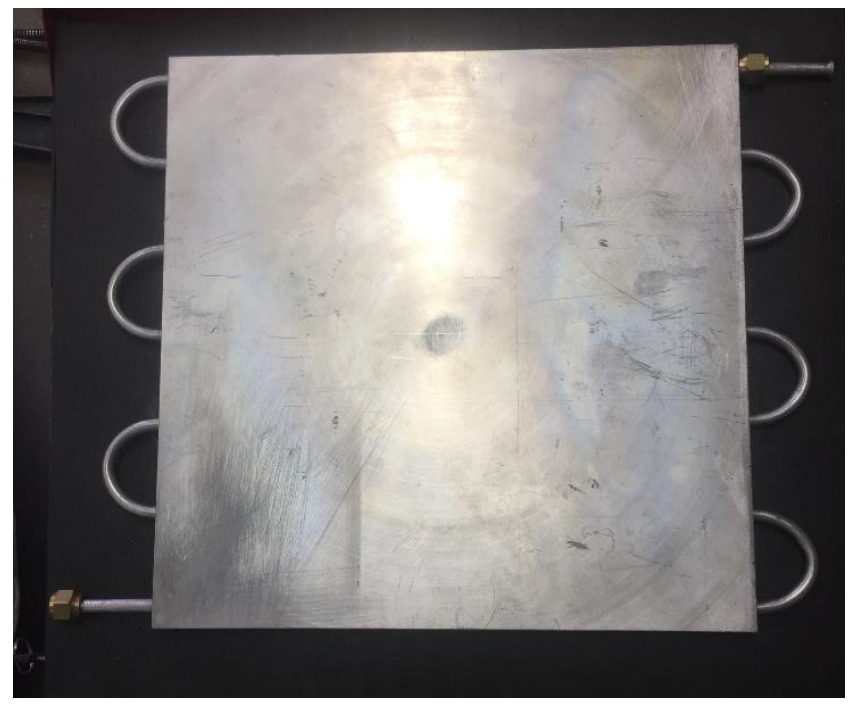

Figure A.2. Plate holes interconnect by the flexible aluminum tubes. 
A hole of the same size as the radiometer has been made in the surface of the plate. A insert of same dimensions as the radiometer has been manufactured to place in the hole, as shown in Figure A.3. Then, the plate has been rectified and a alumina coating $\left(\mathrm{Al}_{2} \mathrm{O}_{3}\right)$ has been added to cover the surface and turn it into a near-Lambertian plate.

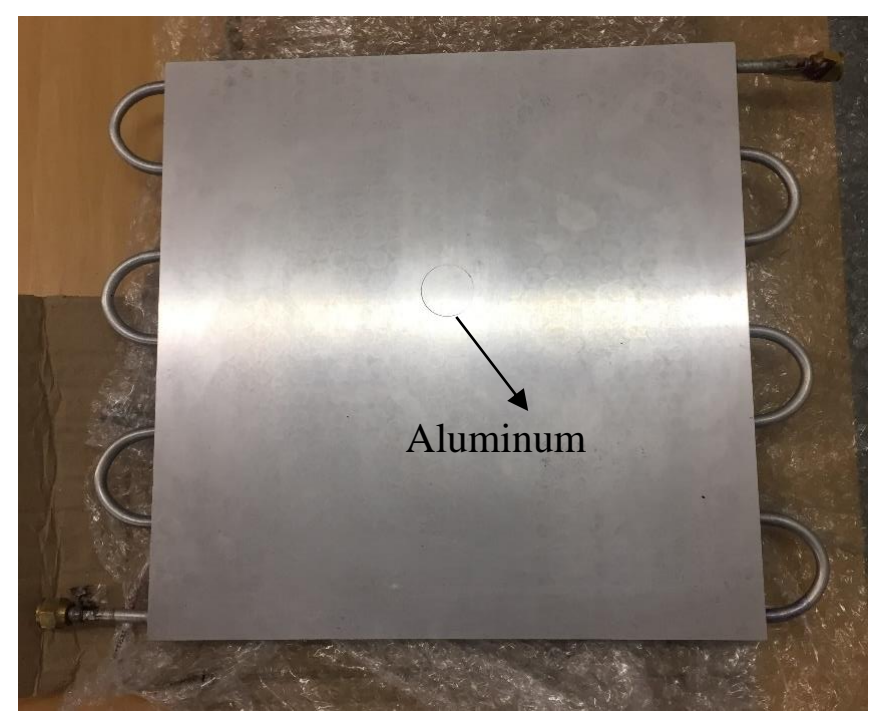

Figure A.3. Plate with aluminum insert. 
ANNEXES 
ANNEX A - XBO 4000 TECHNICAL SHEET.

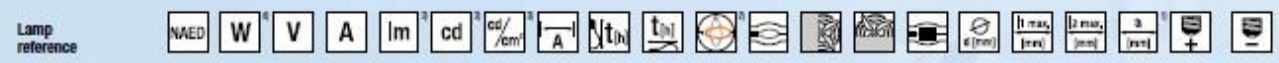

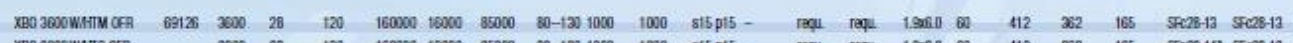

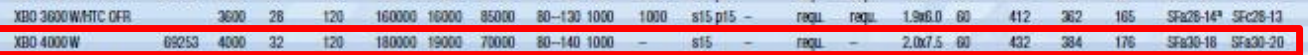

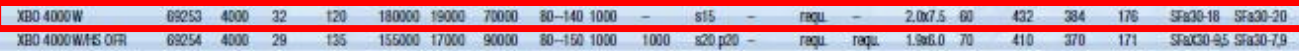

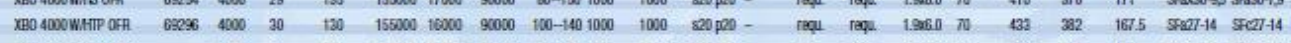

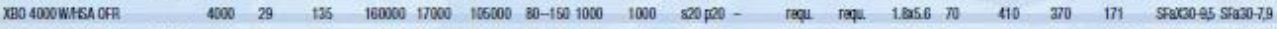

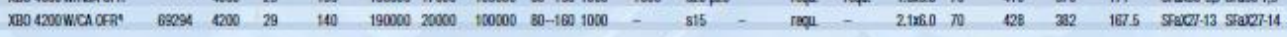

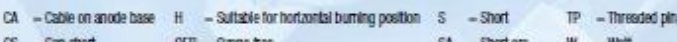

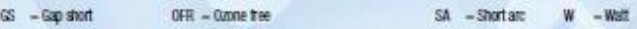

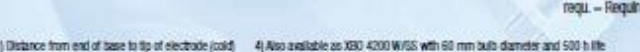

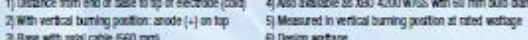

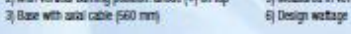

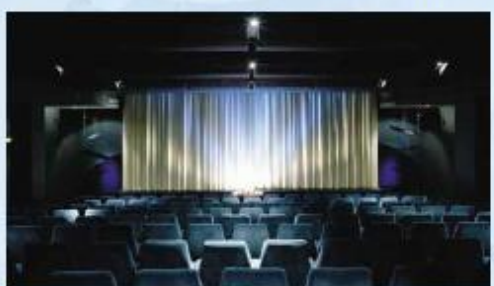


ANNEX B - CALIBRATION CURVE OF THE HEAT GAUGE PROVIDED BY VATELL CORPORATION.

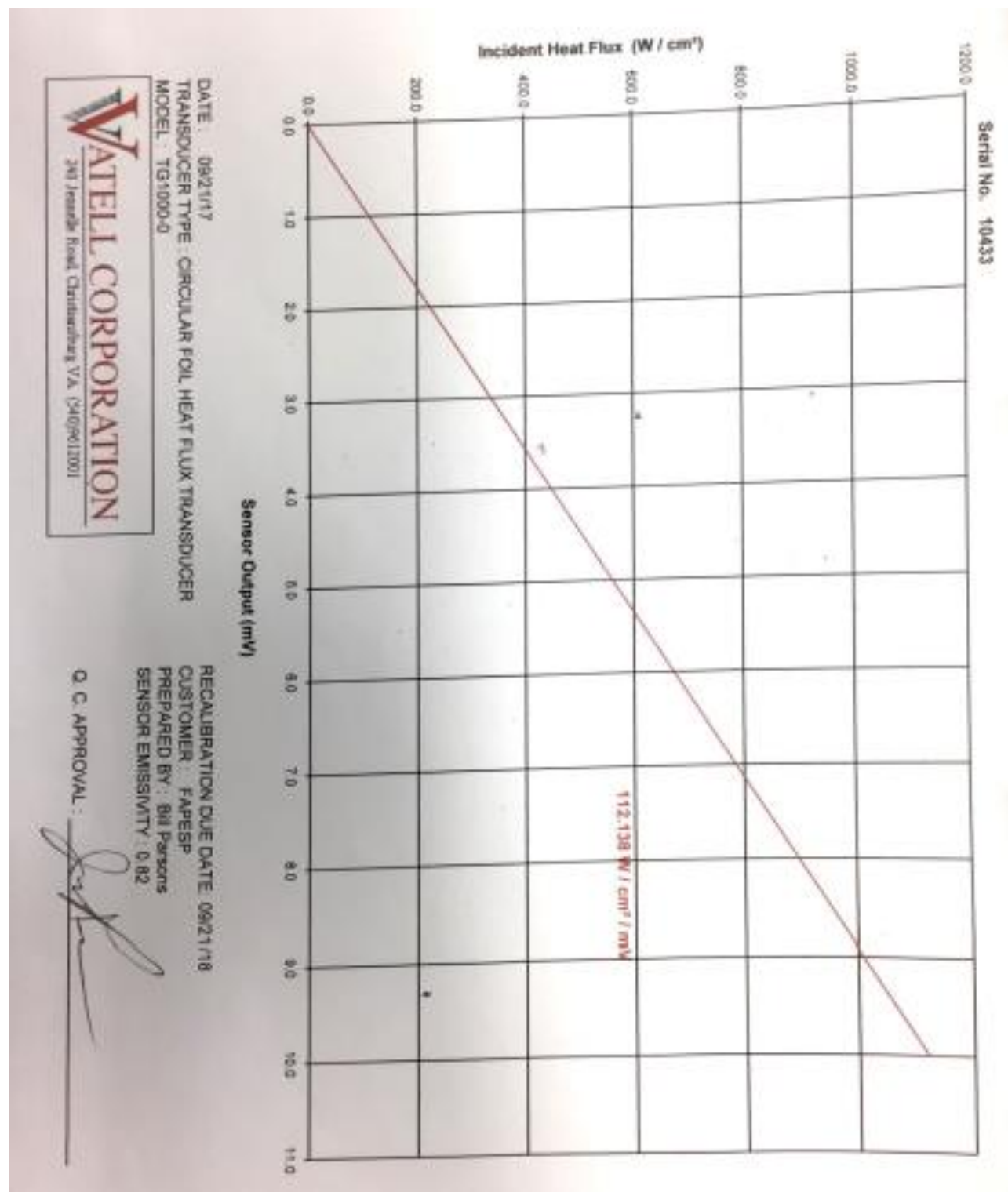


ANNEX C - SPECTRAL SENSITIVITY OF THE CAMERA AVAILABLE AT THE MANUFACTURE'S MANUAL.

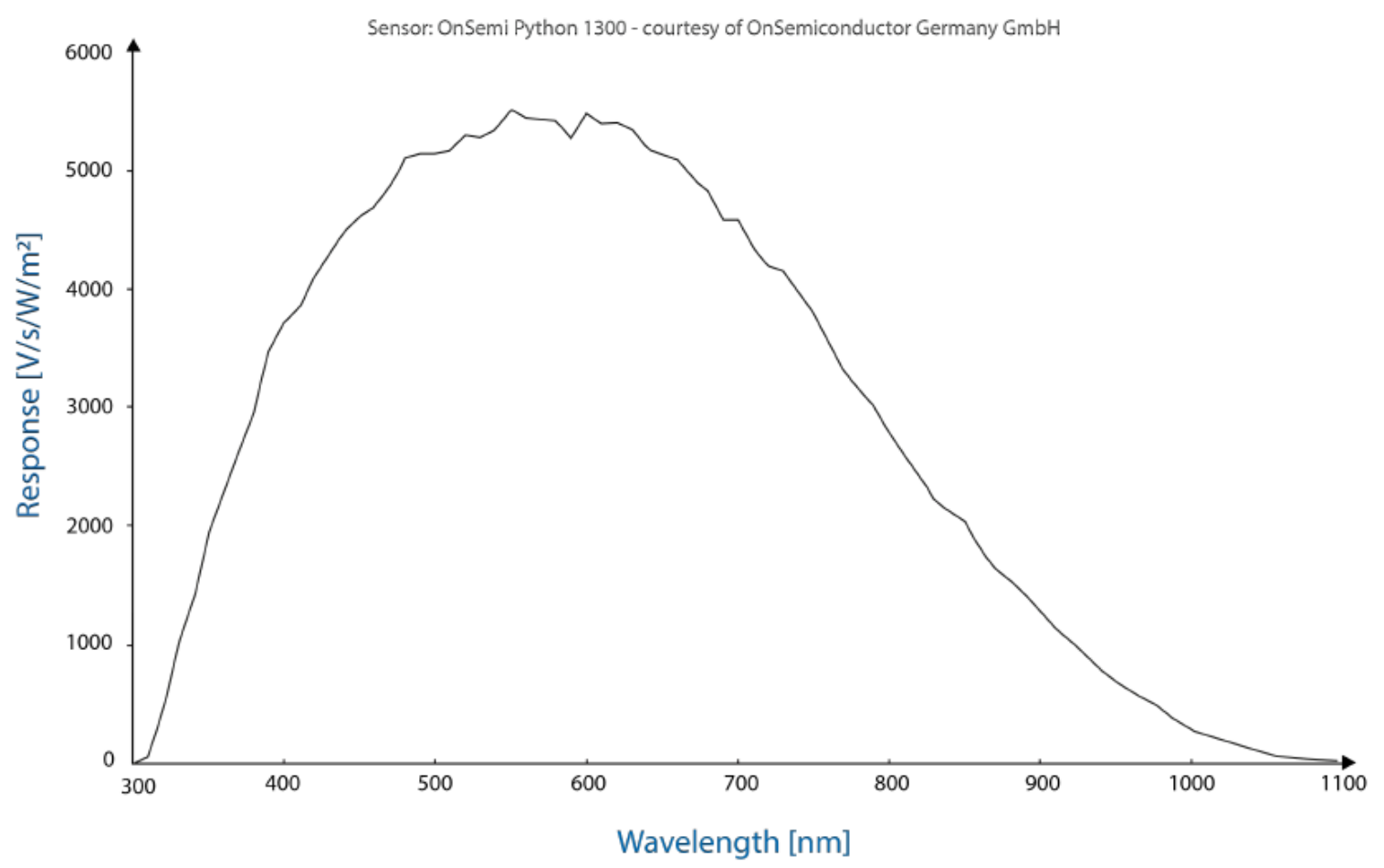

